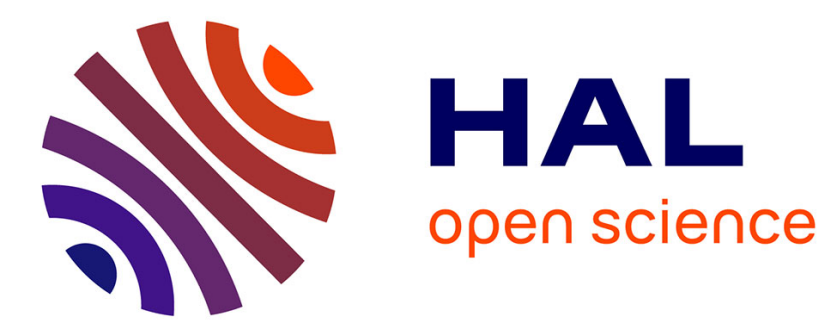

\title{
Structure-based design of human immuno- and constitutive proteasomes inhibitors
}

\author{
N. Richy, D. Sarraf, X. Maréchal, N. Janmamode, E. Genin, M. \\ Reboud-Ravaux, J. Vidal, Rémy Le Guével
}

\section{- To cite this version:}

N. Richy, D. Sarraf, X. Maréchal, N. Janmamode, E. Genin, et al.. Structure-based design of human immuno- and constitutive proteasomes inhibitors. European Journal of Medicinal Chemistry, 2018, 145, pp.570-587. 10.1016/j.ejmech.2018.01.013 . hal-01713510

HAL Id: hal-01713510 https://hal-univ-rennes1.archives-ouvertes.fr/hal-01713510

Submitted on 25 Apr 2018

HAL is a multi-disciplinary open access archive for the deposit and dissemination of scientific research documents, whether they are published or not. The documents may come from teaching and research institutions in France or abroad, or from public or private research centers.
L'archive ouverte pluridisciplinaire HAL, est destinée au dépôt et à la diffusion de documents scientifiques de niveau recherche, publiés ou non, émanant des établissements d'enseignement et de recherche français ou étrangers, des laboratoires publics ou privés. 


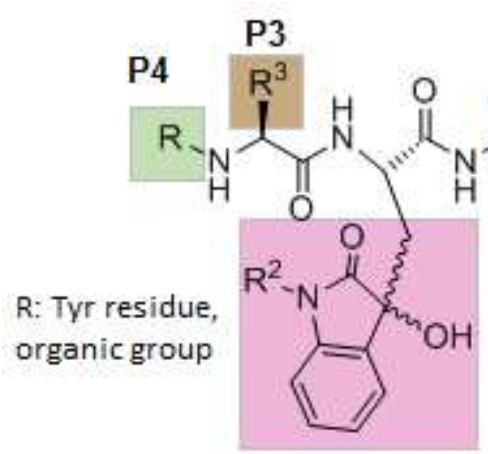

P2
P1

$R^{1}$

Human 20 S proteasome

ChT-L: IC S0 $_{50}=7.1 \mathrm{nM}$

PA: $I_{50}=31.9 \mu \mathrm{M}$

Cancer cell lines

T-L: IC $50=13.2 \mu \mathrm{M}$

$\mathrm{EC}_{50}=0.2-2 \mu \mathrm{M}$ 


\title{
Structure-based design of human immuno- and constitutive proteasomes inhibitors
}

Nicolas Richy ${ }^{\mathrm{a}}$, Daad Sarraf ${ }^{\mathrm{a}}$, Xavier Maréchal ${ }^{\mathrm{b}}$, Naëla Janmamode ${ }^{\mathrm{a}}$, Rémy Le Guével ${ }^{\mathrm{c}}$,

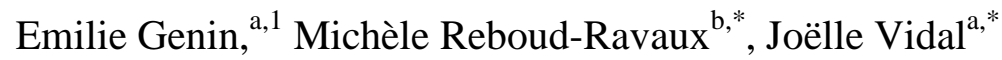

${ }^{a}$ Université Rennes 1, Institut des Sciences Chimiques de Rennes, CNRS UMR 6226, Bâtiment 10A, Campus de Beaulieu, 35042 Rennes Cedex, France.

${ }^{\mathrm{b}}$ Sorbonne Universités, UPMC Univ Paris 06-CNRS, IBPS, UMR 8256, Inserm ERL1164, B2A, 7 Quai Saint Bernard, F75005 Paris, France.

${ }^{\mathrm{c}}$ Université Rennes 1, Technology platform ImPACcell, SFR UMS CNRS 3480 - INSERM 018, Bâtiment 8, Campus de Villejean, 35043 Rennes Cedex, France.

${ }^{1}$ Current adress: Univ. Bordeaux, Institut des Sciences Moléculaires, UMR CNRS 5255, 351

Cours de la Libération, F-33405, Talence Cedex, France

*Corresponding authors

E-mail addresses: joelle.vidal@univ-rennes1.fr (J.VVidal), michele.reboud@upmc.fr (M. Reboud-Ravaux)

\begin{abstract}
Starting from the X-ray structure of our previous tripeptidic linear mimics of TMC-95A in complex with yeast $20 \mathrm{~S}$ proteasome, we introduced new structural features to induce a differential inhibition between human constitutive and immunoproteasome $20 \mathrm{~S}$ particles. Libraries of 24 tripeptidic and 6 dipeptidic derivatives were synthesized. The optimized preparation of 3-hydroxyoxindolyl alanine residues from tryptophan and their incorporation in peptides were described. Several potent inhibitors of human constitutive proteasome and immunoproteasome acting at the nanomolar level $\left(\mathrm{IC}_{50}=7.1 \mathrm{nM}\right.$ against the chymotrypsinlike activity for the best inhibitor) were obtained. A cytotoxic effect at the submicromolar level was observed against 6 human cancer cell lines.
\end{abstract}

\section{Graphical abstract:}




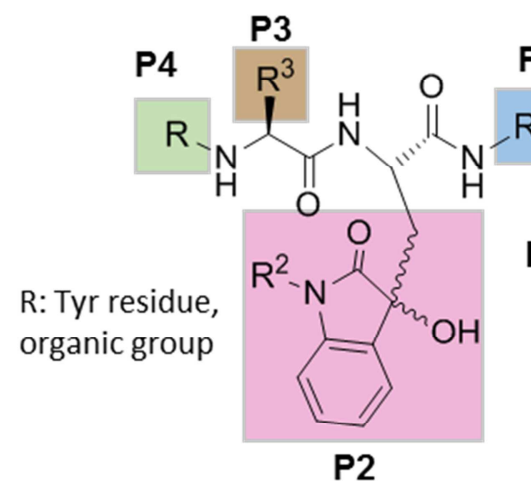

P1 $\mathrm{H}$

Human 20S proteasome

ChT-L: IC $\mathrm{C}_{50}=7.1 \mathrm{nM}$

PA: IC $C_{50}=31.9 \mu \mathrm{M}$

Cancer cell lines

$\mathrm{T}-\mathrm{L}: \mathrm{IC}_{50}=13.2 \mu \mathrm{M}$

$\mathrm{EC}_{50}=0.2-2 \mu \mathrm{M}$

\section{Highlights}

- X-ray structures drive design of immuno- and constitutive proteasome inhibitors.

- Di- and tripeptide inhibitors are tailored in order to gain subunit selectivity.

- Enantiopure 3-hydroxyoxindolylalaninamide derivatives are efficiently synthesized.

- One, 2 or 3 activities of the proteasomes are inhibited in the nanomolar range.

- The most potent inhibitors are cytotoxic against cancer cell lines.

\section{Keywords}

Proteasome inhibitors

Immunoproteasome

Constitutive proteasome

3-Hydroxyoxindolylalanine derivatives

Tryptophan oxidation

\section{Introduction}

At the end of the ubiquitin-proteasome pathway, the proteasome is a central hub of non lysosomal cellular proteolysis in the cytoplasm as well as in the nucleus of eukaryotic cells [1, 2]. Its inhibition leads to a large variety of cellular responses such a cell cycle arrest and increase of proapoptotic factors and tumor suppressors. The proteasome is an established drug target in the treatment of hematologic malignancies with three approved drugs, bortezomib $\left(\right.$ Velcade $^{\circledR}$ ) [3], carfilzomib (Kyprolis ${ }^{\circledR}$ ) [4] and the orally administered ixazomib (Ninlaro ${ }^{\circledR}$ ) [5] (Figure 1). 


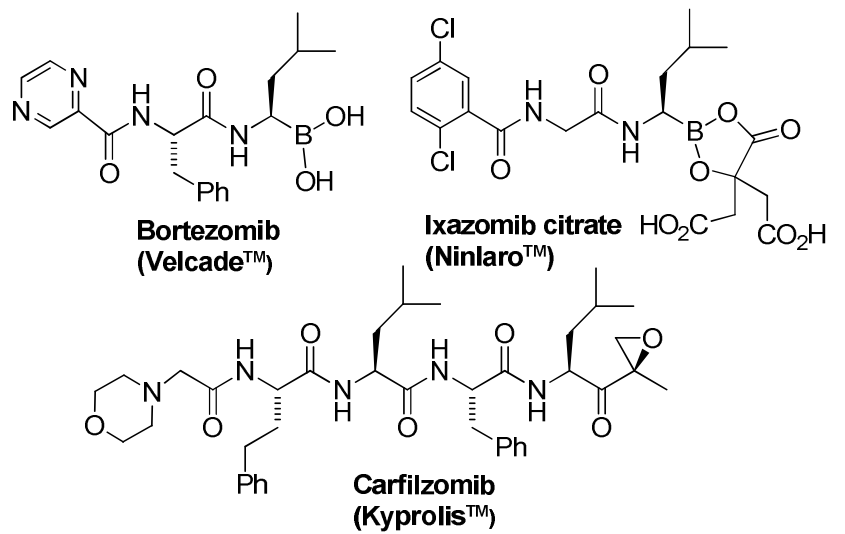

Figure 1: Covalent inhibitors used in cancer therapy.

All these approved molecules target the 20S catalytic core with covalent modification of the $\mathrm{Thr}^{\gamma} \mathrm{O}^{\gamma}$ group of the catalytic subunits. Moreover, proteasome is a potential target for immune diseases [2], tuberculosis [6] or malaria [7]. Devoid of a reactive function, noncovalent inhibitors have also been developed and have some advantages over covalent ones, such as better tissue penetration, inhibitor stability, lower reactivity and potentially higher selectivity [8]. Several peptides are noncovalent inhibitors [9], such as the natural TMC-95A and its cyclic and linear mimics 1a and 2a [10-17], dipeptides (e.g. 3-4) [18-24], and pseudopeptides [25-27] (Figure 2).

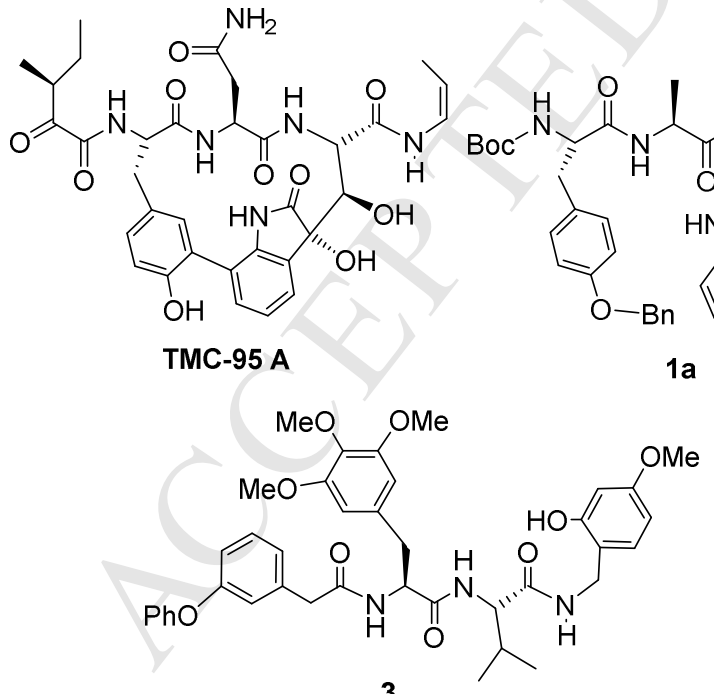

3

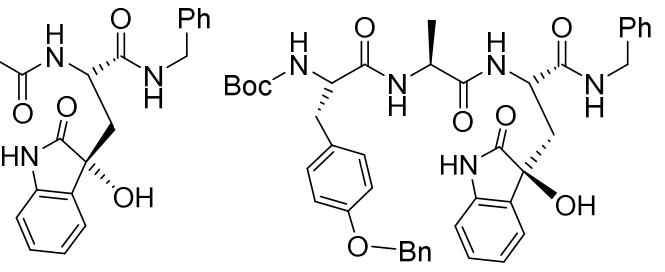

2a

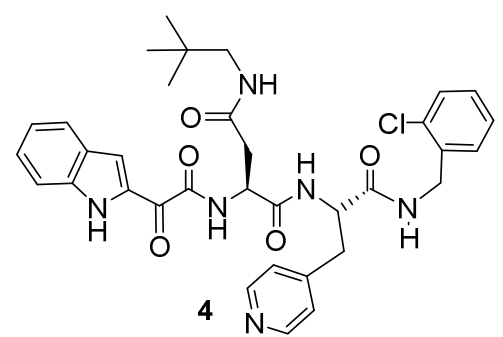

Figure 2: Some noncovalent peptide inhibitors.

Nonpeptidic noncovalent inhibitors have also been described (e. g. sulfonamides [28-31], hydroxyurea [32], 1,2,4-oxadiazoles [33], pyrazoles [34], phakellins [35], quinolines [36], psoralene [37]). The three approved covalent drugs inhibit mainly the $\beta 5$ activity of the 
catalytic core of the constitutive proteasome (cCP) but also that of the inducible immunoproteasome (iCP). This partly explain side-effects and resistance observed during cancer treatments [38]. The $\mathrm{cCP}$ and iCP catalytic cores are both made of two outer rings of 7 $\alpha$-subunits and two inner rings of $\beta$-subunits. The $2 \beta 1 \mathrm{c}, 2 \beta 2 \mathrm{c}$ and $2 \beta 5 \mathrm{c}$ catalytic units of $\mathrm{cCP}$ are replaced by the inducible $2 \beta 1 \mathrm{i}, 2 \beta 2 \mathrm{i}$ and $2 \beta 3 \mathrm{i}$ subunits in $\mathrm{iCP}$. The $\beta 1, \beta 2$ and $\beta 5$ catalytic units exhibit caspase-like or post-acid (C-L), trypsin-like (T-L) and chymotrypsinlike (ChT-L) activities, respectively. The catalytic pockets of $\mathrm{CCP}$ and iCP show subtle differences that can be exploited to discriminate between the inhibitors targeting proteasomes [39]. Our successes in developing linear mimics of TMC-95A either monovalent 1a and 2a $[16,17]$ or bivalent $[40,41]$ and their cellular penetration [42] prompted us to pursue their structure-driven development. Based on previous co-crystals of compounds 1a and 2a complexed with yeast cCP (Figure 1S, supporting information) [17], and using the reported structural data obtained with mouse constitutive and immunoproteasome 20S particles [39], we decided to explore potential structure-based improvements of the inhibitory effect of tripeptidic $(\mathbf{1}, \mathbf{2})$ and dipeptidic (5) linear mimics. The influence on the ChT-L, T-L and C-L activities of both $\mathrm{cCP}$ and $\mathrm{iCP}$ of the structural variations of residues $\mathrm{P} 1, \mathrm{P} 2, \mathrm{P} 3$ and $\mathrm{P} 4$ present in the starting molecules $\mathbf{1 a}$ and $\mathbf{2 a}$ was systematically explored (Figure 3). We report here the synthesis of molecules $\mathbf{1}, \mathbf{2}$ and $\mathbf{5}$ from the original enantiopure 3hydroxyoxindolylalaninamide residues $\mathbf{6}$ and 7, efficiently prepared from Z-tryptophan. After the in vitro enzymatic evaluation, the best inhibitors were selected and assayed on seven human tumor cell lines to evaluate their potential as cytotoxic tumor agents. 


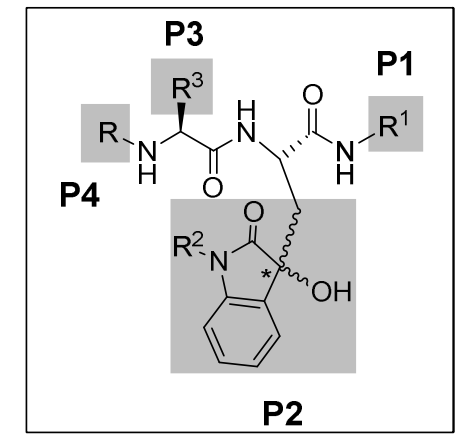

1 or 2: tripeptides with $\mathrm{R}=\mathrm{Tyr}$ residue 5: dipeptides
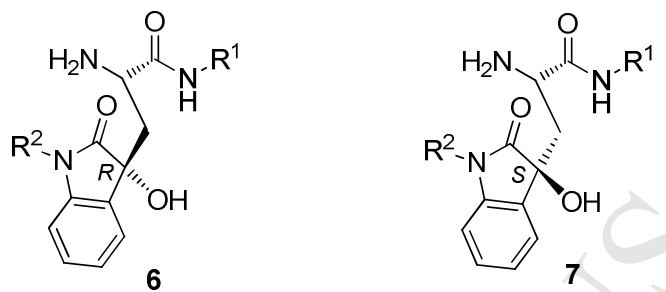

Figure 3: Structures of the studied noncovalent inhibitors 1a-v, 2a-c and 5a-f and their 3hydroxyoxindolyl alanine chemical precursors 6 and 7. The occupancy of the S1-S4 binding pockets by P1-P4 groups, respectively, is deduced from co-crystallization of compounds 1a and $2 \mathbf{a}$ with yeast proteasome [17].

\section{Results and discussion}

\subsection{Structure driven drug-design}

The design started from the X-ray structure of epimeric tripeptides 1a and 2a in complex with yeast $\mathrm{cCP}$, that showed an antiparallel $\beta$-sheet in the substrate binding channel implicating the $\beta 5 / \beta 6$ subunits. Their binding were identical, except for the epimeric oxindole moiety of the side chain in P2 which was rotated (Figure 1S) [17]. The crystallographic knowledge gained from the structures of mouse $\mathrm{cCP}$ and $\mathrm{iCP}$ and their covalent complexes with the tripeptide epoxy ketone ONX-0914 (PR-957, Figure 2S) was also used [39], as well as the crystallographic structure of human constitutive proteasome [43]. Structural features have been identified in order to potentially target $\beta 1 \mathrm{i}$ or $\beta 5 \mathrm{i}$ subunits preferentially to $\beta 1 \mathrm{c}$ or $\beta 5 \mathrm{c}$ ones [39]. In the $\beta 5$ i subunit, the subsite $S 1$ appears significantly more spacious than that of $\beta 5 \mathrm{c}$, and the subsite S3 is smaller and more hydrophilic. A defined and shallow S2 pocket is also present in $\beta 5 \mathrm{i}$. Regarding the $\beta 1 \mathrm{i}$ subunit, the $\mathrm{S} 1$ pocket is small and hydrophobic whereas the corresponding one in $\beta 1 \mathrm{c}$ accommodates $\mathrm{P} 1$ negatively charged residues. Lastly, 
the $\mathrm{S} 3$ subsite of $\beta 1 \mathrm{i}$ is smaller and more polar than that of $\beta 1 \mathrm{c}$. As $\mathrm{P} 1$ and $\mathrm{P} 3$ residues play a major role, the main structural variations in $\mathbf{1}$ were introduced in the $\mathrm{R}^{1}$ and $\mathrm{R}^{3}$ groups (Table 1). For $\mathrm{R}^{1}$, the methylene group mimicking the $\alpha$-carbon of a decarboxylated peptide was substituted by hydrogen (1b, 2b), aromatic groups with variable bulkiness (1a, 1c, 1f-i), primary (1j-m), secondary (1n) and tertiary (1o-p) aliphatic groups. The Ala residue (P3) of reference compound 1a, was replaced by the smaller Gly residue (1r), D-Ala (1q), the more polar and hydrophilic Asn, Thr or Lys (1s-v) residues. Modifications of the oxindole group at P2 (configuration of the C3-carbon: $(R)$ for tripeptides 1 or $(S)$ for tripeptides $\mathbf{2}, N$-substitution 1c and 2c) were also introduced. The peptide sequence was also shortened by removing the Tyr residue of tripeptides 1 (P4 modulation) in order to explore the activity of dipeptides 5 (Table 2).

\subsection{Chemistry}

Molecules 1, 2 and 5 were prepared starting from epimeric 3-hydroxy-2-oxindole derivatives 6 and 7 (Scheme 1). The key intermediates in the preparation of these non-proteogenic amino acids 6 and 7 were respectively the epimeric $N-Z$ spirolactones 9 and 10.

They were obtained in $64-82 \%$ total yield by oxidation of Z-L-tryptophan 8 with DMSO in the presence of $t$ - $\mathrm{BuBr}[44,45]$, as mixtures with a moderate amount of the corresponding brominated derivative $(\mathrm{X}=\mathrm{Br})$, when $\mathrm{R}^{2}=\mathrm{H}$, indicating that electrophilic bromine was released in the medium. In order to avoid bromination of the aromatic ring, attempts using DMSO activated with methanesulfonic anhydride [46] or oxalyl chloride [47], were performed and led to very low yields $(c a 10 \%)$ in 9a and 10a $(\mathrm{X}=\mathrm{H})$. As $t$-BuBr could generate hydrogen bromide at $45^{\circ} \mathrm{C}$ in the presence of DMSO (Scheme 2), the charge-transfer complex $\mathrm{Br}_{2}-\mathrm{Me}_{2} \mathrm{~S}$ was formed rather than the electrophilic sulfonium [48]. It became the source of electrophilic bromine [48, 49], that reacted with the nucleophilic enanime moiety of the indole ring to give intermediate $\mathbf{A}$ (Scheme 2). After trapping of the iminium cation by DMSO and bromo-lactonization, intermediate $\mathbf{B}$ might lead to spiro-oxindole $\mathbf{C}$. The more difficult electrophilic bromination of the benzene ring in $\mathbf{C}$ gave a small amount of $\mathbf{D}$ (Scheme 2). The oxidative lactonization of indole propanoic acids mediated by oxygen peroxide and catalytic iodide [50] was also applied to Z-tryptophan 8a and afforded the expected pure 9a $(\mathrm{X}=\mathrm{H})$ and $\mathbf{1 0 a}(\mathrm{X}=\mathrm{H})$ in 53\% overall yield, which was lower than that obtained using DMSO and $t$ - $\mathrm{BuBr}(c a 82 \%, \mathrm{X}=\mathrm{H}$ or $\mathrm{Br}$ ). We found that the epimeric lactones 9 and $\mathbf{1 0}$ could be separated by column chromatography over silica gel on a $12 \mathrm{~g}$ scale in respectively $22-37 \%$ and $42-45 \%$ yields. Opening of the lactone ring in $\mathbf{9}$ or $\mathbf{1 0}$ by 
diversely substituted primary amines was easy at room temperature. The presence of the small amount of brominated derivative $(\mathrm{X}=\mathrm{Br})$ was not a problem, since further hydrogenation in the presence of palladium on charcoal cleaved the $\mathrm{Z}$ group and also the carbon bromine bond. The expected derivatives $\mathbf{6}$ or $\mathbf{7}$ were obtained as their stable hydrochloride or TFA salts in 15-39\% overall yields from Z-tryptophan $\mathbf{8}$. The formation of the rigid lactams $\mathbf{1 1}$ and $\mathbf{1 2}$ by the slow isomerization of the free amine compounds $\mathbf{6 a}$ and 7a [51], allowed the configuration determination of the quaternary asymmetric carbon using ${ }^{1} \mathrm{H}$ NMR NOESY experiments in DMSO- $\mathrm{D}_{6}$ solvent (scheme 1).

Scheme 1: Synthesis of 3-hydroxyoxindolyl alanine precursors 6 and 7 and assignment of the configuration at the created asymmetric carbon in $\mathbf{1 1}$ and $\mathbf{1 2}$ by ${ }^{1} \mathrm{H}$ NMR NOESY experiment.
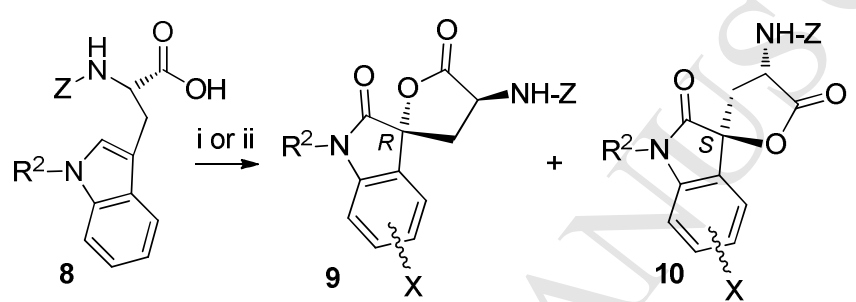

8a: $R^{2}=H$ 9a: $R^{2}=H, X=H$ or $B r \quad$ 10a: $R^{2}=H, X=H$ or $B r$ 8b: $R^{2}=M e$ 9b: $R^{2}=M e X=H$ 10b: $R^{2}=M e, X=H$
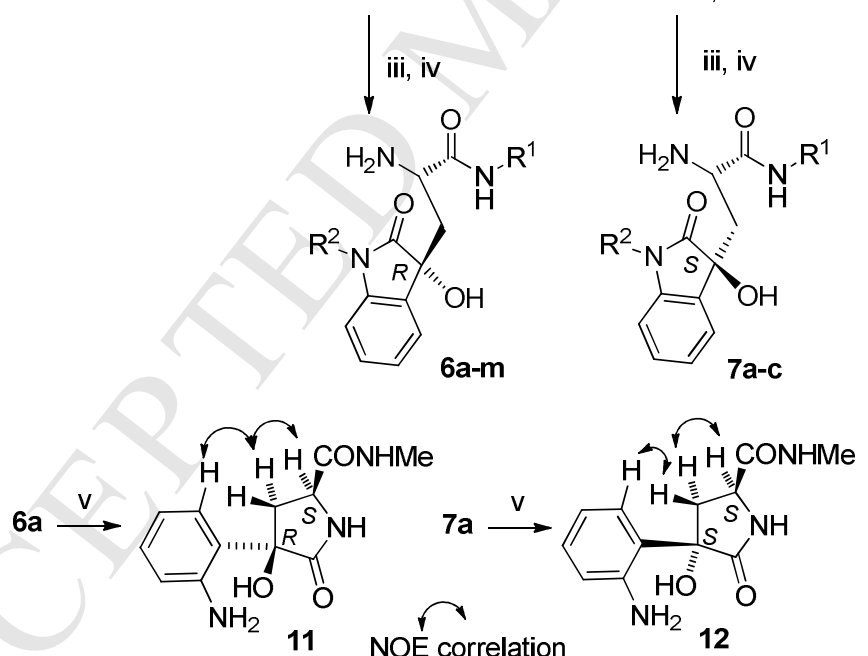

Reagents and conditions: i. DMSO, $t$-BuBr, $45{ }^{\circ} \mathrm{C}, 24 \mathrm{~h}$, separation of $\mathbf{9}$ and $\mathbf{1 0}$ by chromatography; ii. $\mathrm{H}_{2} \mathrm{O}_{2}$, catalytic $\mathrm{KI}(11 \%), \mathrm{CH}_{3} \mathrm{CN}$, RT, $18 \mathrm{~h}$, separation of 9a and 10a by chromatography. iii. $\mathrm{R}^{1} \mathrm{NH}_{2}$, THF, RT, 1.5 to 18 h; iv. $\mathrm{H}_{2}, \mathrm{Pd} / \mathrm{C}, \mathrm{MeOH}, \mathrm{RT}$, overnight, then 1 eq. anhydrous $\mathrm{HCl}$ or TFA; v. water, $72 \mathrm{~h}$, RT, more than $85 \%$ conversion.

Scheme 2: Proposed mechanism for the oxidative lactonization of indole propanoic acid mediated by $\mathrm{DMSO} / \mathrm{t}-\mathrm{BuBr}$. 


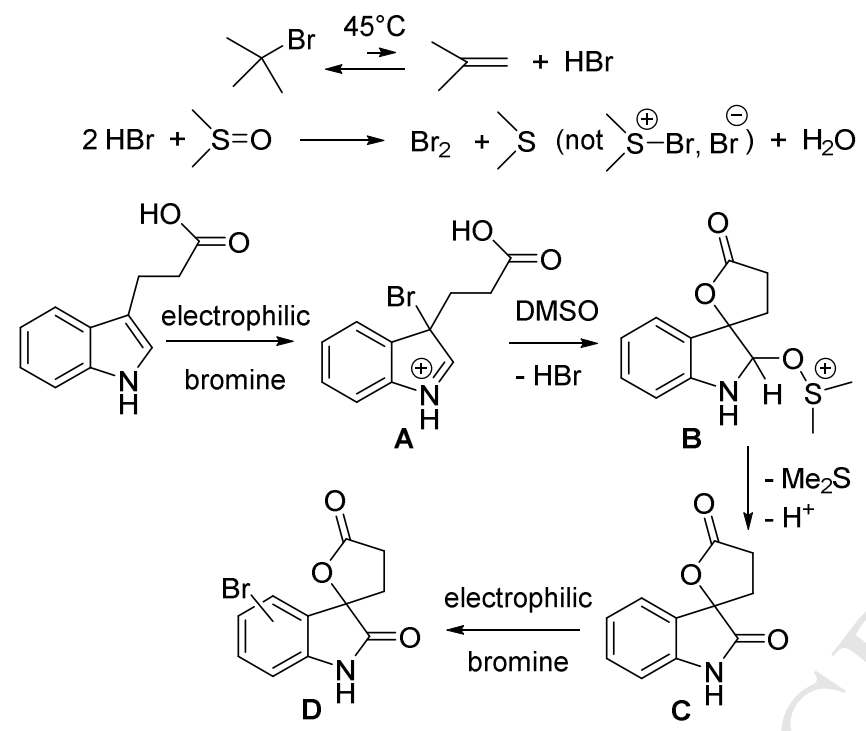

A library of peptides 1, 2 and $\mathbf{5}$ was then prepared from the 3-hydroxyoxindolyl alanine residues 6 and 7 using peptide conventional liquid-phase synthesis [52] (scheme 3 and tables 1 and 2). As the tertiary alcohol of the side chain in 6 or 7 was not protected, a mild activation of the peptide coupling partner was required and was realized by the pre-formed succinimidyl $\mathrm{(Su})$ esters. In the convergent synthesis, the succinimidyl esters of dipeptides 13 [16] were coupled to the 3-hydroxyoxindolyl alanine residues $\mathbf{6}$ and 7 to give the expected tripeptides 1a-c, 1f-i, 1o-r, $1 \mathbf{u}$ in 31-76\% yields. As some epimerization of activated dipeptide $\mathbf{1 3}$ was sometimes observed in large scale experiments, the linear synthesis of tripeptides 1-2 was also performed. $\mathrm{N}$-Z-dipeptides $\mathbf{5}$ were obtained in 56-88\% yields from $\mathbf{6}$ and commercial activated Z-amino acids 14. Hydrogenolysis of $\mathbf{5}$ followed by coupling with the tyrosine residue afforded expected tripeptides 1 in 26-64\% overall yields from the corresponding 6 . In the case of the reference compound 1a, the linear synthesis worked better than the convergent one and was applied to a gram scale preparation. Cleavage of protecting groups in tripeptides $\mathbf{1 a}, \mathbf{1} \mathbf{u}$ or $\mathbf{1 j}$ was also realized. Hydrogenolysis of the O-benzyl residue in $\mathbf{1 a}$ led to $\mathbf{1 d}$ in quantitative yield. Acidic cleavage of the Boc residue in 1a and 1u to give 1e and 1v was complete in less than $30 \mathrm{~min}$ at $0^{\circ} \mathrm{C}$ and should be controlled, since higher temperature or longer reaction time resulted in extensive decomposition of the compounds. Saponification of the methyl ester in $\mathbf{1 j}$ gave quantitatively $\mathbf{1 k}$. The $N$-terminus groups $\mathrm{R}$ encountered in peptide 3 [18] and an isomeric group [19] were also introduced in $N$-capped dipeptides 5d-f by deprotection of dipeptides $\mathbf{5 a}$ or $\mathbf{5 b}$ followed by coupling with the corresponding activated esters R-OSu. 
Scheme 3: Synthesis of non-covalent inhibitors 1a-v, 2a-c and 5a-g.

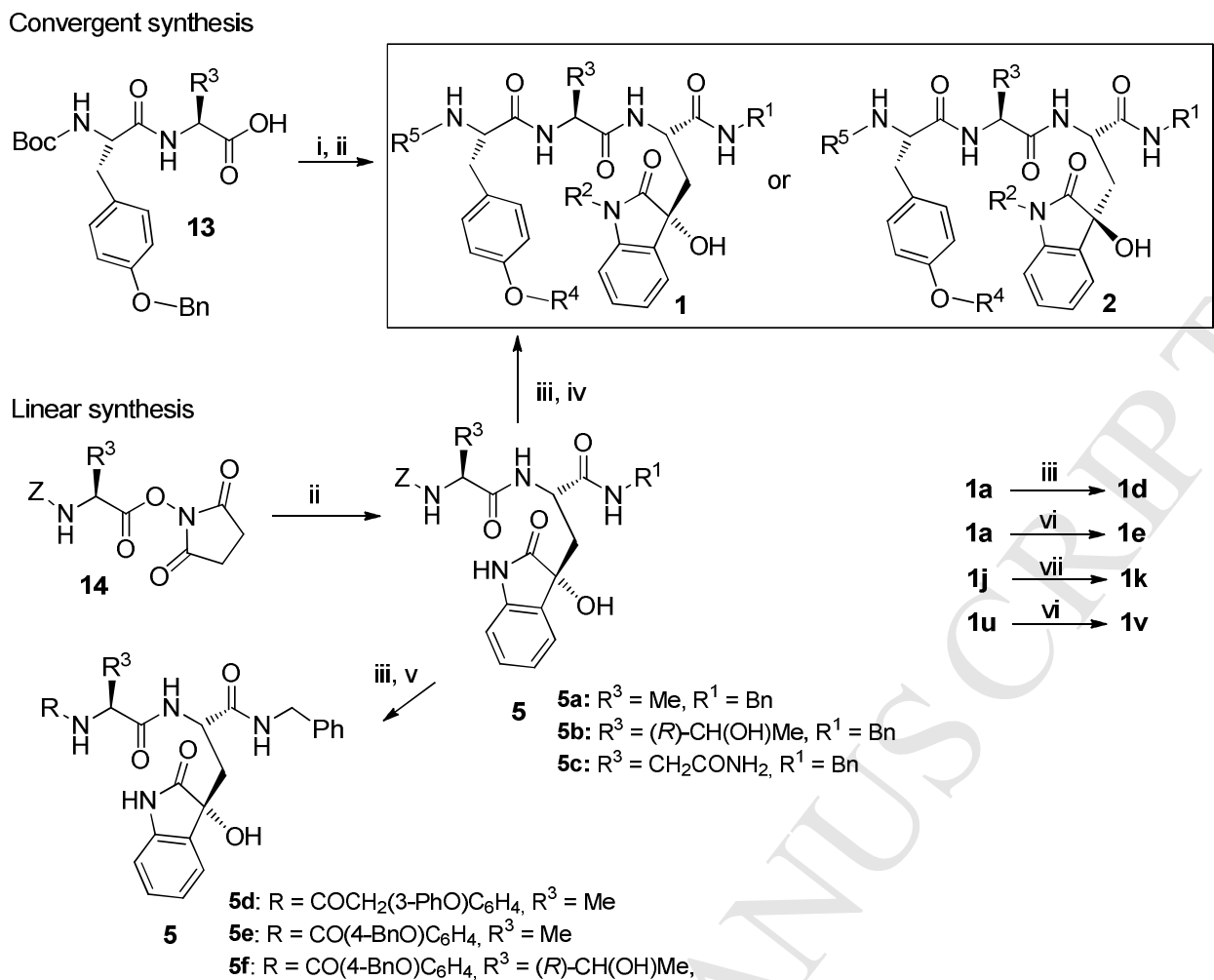

Reagents and conditions: i. DCC, HOSu, DME, overnight; ii. $\mathrm{HCl}, 6$ or $\mathrm{HCl}, 7, \mathrm{Et}_{3} \mathrm{~N}$, $\mathrm{DMF} / \mathrm{CH}_{2} \mathrm{Cl}_{2}, \mathrm{RT}$, overnight; iii. $\mathrm{H}_{2}, \mathrm{Pd} / \mathrm{C}, \mathrm{MeOH}$; iv. Boc-Tyr(Bn)-OSu, RT, overnight; v. (3-PhO) $\mathrm{C}_{6} \mathrm{H}_{4} \mathrm{CH}_{2} \mathrm{CO}_{2} \mathrm{Su}$ or (4- $\left.\mathrm{BnO}\right)-\mathrm{C}_{6} \mathrm{H}_{4} \mathrm{CO}_{2} \mathrm{Su}$; vi. anhydrous $\mathrm{HCl}, \mathrm{MeOH}, 0{ }^{\circ} \mathrm{C}, 30 \mathrm{~min}$; vii: $\mathrm{LiOH}, \mathrm{H}_{2} \mathrm{O} / \mathrm{THF}$, then aqueous $\mathrm{HCl}$.

\subsection{In vitro inhibition studies}

The inhibitory activities of compounds 1a-v, 2a-c and 5a-f on the rate of hydrolysis of the $\beta 5$ substrate Suc-LLVY-AMC and the $\beta 2$ substrate Boc-LLR-AMC catalyzed by cCP and iCP were determined (Figure 4, Tables 1 and 2). The $\beta 1$ substrates Z-LLE- $\beta$ NA and AcPAL-AMC were used to detect the activities of $\mathrm{cCP}$ and iCP respectively.
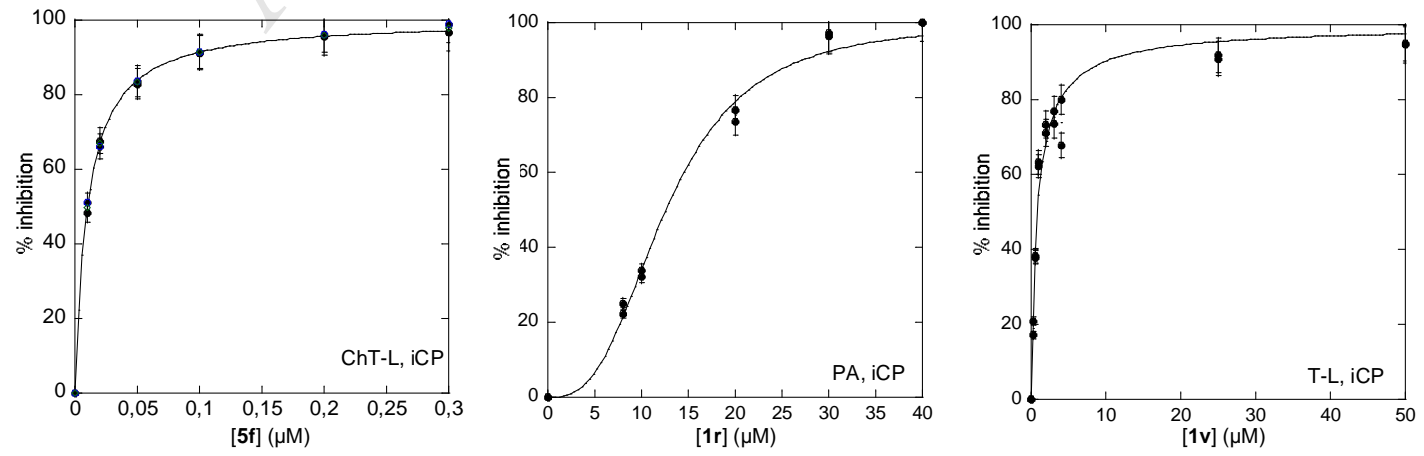

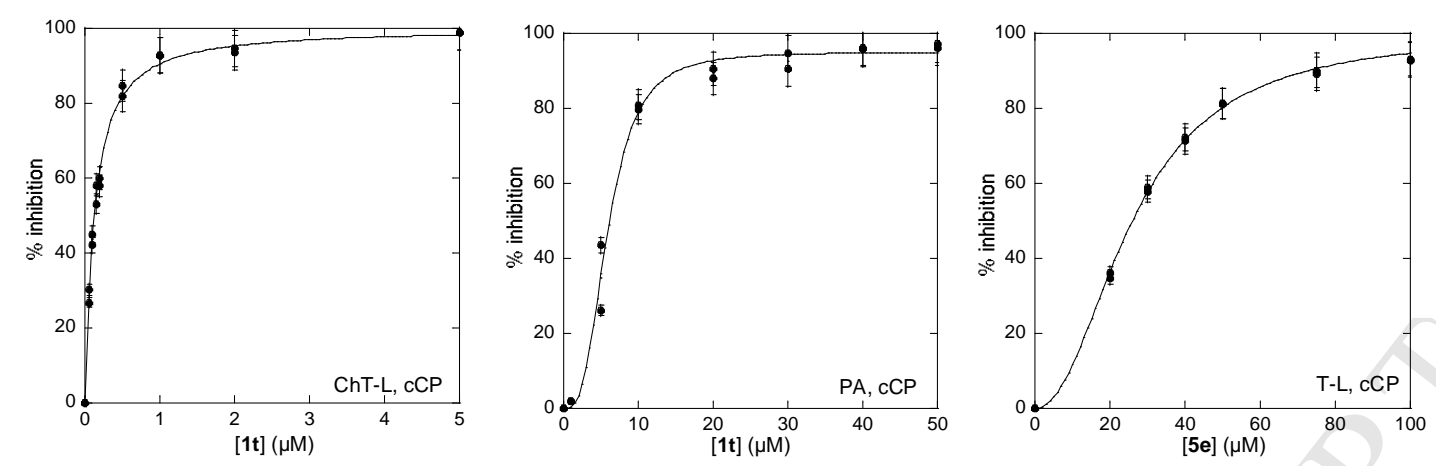

Figure 4: Inhibition profile of the ChT-L, C-L and T-L activities of cCP and iCP by compounds $\mathbf{1 r}, \mathbf{t , v}$ or $\mathbf{5 e , f}$ at $\mathrm{pH} 8$ and $37^{\circ} \mathrm{C}$. $[\mathrm{cCP}]=[\mathrm{iCP}]=0.3 \mathrm{nM}$; [Suc-LLVY-AMC $]_{0}=$ $20 \mu \mathrm{M}$ (ChT-L activity); [Boc-LLR-AMC] $]_{0}=50 \mu \mathrm{M}$ (T-L activity); [Z-LLE- $\left.\beta N A\right]_{0}=50 \mu \mathrm{M}$ (C-L activity of cCP); [Ac-PAL-AMC $]_{0}=50 \mu \mathrm{M}$ (C-L activity of iCP). Experimental points were fitted to equation 1 or 2.

A similar efficiency of the starting compound $1 \mathbf{a}$ was observed against cCP and iCP ChT-L and C-L activities whereas the inhibition of the iCP T-L activity was quasi-abolished. Reduced inhibitory activity was observed when the P1 benzylic group was replaced by the smaller methyl group (1a/1b) with a larger effect for iCP inhibition. This was expected since based on the mouse crystallographic structures of cCP and iCP [39], $\beta 5 \mathrm{i}$ seems able to accommodate larger amino acid side chain at position P1 than $\beta 5 \mathrm{c}$. The epimerization at carbon $3(\mathbf{2 a} / \mathbf{1 a}$ and $\mathbf{2 b} / \mathbf{1} \mathbf{b})$ resulted in a significantly loss of activity whereas no significant effect was observed for $\mathbf{1 c / 2 c}$ in which $\mathrm{P} 2$ substituent $\mathrm{R}^{2}=\mathrm{H}$ present in both $\mathbf{1 a}$ and $\mathbf{2 a}$ was replaced by a methyl group. The replacement of the larger $R^{5}$ Boc group (1a) by $H$ (compound 1e) led to a similar decrease effect by a factor $\approx 3$ on the ChT-L, C-L and T-L inhibition of $\mathrm{cCP}$ and $\mathrm{iCP}$. The removal of the $\mathrm{R}^{4}$ benzyl group (1d versus 1a) was very unfavorable. For further potential optimization, we enlarged side chains at $\mathrm{P} 1$ using $\mathrm{CH}_{2}(1-$ Naphthyl) (1f), $\mathrm{CH}(\mathrm{Ph})_{2}(\mathbf{1 g}), \mathrm{CH}_{2}-\left(4-\mathrm{PhC}_{6} \mathrm{H}_{4}\right)$ (1h) and $\mathrm{CH}_{2}-\left(4-i \mathrm{PrC}_{6} \mathrm{H}_{4}\right)$ (1i) to be compared to the side chain Bn (1a). Their efficiencies against ChT-L and C-L activities of both proteasomes were quite similar, except for $\mathbf{1 f}$ and $\mathbf{1 g}$ which were more efficient (factors 1.8 to 5.4) on the ChT-L and PA activities of $\mathrm{cCP}$ and iCP. Whereas compounds 1g-i were inefficient to inhibit iCP and cCP T-L activity, $\mathbf{1 f}$ inhibited T-L activities as efficiently than $\mathrm{C}$-L one $\left(\mathrm{IC}_{50}\right.$ of $\left.2.7 \mu \mathrm{M}\right)$. The adamantyl compound $\mathbf{1 p}$ was significantly less potent on iCP 
ChT-L and C-L activities than on the same cCP activities (factors of 4.7 and 2.2, respectively). The ONX-0914 derivative bearing an adamantyl at P1 failed to inhibit both CPs [53].

Attempts to enhance efficiency against C-L activity by introducing Asp analogs (compounds $\mathbf{1 j}$ and 1k) were unsuccessful. Conversely to that observed for epoxyketone peptides [53], a cyclohexyl group at the P1 position did not enhance $\beta 5$ i selectivity (compounds $\mathbf{1 m}$ and $\mathbf{1 n}$ ). Whereas the efficiency against ChT-L activity of both CPs did not vary compared to that of 1a, the efficiency against C-L activity was improved (factors of 1.3-3.7) and the effect on the T-L activity was poorer or lost. We investigated the SAR of the P3 residues. The D-Ala residue (1q) was less favorable than the L-Ala one (1a). The Asn residue also found in the natural product TMC-95A favored inhibition of the ChT-L activity of both CPs (factors of 2). An enhanced ChT-L inhibitory activity was observed when the P3 methyl group (compound 1t) was replaced by the polar lateral chain of Thr (factors of 28 for cCP and 17 for $\mathrm{iCP})$. The inhibition of the C-L activity of both CPs was poorly affected whereas the iCP T-L activity was noticeable $\left(\mathrm{IC}_{50}=5.8 \pm 0.3 \mu \mathrm{M}\right.$ ). Finally, the Lys side chain (compound $\mathbf{1 v}$ ) but not its Boc form (compound 1u) were active against the T-L activity of both CPs at the submicromolar level. The most important improvement was obtained with dipeptides $\mathbf{5}$. As for tripeptide derivatives, a favorable effect of the Asn (5b) and Thr (5c) on the ChT-L activity was observed in comparison with 5a, factors of 14 for $\mathrm{CCP}$ and 9.4 for iCP (compound 5b) and of 5.8 for $\mathrm{cCP}$ and 7 for iCP (compound $\mathbf{5 c}$ ). The T-L activity was not affected whereas the $\mathrm{C}-\mathrm{L}$ one was very poorly inhibited only for compound 5c. The $\mathrm{CO}(4-$ BnO) $\mathrm{C}_{6} \mathrm{H}_{4} \quad N$-terminal blocking group known to potentially occupy small accessory hydrophobic pockets AS1 and AS2 [18, 25] led to efficient and selective ChT-L inhibition (5f and $\mathbf{5 e}$ ). This effect was increased by more than one order of magnitude when the $\mathrm{R}^{3}$ alanine group (5e) was replaced with the threonine residue $(\mathbf{5 f})$. The $\mathrm{IC}_{50}$ values of compound $\mathbf{5 f}$ for the ChT-L activity were of $7.1 \pm 0.2 \mathrm{nM}(\mathrm{cCP})$ and $10.2 \pm 0.1 \mathrm{nM}(\mathrm{iCP})$. Finally, after $15 \mathrm{~min}$ treatment, compound $\mathbf{5 f}$ appeared to be more efficient than the covalent inhibitor ONX-0914 against ChT-L activity by a factor of 2 (cCP) and 5 (iCP). This compound is known to act selectively on the ChT-L activity of immunoproteasome [54]. 
Table 1: Inhibition by tripeptides $\mathbf{1 a - v}$ and $\mathbf{2 a - c}$ of purified human $20 \mathrm{~S}$ constitutive proteasome (values displayed in normal characters) and human $20 \mathrm{~S}$ immunoproteasome (values in bold) at $\mathrm{pH} 8$ and $37^{\circ} \mathrm{C}^{\mathrm{a}}$

\begin{tabular}{|c|c|c|c|c|c|c|c|c|}
\hline & $\mathrm{R}^{1}$ & $\mathrm{R}^{2}$ & $\mathrm{R}^{3}$ & $\mathrm{R}^{4}$ & $\mathrm{R}^{5}$ & & $\mathrm{IC}_{50}(\mu \mathrm{M})$ & $\mathrm{T} T$ \\
\hline $1 a^{b, c}$ & $\mathrm{Bn}$ & $\mathrm{H}$ & $\mathrm{Me}$ & $\mathrm{Bn}$ & Boc & $3.2 \pm 0.1$ & $11.5 \pm 0.5$ & $\frac{1-\mathrm{L}}{7.1 \pm 0.2}$ \\
\hline & & & & & & $2.53 \pm 0.07$ & $9.9 \pm 0.3$ & $28 \pm 2$ \\
\hline $1 b^{c}$ & $\mathrm{Me}$ & $\mathrm{H}$ & $\mathrm{Me}$ & $\mathrm{Bn}$ & Boc & $\begin{array}{l}79 \pm 2 \\
\mathbf{2 4 \%}\end{array}$ & $\begin{array}{l}20 \% \\
13 \%\end{array}$ & $\begin{array}{c}36 \% \\
\mathbf{7 9} \pm \mathbf{3}\end{array}$ \\
\hline $1 \mathrm{c}$ & $\mathrm{Bn}$ & $\mathrm{Me}$ & $\mathrm{Me}$ & $\mathrm{Bn}$ & Boc & $\begin{array}{c}5.1 \pm 0.1 \\
\mathbf{3 . 9 3} \pm \mathbf{0 . 0 8}\end{array}$ & $\begin{array}{c}11.4 \pm 0.3 \\
\mathbf{1 0 . 3 2} \pm \mathbf{0 . 0 7}\end{array}$ & $\begin{array}{l}19 \% \\
27 \%\end{array}$ \\
\hline $2 a^{c}$ & $\mathrm{Bn}$ & $\mathrm{H}$ & $\mathrm{Me}$ & $\mathrm{Bn}$ & Boc & $\begin{array}{l}7.0 \pm 0.3 \\
7.3 \pm 0.2\end{array}$ & $\begin{array}{l}17.2 \pm 0.4 \\
10.6 \pm 0.2\end{array}$ & $\begin{array}{c}\mathrm{ni} \\
\mathbf{3 4} \pm \mathbf{9}\end{array}$ \\
\hline $2 \mathbf{b}^{\mathrm{c}}$ & $\mathrm{Me}$ & $\mathrm{H}$ & $\mathrm{Me}$ & $\mathrm{Bn}$ & Boc & $\begin{array}{c}\text { ni } \\
8 \%\end{array}$ & $\begin{array}{l}\text { ni } \\
10 \%\end{array}$ & $\begin{array}{l}13 \% \\
19 \%\end{array}$ \\
\hline $2 \mathrm{c}$ & $\mathrm{Bn}$ & $\mathrm{Me}$ & $\mathrm{Me}$ & $\mathrm{Bn}$ & Boc & $\begin{array}{l}6.8 \pm 0.2 \\
\mathbf{6 . 1} \pm \mathbf{0 . 1}\end{array}$ & $\begin{array}{c}13.4 \pm 0.5 \\
8.9 \pm 0.2\end{array}$ & $\begin{array}{l}56 \% \\
18 \%\end{array}$ \\
\hline $1 d^{c}$ & $\mathrm{Bn}$ & $\mathrm{H}$ & $\mathrm{Me}$ & $\mathrm{H}$ & Boc & $\begin{array}{l}32 \pm 2 \\
\mathbf{3 4} \pm \mathbf{2}\end{array}$ & $\begin{array}{c}\mathrm{ni} \\
12 \%\end{array}$ & $\begin{array}{l}19 \% \\
10 \%\end{array}$ \\
\hline $1 \mathrm{e}^{\mathrm{c}}$ & $\mathrm{Bn}$ & $\mathrm{H}$ & $\mathrm{Me}$ & $\mathrm{Bn}$ & $\mathrm{H}$ & $\begin{array}{c}10.7 \pm 0.2 \\
\mathbf{1 3} \pm \mathbf{1}\end{array}$ & $\begin{array}{c}30 \pm 1 \\
\mathbf{2 1 . 5} \pm \mathbf{0 . 6}\end{array}$ & $\begin{array}{l}24.8 \pm 0.9 \\
\mathbf{2 7 . 2} \pm \mathbf{0 . 8}\end{array}$ \\
\hline 1f & $\mathrm{CH}_{2}$ (1-Naph) & $\mathrm{H}$ & $\mathrm{Me}$ & $\mathrm{Bn}$ & Boc & $\begin{array}{l}1.40 \pm 0.01 \\
\mathbf{1 . 9 0} \pm \mathbf{0 . 0 3}\end{array}$ & $\begin{array}{l}2.14 \pm 0.09 \\
\mathbf{2 . 7 7} \pm \mathbf{0 . 0 8}\end{array}$ & $\begin{array}{l}2.9 \pm 0.1 \\
\mathbf{2 . 7} \pm \mathbf{0 . 1}\end{array}$ \\
\hline $1 \mathrm{~g}$ & $\mathrm{CH}(\mathrm{Ph})_{2}$ & $\mathrm{H}$ & $\mathrm{Me}$ & $\mathrm{Bn}$ & Boc & $\begin{array}{l}1.74 \pm 0.03 \\
\mathbf{2 . 7 0} \pm \mathbf{0 . 0 6}\end{array}$ & $\begin{array}{c}2.2 \pm 0.2 \\
4 \pm 1\end{array}$ & $\begin{array}{c}30 \% \\
\mathbf{n i}\end{array}$ \\
\hline $1 \mathrm{~h}$ & $\mathrm{CH}_{2}-\left(4-\mathrm{PhC}_{6} \mathrm{H}_{4}\right)$ & $\mathrm{H}$ & $\mathrm{Me}$ & $\mathrm{Bn}$ & Boc & $\begin{array}{l}28.7 \pm 0.9 \\
19.7 \pm 0.7\end{array}$ & $\begin{array}{c}17.6 \pm 0.4 \\
\mathbf{1 3} \pm \mathbf{1}\end{array}$ & $\begin{array}{c}\mathrm{ni} \\
\mathbf{x} \mathbf{1 . 5}^{\mathbf{d}}\end{array}$ \\
\hline $\mathbf{1 i}$ & $\mathrm{CH}_{2}-\left(4-i \mathrm{PrC}_{6} \mathrm{H}_{4}\right)$ & $\mathrm{H}$ & $\mathrm{Me}$ & $\mathrm{Bn}$ & Boc & $\begin{array}{l}10.0 \pm 0.4 \\
\mathbf{1 7 . 1}+\mathbf{0 . 9}\end{array}$ & $\begin{array}{c}37 \% \\
\mathbf{4 6}+\mathbf{3}\end{array}$ & $\begin{array}{c}\mathrm{ni} \\
\mathbf{x} 1.3^{\mathrm{d}}\end{array}$ \\
\hline $\mathbf{1 j}$ & $\left(\mathrm{CH}_{2}\right)_{2} \mathrm{CO}_{2} \mathrm{Me}$ & $\mathrm{H}$ & $\mathrm{Me}$ & $\mathrm{Bn}$ & Boc & $\begin{array}{c}64 \pm 6 \\
31 \%\end{array}$ & $\begin{array}{l}15 \% \\
17 \%\end{array}$ & $\begin{array}{c}14 \% \\
106 \pm 7\end{array}$ \\
\hline $1 \mathrm{k}$ & $\left(\mathrm{CH}_{2}\right)_{2} \mathrm{CO}_{2} \mathrm{H}$ & $\mathrm{H}$ & & $\mathrm{Bn}$ & Boc & $\begin{array}{l}18 \% \\
14 \%\end{array}$ & $\begin{array}{l}19 \% \\
17 \%\end{array}$ & $\begin{array}{c}37.6 \pm 0.7 \\
\mathbf{2 2} \pm \mathbf{2}\end{array}$ \\
\hline 11 & $\left(\mathrm{CH}_{2}\right)_{2} \mathrm{Ph}$ & $\mathrm{H}$ & $\mathrm{Me}$ & $\mathrm{Bn}$ & Boc & $\begin{array}{l}6.0 \pm 0.1 \\
6.5 \pm 0.1\end{array}$ & $\begin{array}{c}4.9 \pm 0.2 \\
\mathbf{7 . 3 1} \pm \mathbf{0 . 0 6}\end{array}$ & $\begin{array}{l}45 \% \\
26 \%\end{array}$ \\
\hline $1 \mathrm{~m}$ & $\left(\mathrm{CH}_{2}\right)_{2}-\mathrm{C}_{6} \mathrm{H}_{11}$ & $\mathrm{H}$ & $\mathrm{Me}$ & $\mathrm{Bn}$ & Boc & $\begin{array}{l}2.8 \pm 0.1 \\
\mathbf{2 . 7} \pm \mathbf{0 . 1}\end{array}$ & $\begin{array}{l}2.7 \pm 0.2 \\
\mathbf{3 . 5} \pm \mathbf{0 . 1}\end{array}$ & $\begin{array}{l}36 \% \\
19 \%\end{array}$ \\
\hline 1n & $\mathrm{CH}_{2}-\mathrm{C}_{6} \mathrm{H}_{11}$ & $\mathrm{H}$ & $\mathrm{Me}$ & $\mathrm{Bn}$ & Boc & $\begin{array}{l}4.3 \pm 0.1 \\
5.2 \pm 0.1\end{array}$ & $\begin{array}{l}4.7 \pm 0.3 \\
4.8 \pm 0.2\end{array}$ & $\begin{array}{c}19.3 \pm 0.4 \\
\mathbf{1 6} \pm \mathbf{1}\end{array}$ \\
\hline 10 & $\mathrm{CH}_{2}-t \mathrm{Bu}$ & $\mathrm{H}$ & $\mathrm{Me}$ & $\mathrm{Bn}$ & Boc & $\begin{array}{l}11.3 \pm 0.2 \\
\mathbf{1 2 . 6} \pm \mathbf{0 . 3}\end{array}$ & $\begin{aligned} 15.1 & \pm 0.3 \\
\mathbf{2 1} & \pm \mathbf{1}\end{aligned}$ & $\begin{array}{l}31 \pm 2 \\
\mathbf{3 0} \pm \mathbf{3}\end{array}$ \\
\hline $1 p$ & $\mathrm{CH}_{2}$-Ada & $\mathrm{H}$ & $\mathrm{Me}$ & $\mathrm{Bn}$ & Boc & $\begin{array}{c}2.13 \pm 0.03 \\
\mathbf{1 0 . 0} \pm \mathbf{0 . 2}\end{array}$ & $\begin{array}{l}2.6 \pm 0.2 \\
\mathbf{5 . 7} \pm \mathbf{0 . 1}\end{array}$ & $\begin{array}{c}19 \% \\
\text { ni }\end{array}$ \\
\hline $1 q$ & $\mathrm{Bn}$ & $\mathrm{H}$ & (D) $\mathrm{Me}$ & $\mathrm{Bn}$ & Boc & $\begin{array}{c}9.2 \pm 0.3 \\
13.2 \pm 0.3\end{array}$ & $\begin{array}{l}17.1 \pm 0.5 \\
\mathbf{1 2 . 5} \pm \mathbf{0 . 9}\end{array}$ & $\begin{array}{l}18.6 \pm 0.2 \\
\mathbf{2 1 . 4} \pm \mathbf{0 . 4}\end{array}$ \\
\hline $1 \mathbf{r}$ & $\mathrm{Bn}$ & $\mathrm{H}$ & $\mathrm{H}$ & $\mathrm{Bn}$ & Boc & $\begin{array}{l}6.2 \pm 0.1 \\
\mathbf{7 . 8} \pm \mathbf{0 . 2}\end{array}$ & $\begin{array}{l}12.4 \pm 0.5 \\
\mathbf{1 2 . 6} \pm \mathbf{0 . 5}\end{array}$ & $\begin{array}{c}30 \pm 1 \\
\mathbf{8 . 9} \pm \mathbf{0 . 2}\end{array}$ \\
\hline $1 \mathrm{~s}$ & $\mathrm{Bn}$ & $\mathrm{H}$ & $\mathrm{CH}_{2} \mathrm{CONH}_{2}$ & $\mathrm{Bn}$ & Boc & $\begin{array}{c}1.48 \pm 0.04 \\
\mathbf{1 . 6} \pm \mathbf{0 . 1}\end{array}$ & $\begin{array}{l}20.1 \pm 0.8 \\
\mathbf{1 6 . 1} \pm \mathbf{0 . 9}\end{array}$ & $\begin{array}{l}\times 1.4^{\mathrm{d}} \\
\times \mathbf{x} 1.3^{\mathrm{d}}\end{array}$ \\
\hline 1t & $\mathrm{Bn}$ & $\mathrm{H}$ & $(R)-\mathrm{CH}(\mathrm{OH}) \mathrm{Me}$ & $\mathrm{Bn}$ & Boc & $\begin{array}{c}0.125 \pm 0.004 \\
\mathbf{0 . 2 0} \pm \mathbf{0 . 0 1}\end{array}$ & $\begin{array}{c}6.08 \pm 0.09 \\
\mathbf{8 . 8} \pm \mathbf{0 . 7}\end{array}$ & $\begin{array}{c}13.5 \pm 0.8 \\
\mathbf{5 . 8} \pm \mathbf{0 . 3}\end{array}$ \\
\hline $1 u$ & $\mathrm{Bn}$ & $\mathrm{H}$ & $\left(\mathrm{CH}_{2}\right)_{4} \mathrm{NHBoc}$ & $\mathrm{Bn}$ & Boc & $\begin{array}{l}22.0 \pm 0.4 \\
\mathbf{2 5 . 1} \pm \mathbf{0 . 9}\end{array}$ & $\begin{array}{c}15 \% \\
\mathbf{5 9} \pm \mathbf{5}\end{array}$ & $\begin{array}{c}\mathrm{ni} \\
\mathbf{x} \mathbf{1 . 3 ^ { \mathrm { d } }}\end{array}$ \\
\hline $1 v$ & $\mathrm{Bn}$ & $\mathrm{H}$ & $\left(\mathrm{CH}_{2}\right)_{4} \mathrm{NH}_{2}$ & $\mathrm{Bn}$ & $\mathrm{H}$ & $\begin{array}{l}2.9 \pm 0.1 \\
3.8 \pm 0.1\end{array}$ & $\begin{array}{c}13.0 \pm 0.9 \\
\mathbf{4 . 3} \pm \mathbf{0 . 6}\end{array}$ & $\begin{array}{l}0.52 \pm 0.08 \\
\mathbf{0 . 8 2} \pm \mathbf{0 . 0 7}\end{array}$ \\
\hline
\end{tabular}

${ }^{a}$ The inhibition was evaluated after 15 min incubation of the enzyme with the respective compound before adding the appropriate fluorogenic substrate (Suc-LLVY-AMC for ChT-L 
activities of cCP and iCP, Z-LLE- $\beta N A$ for C-L activity of cCP, Ac-PAL-AMC for C-L activity of $\mathrm{iCP}$ and Boc-LLR-AMC for T-L activities). ni: no inhibition. $\mathrm{IC}_{50}$ values were determined when the $\%$ inhibition was higher than $85 \%$ at $50 \mu \mathrm{M}$. The $\%$ inhibition at $50 \mu \mathrm{M}$ is displayed in italicized text. ${ }^{b}$ Published results [42]. ${ }^{\mathrm{c}}$ Inhibition of the ChT-L activity of yeast proteasome was previously published [17]. ${ }^{\mathrm{d}}$ Activation factor at $50 \mu \mathrm{M}$.

Table 2: Inhibition by dipeptides 5a-f of purified human $20 \mathrm{~S}$ constitutive proteasome (values displayed in normal characters) and human $20 \mathrm{~S}$ immunoproteasome (values in bold) at $\mathrm{pH} 8$ and $37^{\circ} \mathrm{C}^{\mathrm{a}}$

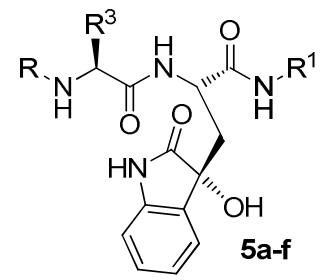

\begin{tabular}{|c|c|c|c|c|c|c|}
\hline & $\mathrm{R}^{1}$ & $\mathrm{R}^{3}$ & $\mathrm{R}$ & $\begin{array}{l}\mathrm{IC}_{50}(\mu \mathrm{M}) \\
\text { ChT-L }\end{array}$ & C-L & T-L \\
\hline $5 \mathbf{5 a}$ & $\mathrm{Bn}$ & $\mathrm{Me}$ & $\mathrm{Z}$ & $5.1 \pm 0.1$ & ni & ni \\
\hline $5 b$ & $\mathrm{Bn}$ & $\mathrm{CH}_{2} \mathrm{CONH}_{2}$ & Z & $\begin{array}{l}\mathbf{3 . 9 6} \pm \mathbf{0 . 0 9} \\
0.36 \pm 0.02 \\
\mathbf{0 . 4 2} \pm \mathbf{0 . 0 1}\end{array}$ & $\begin{array}{l}45 \pm 2 \\
\text { ni } \\
\text { ni }\end{array}$ & $\begin{array}{l}\text { ni } \\
\text { ni } \\
\text { ni }\end{array}$ \\
\hline $5 c$ & $\mathrm{Bn}$ & $(R)-\mathrm{CH}(\mathrm{OH}) \mathrm{Me}$ & $\mathrm{Z}$ & $\begin{array}{l}0.88 \pm 0.02 \\
\mathbf{0 . 5 7 2} \pm \mathbf{0 . 0 0 5}\end{array}$ & $\begin{array}{l}20 \% \\
\mathbf{2 4 . 6} \pm \mathbf{0 . 7}\end{array}$ & ni \\
\hline $5 d$ & $\mathrm{Bn}$ & $\mathrm{Me}$ & $\mathrm{COCH}_{2}(3-\mathrm{PhO}) \mathrm{C}_{6} \mathrm{H}_{4}$ & $\begin{array}{l}0.35 \pm 0.01 \\
\mathbf{0 . 2 6}+\mathbf{0 . 0 1}\end{array}$ & $\begin{array}{l}40 \pm 1 \\
14+1\end{array}$ & $\begin{array}{l}16.2 \pm 0.7 \\
14.3+0.6\end{array}$ \\
\hline $5 e$ & $\mathrm{Bn}$ & $\mathrm{Me}$ & $\mathrm{CO}(4-\mathrm{BnO}) \mathrm{C}_{6} \mathrm{H}_{4}$ & $\begin{array}{l}0.113 \pm 0.006 \\
\mathbf{0 . 1 7 0} \pm \mathbf{0 . 0 0 4}\end{array}$ & $\begin{array}{l}35 \pm 1 \\
\mathbf{5 2} \pm \mathbf{2}\end{array}$ & $\begin{array}{l}26.0 \pm 0.3 \\
\mathbf{2 8 . 3} \pm \mathbf{0 . 7}\end{array}$ \\
\hline $5 f$ & $\mathrm{Bn}$ & $(R)-\mathrm{CH}(\mathrm{OH}) \mathrm{Me}$ & $\mathrm{CO}(4-\mathrm{BnO}) \mathrm{C}_{6} \mathrm{H}_{4}$ & $\begin{array}{l}0.0071 \pm 0.0002 \\
\mathbf{0 . 0 1 0 2} \pm \mathbf{0 . 0 0 0 1}\end{array}$ & $\begin{array}{l}31.9 \pm 0.6 \\
\mathbf{2 3 . 8} \pm \mathbf{0 . 7}\end{array}$ & $\begin{array}{l}13.2 \pm 0.5 \\
\mathbf{6 . 6} \pm \mathbf{0 . 6}\end{array}$ \\
\hline ONX-0914 & - & - & & $\begin{array}{l}0.15 \pm 0.02 \\
\mathbf{0 . 0 5 2} \pm \mathbf{0 . 0 0 7}\end{array}$ & $\begin{array}{l}22 \pm 1 \\
\mathbf{0 . 5 9} \pm \mathbf{0 . 0 3}\end{array}$ & $\begin{array}{l}4.7 \pm 0.6 \\
\mathbf{4 . 8 5} \pm \mathbf{0 . 0 7}\end{array}$ \\
\hline
\end{tabular}

${ }^{\mathrm{a}}$ The inhibition was evaluated after $15 \mathrm{~min}$ incubation of the enzyme with the respective compound before adding the appropriate fluorogenic substrate (Suc-LLVY-AMC for ChT-L activities of $\mathrm{cCP}$ and iCP, Z-LLE- $\beta \mathrm{NA}$ for C-L activity of cCP, Ac-PAL-AMC for C-L activity of $\mathrm{iCP}$ and Boc-LLR-AMC for T-L activities). ni: no inhibition. $\mathrm{IC}_{50}$ values were determined when the $\%$ inhibition was higher than $85 \%$ at $50 \mu \mathrm{M}$. The $\%$ inhibition at $50 \mu \mathrm{M}$ is displayed in italicized text.

\subsection{Tumor cells assays}

The cell viability of the best inhibitors was evaluated on several cancer cell lines: hepatocellular carcinoma Huh-7, colorectal adenocarcinoma Caco2, colorectal carcinoma HCT-116, breast carcinoma MDA-MB 231, breast carcinoma MCF7, prostate carcinoma PC3 
and lung carcinoid NCI-H727) (Table 3, Figure S3). Human skin fibroblasts were the reference for non-tumor cells. DMSO was used as negative control and the proteasome inhibitor ONX-0914 as positive control. After $48 \mathrm{~h}$ treatment with the inhibitors, cells were fixed and the nuclei were stained with Hoechst 33342, and then counted. The survival percentages were calculated as the number of cells after compound treatment over the number of cells after DMSO treatment. According to dose-response curves, the $\mathrm{EC}_{50}$ values were determined (Table 3). Dipeptides 5e,f were more cytotoxic than tripeptides 1a,s-t. Dipeptide 5f displayed toxicities in the sub-micromolar range against 6 over 7 cancer cell lines. Its effect was close to that obtained with ONX-0914 on MDA-MB 231, HCT-116, PC3, NCI-H727 and MCF7. Noticeably, normal fibroblasts were not affected by treatment with our compounds.

Table 3. Effect of compounds 1a,s,t and 5e,f on the survival of human cancer cells and normal human skin fibroblasts using Hoechst 3342 staining.

\begin{tabular}{lllllllll}
\hline & & \multicolumn{7}{c}{$\mathrm{EC}_{50}(\mu \mathrm{M})$} \\
& HuH7 & CaCo-2 & MDA-MB-231 & HCT-116 & PC3 & NCI-H727 & MCF7 & Fibroblasts \\
\hline 1a & ne & ne & ne & 32 & ne & ne & 26 & ne \\
$\mathbf{1 s}$ & ne & ne & ne & ne & ne & ne & ne & ne \\
$\mathbf{1 t}$ & ne & 32 & 9 & 9 & 10 & ne & 9 & ne \\
$\mathbf{5 e}$ & ne & ne & 23 & 10 & 24 & ne & 21 & ne \\
$\mathbf{5 f}$ & ne & 5 & 0.7 & 0.2 & 0.4 & 2 & 0.7 & ne \\
ONX-0914 & 0.39 & 1.3 & 0.27 & 0.11 & 0.33 & 0.3 & 0.26 & 0.16 \\
\hline
\end{tabular}

ne: no effect at $25 \mu \mathrm{M}$.

\section{Conclusion}

We have designed and synthesized 22 new tripeptidic and 6 dipeptidic linear analogs of the natural non covalent inhibitor TMC-95A and analyzed their inhibitory activity against human cCP and iCP. We investigated analogs with various P1 and P3 residues for tripeptides, and various $\mathrm{P} 1, \mathrm{P} 3$ residues and $N$-terminal groups for dipeptides reasoning that the interaction of these residues with the enzyme subsites described in previous studies by us [17] or others [1921] would contribute to affinity and orientate the inhibitor selectivity towards iCP over cCP. Conversely to that observed with covalent inhibitors such as epoxyketones [53, 55], bulky P1 groups such as naphtyl, 4-isopropyl, 4-biphenyl or cyclohexyl groups did not favor the inhibition of iCP over cCP. The simultaneous introduction of the threonine residue at the P3 position and the $\mathrm{CO}\left(4-\mathrm{BnOC}_{6} \mathrm{H}_{4}\right)$ as $\mathrm{N}$-terminal group in dipeptides led to the inhibition of both $\mathrm{cCP}$ and $\mathrm{iCP}$ at the nanomolar level. Discrepancies between covalent and noncovalent 
inhibitors may be correlated to differences in conformational changes upon their binding with the catalytic subsites and the formation of a covalent bond with $\mathrm{Thr}_{10}^{\gamma}$ in the case of covalent inhibitors $[56,57]$.

\section{Experimental section}

\subsection{Chemistry}

General chemistry methods are described in the supporting information.

\subsubsection{Synthesis of 3-hydroxyoxindolyl alanine residues 6 and 7}

\subsubsection{General procedure for the preparation of spirolactones $9 \mathbf{a}$ and $10 \mathrm{a}$}

To a solution of Z-L-Trp-OH (12.00 g, $35.5 \mathrm{mmol})$ in DMSO (26.8 mL, $377 \mathrm{mmol})$, was added slowly $t$ - $\mathrm{BuBr}(41.5 \mathrm{~mL}, 357 \mathrm{mmol})$. The mixture was stirred at $45^{\circ} \mathrm{C}$ for 20 hours. The excess of $t$ - $\mathrm{BuBr}$ and DMSO was removed under reduced pressure. After dilution by $\mathrm{CH}_{2} \mathrm{Cl}_{2}$ $(150 \mathrm{~mL})$, the mixture was washed by iced water twice $(2 \times 20 \mathrm{~mL})$. The organic phase was concentrated in vacuo and the residue was purified by chromatography over silica gel (835 g, eluent $5,10,15,20 \%$ of AcOEt in $\left.\mathrm{CH}_{2} \mathrm{Cl}_{2}\right)$ to afford two fractions: the less polar $3(R)$ spirolactones 9a as a brown amorphous solid (4.90 g, 70/30 mixture of non brominated (X $=\mathrm{H}) /$ brominated $(\mathrm{X}=\mathrm{Br})$ derivatives, $c$ a $37 \%$ yield $)$ and the more polar $3(S)$-spirolactones 10a as a brown amorphous solid $(6.00 \mathrm{~g}, 70 / 30$ mixture of non brominated $(\mathrm{X}=\mathrm{H}) /$ brominated $(\mathrm{X}=\mathrm{Br})$ derivatives, $c a 45 \%$ yield). An authentic sample of 9a $(\mathrm{X}=\mathrm{H})$ and 10a $(\mathrm{X}=\mathrm{H})$ was obtained by reaction at room temperature of Z-L-Trp-OH $(0.364 \mathrm{~g}, 1.07 \mathrm{mmol})$ in acetonitrile $(6 \mathrm{~mL})$ with potassium iodide $(20.3 \mathrm{mmg}, 0.12 \mathrm{mmol})$ and $35 \%$ hydrogene peroxide $(0.57 \mathrm{~mL}, 7.04 \mathrm{mmol})$. The brownish reaction mixture was stirred overnight at room temperature, and then concentrated in vасио. After chromatography over silica gel (16 g, eluent $\mathrm{AcOEt}$ in $\left.\mathrm{CH}_{2} \mathrm{Cl}_{2}\right)$, spirolactones 9a $(\mathrm{X}=\mathrm{H}, 57 \mathrm{mg}, 15 \%$ yield $)$ and 10a $(\mathrm{X}=\mathrm{H}, 142$ $\mathrm{mg}, 38 \%$ ) were afforded as solids.

3(R)-spirolactone 9a $(\mathrm{X}=\mathrm{H})$. Yellowish solid. Mp (decomposition) $150{ }^{\circ} \mathrm{C}$. ${ }^{1} \mathrm{H}$ NMR (300 $\left.\mathrm{MHz}, \mathrm{CDCl}_{3}\right) \delta 2.49(\mathrm{dd}, J=14.1,5.4 \mathrm{~Hz}, 1 \mathrm{H}), 2.83(\mathrm{dd}, J=14.1,9.6 \mathrm{~Hz}, 1 \mathrm{H}), 5.11(\mathrm{~m}, 1 \mathrm{H})$, $5.19(\mathrm{~s}, 2 \mathrm{H}), 6.22(\mathrm{~d}, J=9.0 \mathrm{~Hz}, 1 \mathrm{H}), 6.93(\mathrm{~d}, J=7.5 \mathrm{~Hz}, 1 \mathrm{H}), 7.15$ (t, $J=6.9 \mathrm{~Hz}, 1 \mathrm{H}), 7.35-$ $7.40(\mathrm{~m}, 7 \mathrm{H}), 7.94$ (br s, $1 \mathrm{H}) .{ }^{13} \mathrm{C} \mathrm{NMR}\left(75.5 \mathrm{MHz}, \mathrm{CD}_{3} \mathrm{COCD}_{3}\right) \delta 37.14\left(\mathrm{CH}_{2}\right), 51.00(\mathrm{CH})$, $67.31\left(\mathrm{CH}_{2}\right), 81.80(\mathrm{C}), 111.67(\mathrm{CH}), 123.97(\mathrm{CH}), 125.09(\mathrm{CH}), 128.03(\mathrm{C}), 128.78(\mathrm{CH})$, $128.82(\mathrm{CH}), 129.24(\mathrm{CH}), 132.05(\mathrm{CH}), 137.82(\mathrm{C}), 142.93(\mathrm{C}), 156.70(\mathrm{C}), 174.47(\mathrm{C})$, 175.79 (C). HRMS (ESI) calcd for $\mathrm{C}_{19} \mathrm{H}_{16} \mathrm{~N}_{2} \mathrm{O}_{5} \mathrm{Na}\left[(\mathrm{M}+\mathrm{Na})^{+}\right]$375.0953, found 375.0955. $R_{f}$ (1/4 AcOEt/ $/ \mathrm{CH}_{2} \mathrm{Cl}_{2}$ ) 0.45 . 
3(S)-spirolactone 10a $(\mathrm{X}=\mathrm{H})$. White solid. Mp (decomposition) $164{ }^{\circ} \mathrm{C} .{ }^{1} \mathrm{H}$ NMR $(300 \mathrm{MHz}$, $\left.\mathrm{CDCl}_{3}\right) \delta 2.76(\mathrm{~m}, 1 \mathrm{H}), 2.92(\mathrm{~m}, 1 \mathrm{H}), 5.00(\mathrm{~m}, 1 \mathrm{H}), 5.14(\mathrm{~s}, 1 \mathrm{H}), 5.68(\mathrm{~d}, J=6.0 \mathrm{~Hz}, 1 \mathrm{H})$, $6.91(\mathrm{~d}, J=7.8 \mathrm{~Hz}, 1 \mathrm{H}), 7.13(\mathrm{~m}, 1 \mathrm{H}), 7.33-7.55(\mathrm{~m}, 7 \mathrm{H}), 8,31(\mathrm{br} \mathrm{s}, 1 \mathrm{H}) .{ }^{13} \mathrm{C} \mathrm{NMR}(75.5$ $\left.\mathrm{MHz}, \mathrm{CD}_{3} \mathrm{COCD}_{3}\right) \delta 36.79\left(\mathrm{CH}_{2}\right), 51.12(\mathrm{CH}), 67.21\left(\mathrm{CH}_{2}\right), 80.78(\mathrm{C}), 111.46(\mathrm{CH}), 123.87$ $(\mathrm{CH}), 125.82(\mathrm{CH}), 127.40(\mathrm{C}), 128.74(\mathrm{CH}), 128.79(\mathrm{CH}), 129.24(\mathrm{CH}), 132.16(\mathrm{CH})$, 137.75 (C), 143.49 (C), 156.81 (C), 174.50 (C), 176.43 (C). HRMS (ESI) calcd for $\mathrm{C}_{19} \mathrm{H}_{16} \mathrm{~N}_{2} \mathrm{O}_{5} \mathrm{Na}\left[(\mathrm{M}+\mathrm{Na})^{+}\right]$375.0953, found 375.0951. $R_{f}\left(1 / 4 \mathrm{AcOEt} / \mathrm{CH}_{2} \mathrm{Cl}_{2}\right)$ 0.3.

\subsubsection{Spirolactones $\mathbf{9 b}$ and $\mathbf{1 0 b}$}

According to the same procedure starting from Z-L-methyltryprophan (4.84 g, $13.7 \mathrm{mmol})$, DMSO (9.9 mL, $140 \mathrm{mmol})$ and tert-butyl bromide $(15.6 \mathrm{~mL}, 139 \mathrm{mmol})$, the less polar spirolactone 9b (1.10 g, $22 \%$ yield) and the more polar spirolactone $\mathbf{1 0 b}$ ( $2.03 \mathrm{~g}, 42 \%$ yield) were obtained as vitreous orange solids after purification by chromatography over silica gel (260 g, eluent 5, 10, 15, 20\% of AcOEt in $\mathrm{CH}_{2} \mathrm{Cl}_{2}$ ).

3(R)-spirolactone 9b: Mp (decomposition) $67{ }^{\circ} \mathrm{C} .{ }^{1} \mathrm{H} \mathrm{NMR}\left(300 \mathrm{MHz}, \mathrm{CDCl}_{3}\right) \delta 2.43(\mathrm{dd}, J$ = 14.0, $5.0 \mathrm{~Hz}, 1 \mathrm{H}), 2.78(\mathrm{dd}, J=14.0,9.3 \mathrm{~Hz}, 1 \mathrm{H}), 3.20(\mathrm{~s}, 3 \mathrm{H}), 5.08(\mathrm{~m}, 1 \mathrm{H}), 5.15(\mathrm{~s}, 2 \mathrm{H})$, $6.42(\mathrm{~d}, J=9.3 \mathrm{~Hz}, 1 \mathrm{H}), 6.89(\mathrm{~d}, J=7.8 \mathrm{~Hz}, 1 \mathrm{H}), 7.15(\mathrm{t}, J=7.3 \mathrm{~Hz}, 1 \mathrm{H}), 7.43-7.47$ (m, 7H). ${ }^{13} \mathrm{C}$ NMR (75.5 MHz, $\left.\mathrm{CDCl}_{3}\right) \delta 26.56\left(\mathrm{CH}_{3}\right), 37.35\left(\mathrm{CH}_{2}\right), 50.07(\mathrm{CH}), 67.36\left(\mathrm{CH}_{2}\right), 81.35$ (C), $109.23(\mathrm{CH}), 123.96(\mathrm{CH}), 124.30(\mathrm{CH}), 125.44(\mathrm{C}), 128.14(\mathrm{CH}), 128.17(\mathrm{CH}), 128.53$ $(\mathrm{CH}), 131.56(\mathrm{CH}), 135.97(\mathrm{C}), 143.68(\mathrm{C}), 155.97(\mathrm{C}), 173.58(\mathrm{C}), 173.84(\mathrm{C})$. HRMS (ESI) calcd for $\mathrm{C}_{20} \mathrm{H}_{18} \mathrm{~N}_{2} \mathrm{O}_{5} \mathrm{Na}\left[(\mathrm{M}+\mathrm{Na})^{+}\right]$389.1108, found 389.1107. $\mathrm{R}_{f}=0.49\left(\mathrm{AcOEt} / \mathrm{CH}_{2} \mathrm{Cl}_{2}\right.$ $5 / 95)$

3(S)-spirolactone 10b: $\mathrm{Mp}$ (decomposition) $140{ }^{\circ} \mathrm{C} .{ }^{1} \mathrm{H}$ NMR $\left(300 \mathrm{MHz}, \mathrm{CDCl}_{3}\right) \delta 2.80(\mathrm{~m}$, $2 \mathrm{H}), 3.18(\mathrm{~s}, 3 \mathrm{H}), 4.94-5.03(\mathrm{~m}, 1 \mathrm{H}), 5.14(\mathrm{~s}, 2 \mathrm{H}), 5.65(\mathrm{~d}, J=6.1 \mathrm{~Hz}, 1 \mathrm{H}), 6.85(\mathrm{~d}, J=7.8$ $\mathrm{Hz}, 1 \mathrm{H}), 7.14(\mathrm{t}, J=7.4 \mathrm{~Hz}, 1 \mathrm{H}),, 7.32-7.43(\mathrm{~m}, 6 \mathrm{H}),, 7.52(\mathrm{~d}, J=7.2 \mathrm{~Hz}, 1 \mathrm{H}) .{ }^{13} \mathrm{C} \mathrm{NMR}$ (75.5 MHz, $\left.\mathrm{CDCl}_{3}\right) \delta 26.34\left(\mathrm{CH}_{3}\right), 36.62\left(\mathrm{CH}_{2}\right), 50.65(\mathrm{CH}), 67.30\left(\mathrm{CH}_{2}\right), 81.13(\mathrm{C}), 108.80$ $(\mathrm{CH}), 123.80(\mathrm{CH}), 125.03(\mathrm{CH}), 125.43(\mathrm{C}), 128.15(\mathrm{CH}), 128.30(\mathrm{CH}), 128.55(\mathrm{CH})$, $131.44(\mathrm{CH}), 135.77$ (C), 144.03 (C), 155.65 (C), 173.70 (C), 173.84 (C). HRMS (ESI) calcd for $\mathrm{C}_{20} \mathrm{H}_{18} \mathrm{~N}_{2} \mathrm{O}_{5} \mathrm{Na}\left[(\mathrm{M}+\mathrm{Na})^{+}\right]$389.1108, found 389.1105. $\mathrm{R}_{f}=0.31\left(\mathrm{AcOEt} / \mathrm{CH}_{2} \mathrm{Cl}_{2}\right.$ 5/95)

4.1.1.3. General procedure for the synthesis of (S)-2-amino-N-methyl-3-((R)-3-hydroxy-2oxoindolin-3-yl)propanamide $\mathbf{6 a}$ : 
Spirolactone 9a (200 mg, ca $0.53 \mathrm{mmol}$, based on a 70:30 ratio of $\mathrm{H}$ - and Br-oxindole starting material, $\mathrm{X}=\mathrm{H}$ or $\mathrm{Br}$ ) was reacted with $2 \mathrm{M} \mathrm{MeNH}_{2}$ in THF ( $2 \mathrm{~mL}, 4 \mathrm{mmol}$ ) for $3 \mathrm{~h}$ at room temperature. Evaporation of the solvent under reduced pressure and chromatography over silica gel $\left(2 \% \mathrm{MeOH}\right.$ in $\left.\mathrm{CH}_{2} \mathrm{Cl}_{2}\right)$ afforded a 70:30 mixture of non-brominated and brominated Z-protected 6a (170 mg, yield $\mathrm{ca} 79 \%$ ) as a yellow amorphous solid. MPLC purification of a small sample $(38 \mathrm{mg})$ over reversed phase silica $(\mathrm{C} 18,5 \mathrm{~g}, 50 \% \mathrm{MeOH}$ in water) afforded after lyophilization, (S)-2-benzyloxycarbonylamino-N-methyl-3-((R)-3-hydroxy-2-oxoindolin3 -yl)propanamide $\left(22.3 \mathrm{mg},{ }^{1} \mathrm{H} \mathrm{NMR}\left(200 \mathrm{MHz}, \mathrm{CDCl}_{3}\right) \delta 2.36\left(\right.\right.$ broad s, $\left.2 \mathrm{H}, \mathrm{CH}_{2} \beta\right), 1.54$ (s, $3 \mathrm{H}, \mathrm{NCH}_{3}$ ), 4.26 (broad s, $1 \mathrm{H}, \mathrm{H \alpha}$ ), 4.88 (s, 2H, $\mathrm{CH}_{2} \mathrm{Ph}$ ), 5.56 (broad s, $\left.1 \mathrm{H}, \mathrm{OH}\right), 6.27-7.14$ (m, 9H, aromatic H), 8.80 (broad s, $1 \mathrm{H}, \mathrm{NH}$ ). HRMS (LSIMS) calcd for $\mathrm{C}_{20} \mathrm{H}_{22} \mathrm{~N}_{3} \mathrm{O}_{5}[\mathrm{M}+\mathrm{H}]^{+}$: 384.1559 , found 384.1550. $R_{f}$ (RP18, $50 \% \mathrm{MeOH}$ in water) 0.18.) and (S)-2benzyloxycarbonylamino-N-methyl-3-((R)-5-bromo-3-hydroxy-2-oxoindolin-3-

yl)propanamide (3.5 mg, HRMS (LSIMS) calcd for $\mathrm{C}_{20} \mathrm{H}_{21}{ }^{79} \mathrm{BrN}_{3} \mathrm{O}_{5}[\mathrm{M}+\mathrm{H}]^{+}: 462.0665$, found 462.0632. $R_{f}(\mathrm{RP} 18,50 \% \mathrm{MeOH}$ in water) 0.05$)$.

A 70:30 mixture of non-brominated and brominated Z-protected 6a (132 mg) was placed overnight with $10 \% \mathrm{Pd}$ on carbon $(20 \mathrm{mg})$ in methanol $(2 \mathrm{~mL})$ under $\mathrm{H}_{2}$ atmosphere. The mixture was filtered through celite and treated with $1 \mathrm{M}$ anhydrous $\mathrm{HCl}$ in methanol $(0.7 \mathrm{~mL}$, $0.7 \mathrm{mmol}$ ). After concentration in vacuo, product $\mathbf{6 a}$, hydrochloride was obtained as a white solid (96.4 mg, 30\% from Z-Trp).

${ }^{1} \mathrm{H}$ NMR $\left(300 \mathrm{MHz}, \mathrm{D}_{2} \mathrm{O}\right) \delta 2.38\left(\mathrm{~s}, 3 \mathrm{H}, \mathrm{NCH}_{3}\right), 2.44\left(\mathrm{~d}, J=6.9 \mathrm{~Hz}, 2 \mathrm{H}, \mathrm{CH}_{2} \beta\right), 4.02(\mathrm{t}, J=$ $6.9 \mathrm{~Hz}, 1 \mathrm{H}, \mathrm{H \alpha}), 7.02(\mathrm{~d}, J=7.5 \mathrm{~Hz}, 1 \mathrm{H}), 7.12(\mathrm{t}, J=7.6 \mathrm{~Hz}, 1 \mathrm{H}),, 7.31-7.35(\mathrm{~m}, 2 \mathrm{H}) .{ }^{13} \mathrm{C}$ NMR (75.5 MHz, D $2 \mathrm{O}) \delta 26.6\left(\mathrm{NCH}_{3}\right), 37.4\left(\mathrm{CH}_{2}\right), 50.2(\mathrm{CH \alpha}), 75.1(\mathrm{C}), 111.9(\mathrm{CH}), 124.4$ $(\mathrm{CH}), 125.0(\mathrm{CH}), 129.5(\mathrm{C}), 131.5(\mathrm{CH}), 140.7(\mathrm{C}), 169.3(\mathrm{C}=\mathrm{O}), 180.2(\mathrm{C}=\mathrm{O}$ oxindole). HRMS (ESI) calcd for $\mathrm{C}_{12} \mathrm{H}_{16} \mathrm{~N}_{3} \mathrm{O}_{3}[\mathrm{M}+\mathrm{H}]^{+}:$250.1192, found 250.1192.

\subsubsection{4. (S)-2-Amino-N-benzyl-3-((R)-3-hydroxy-2-oxoindolin-3-yl)propanamide $6 \mathbf{b}$ :}

According to the general procedure described above, spirolactone 9a (314 mg, ca $0.83 \mathrm{mmol}$ based on a 70:30 ratio of $\mathrm{H}$ - and Br-oxindole starting material) and benzylamine $(110 \mu \mathrm{L}$, $0.96 \mathrm{mmol}$ ) were reacted overnight. Purification by chromatography over silica gel (23.6 g, eluent $40 \%$ of AcOEt in $\mathrm{CH}_{2} \mathrm{Cl}_{2}$ then AcOEt) afforded an orange amorphous solid (419 mg) that was hydrogenated according to the general procedure. Product $\mathbf{6 b}$, hydrochloride was obtained as a white solid (221 mg, 27\% from Z-Trp). 
${ }^{1} \mathrm{H}$ NMR $\left(300 \mathrm{MHz}, \mathrm{DMSO}-\mathrm{d}_{6}\right) \delta 2.08(\mathrm{dd}, J=13.5,3.0 \mathrm{~Hz}, 1 \mathrm{H}, \mathrm{CH} \beta), 2.26(\mathrm{dd}, J=13.5$, $9.0 \mathrm{~Hz}, 1 \mathrm{H}, \mathrm{CH} \beta), 4.15$ and 4.27 (ABX system, $J_{A B}=15.0 \mathrm{~Hz}, J_{A X}=J_{B X}=5.7 \mathrm{~Hz}, 2 \mathrm{H}$, $\left.\mathrm{NCH}_{2}\right), 4.41(\mathrm{t}, J=4.5 \mathrm{~Hz}, 1 \mathrm{H}, \mathrm{H \alpha}), 6.87(\mathrm{~d}, J=6.0 \mathrm{~Hz}, 1 \mathrm{H}, \mathrm{H}$ aromatic), $7.02(\mathrm{td}, J=7.5$, $1.5 \mathrm{~Hz}, 1 \mathrm{H}, \mathrm{H}$ aromatic), 7.2-7.46 (m, 7H, aromatics), 8.08-8.10 (d, $\left.J=3.0 \mathrm{~Hz}, 3 \mathrm{H}, \mathrm{NH}_{3}{ }^{+}\right)$, $8.83(\mathrm{t}, J=6.0 \mathrm{~Hz}, 1 \mathrm{H}, \mathrm{NH}), 10.54\left(\mathrm{~s}, 1 \mathrm{H}, \mathrm{NH}\right.$ oxindole). ${ }^{1} \mathrm{H} \mathrm{NMR}\left(300 \mathrm{MHz}, \mathrm{D}_{2} \mathrm{O}+\mathrm{HCl}\right) \delta$ 2.37 and $2.44\left(\mathrm{ABX}\right.$ system, $\left.2 \mathrm{H}, J_{A X}=6.7 \mathrm{~Hz}, J_{B X}=7 \mathrm{~Hz}, J_{A B}=14.7 \mathrm{~Hz}, \mathrm{CH}_{2} \beta\right), 3.96$ and $4.11\left(\mathrm{AB}\right.$ system, $\left.J_{A B}=14.7 \mathrm{~Hz}, 2 \mathrm{H}, \mathrm{CH}_{2} \mathrm{Ph}\right), 4.20(\mathrm{t}, J=6.8 \mathrm{~Hz}, 1 \mathrm{H}, \mathrm{CH \alpha}), 6.95$ (d, $J=8.0$ $\mathrm{Hz}, 1 \mathrm{H}), 7.06-7.15(\mathrm{~m}, 3 \mathrm{H}), 7.23-7.33(\mathrm{~m}, 5 \mathrm{H}) .{ }^{13} \mathrm{C} \mathrm{NMR}\left(75.5 \mathrm{MHz}, \mathrm{D}_{2} \mathrm{O}+\mathrm{HCl}\right) \delta 37.5$ $\left(\mathrm{CH}_{2}\right), 44.1\left(\mathrm{CH}_{2}\right), 50.1(\mathrm{CH}), 75.1(\mathrm{C}), 111.9(\mathrm{CH}), 124.4(\mathrm{CH}), 124.9(\mathrm{CH}), 128.1(\mathrm{CH})$, $128.3(\mathrm{CH}), 129.4(\mathrm{CH}), 129.9(\mathrm{C}), 131.5(\mathrm{CH}), 137.6(\mathrm{C}), 140.6(\mathrm{C}), 169.0(\mathrm{C}=\mathrm{O}), 180.3$ (CO oxindole). HRMS (ESI) calcd for $\mathrm{C}_{18} \mathrm{H}_{19} \mathrm{~N}_{3} \mathrm{O}_{3} \mathrm{Na}[\mathrm{M}+\mathrm{Na}]^{+}: 348.1324$, found 348.1323.

4.1.1.5. (S)-2-Benzyloxyamino-N-benzyl-3-((R)-3-hydroxy-1-methyl-2-oxoindolin-3-yl) propanamide:

According to the general procedure described above, spirolactone $9 \mathrm{~b}(1.60 \mathrm{~g}, 4.75 \mathrm{mmol})$ and benzylamine $(560 \mu \mathrm{L}, 5.12 \mathrm{mmol})$ were reacted overnight. The solid was filtered and washed with $\mathrm{CH}_{2} \mathrm{Cl}_{2}$ to afford (S)-2-benzyloxyamino-N-benzyl-3-((R)-3-hydroxy-1-methyl-2oxoindolin-3-yl)propanamide (N-Z-protected 6c) as a white solid (1.52g, 68\%). Mp 156-158 ${ }^{\circ} \mathrm{C} .{ }^{1} \mathrm{H}$ NMR $\left(300 \mathrm{MHz}, \mathrm{CDCl}_{3}\right) \delta 2.25(\mathrm{dd}, J=15.6,4.5 \mathrm{~Hz}, 1 \mathrm{H}), 2.50(\mathrm{dd}, J=15.6,4.2 \mathrm{~Hz}$, 1H), $3.01(\mathrm{~s}, 3 \mathrm{H}), 4.33(\mathrm{dd}, J=14.8,5.1 \mathrm{~Hz}, 1 \mathrm{H}), 4.48(\mathrm{dd}, J=14.6,6.3 \mathrm{~Hz}, 1 \mathrm{H}), 4.78(\mathrm{br}$, $1 \mathrm{H}), 5.13(\mathrm{~m}, 2 \mathrm{H}), 6.54(\mathrm{~d}, J=6.5 \mathrm{~Hz}, 1 \mathrm{H}), 6.78(\mathrm{~d}, J=7.6 \mathrm{~Hz}, 1 \mathrm{H}), 7.10(\mathrm{t}, J=7.5 \mathrm{~Hz}, 1 \mathrm{H})$, 7.43-7.47 (m, 14H). ${ }^{13} \mathrm{C}$ NMR (75.5 MHz, $\left.\mathrm{CDCl}_{3}\right) \delta 26.09\left(\mathrm{CH}_{3}\right), 42.23\left(\mathrm{CH}_{2}\right), 43.55\left(\mathrm{CH}_{2}\right)$, $50.13(\mathrm{CH}), 67.35\left(\mathrm{CH}_{2}\right), 74.28(\mathrm{C}), 108.60(\mathrm{CH}), 123.64(\mathrm{CH}), 123.68(\mathrm{CH}), 127.47(\mathrm{CH})$, $127.56(\mathrm{CH}), 128.21(\mathrm{CH}), 128.31(\mathrm{CH}), 128.57(\mathrm{CH}), 128.67(\mathrm{CH}), 129.88(\mathrm{CH}), 130.97$ (C), 135.89 (C), 137.70 (C), 142.44 (C), 156.66 (C), 171.29 (C), 178.60 (C). HRMS (ESI) calcd for $\mathrm{C}_{27} \mathrm{H}_{27} \mathrm{~N}_{3} \mathrm{O}_{5} \mathrm{Na}\left[(\mathrm{M}+\mathrm{Na})^{+}\right]$496.1843, found 496.1844. $R_{f}\left(2 / 3 \mathrm{AcOEt} / \mathrm{CH}_{2} \mathrm{Cl}_{2}\right) 0.31$.

4.1.1.6. (S)-2-Amino-N-benzyl-3-((R)-3-hydroxy-1-methyl-2-oxoindolin-3-yl)propanamide 6c: Hydrogenation of $(S)$-2-benzyloxyamino- $N$-benzyl-3-((R)-3-hydroxy-1-methyl-2-oxoindolin3-yl)propanamide (965 $\mathrm{mg}, 2.04 \mathrm{mmol}$ ) according to the general procedure afforded $\mathbf{6 c}$ as a white solid (691 mg, quantitative, 15\% from Z-L-methyl tryptophan). ${ }^{1} \mathrm{H}$ NMR (300 MHz, DMSO-d $\left._{6}\right) \delta 1.88-2.04(\mathrm{~m}, 2 \mathrm{H}), 3.09(\mathrm{~s}, 3 \mathrm{H}), 3.64(\mathrm{dd}, J=10.5,3.90 \mathrm{~Hz}, 1 \mathrm{H}), 4.20(\mathrm{~d}, J=4.2$ $\mathrm{Hz}, 2 \mathrm{H}), 6.95(\mathrm{~d}, J=7.5 \mathrm{~Hz}, 1 \mathrm{H}), 7.03(\mathrm{t}, J=7.2 \mathrm{~Hz}, 1 \mathrm{H}), 7.17-7.32(\mathrm{~m}, 1 \mathrm{H}), 8.38$ (br s, 1H) 
4.1.1.7.

(S)-2-Amino-3-((R)-3-hydroxy-2-oxoindolin-3-yl)-N-(naphthalen-1-ylmethyl)

propanamide 6d: According to the general procedure described above, spirolactone 9a (208 $\mathrm{mg}$, ca $0.55 \mathrm{mmol}$ based on a 70:30 ratio of $\mathrm{H}$ - and Br-oxindole starting material) and naphtylmethylene amine $(140 \mu \mathrm{L}, 0.90 \mathrm{mmol})$ were reacted overnight. Purification by chromatography over silica gel $\left(8.1 \mathrm{~g}\right.$, eluent $10 \%$ of AcOEt in $\mathrm{CH}_{2} \mathrm{Cl}_{2}$ then then $25 \% \mathrm{AcOEt}$ in $\mathrm{CH}_{2} \mathrm{Cl}_{2}$ ) afforded an orange amorphous solid $(291 \mathrm{mg})$ that was hydrogenated according to the general procedure. Product 6d, hydrochloride was obtained as a white solid (191 $\mathrm{mg}, 31 \%$ from Z-Trp).

${ }^{1} \mathrm{H}$ NMR $\left(300 \mathrm{MHz}, \mathrm{CD}_{3} \mathrm{OD}\right) \delta 2.14(\mathrm{dd}, J=15.3,3.0 \mathrm{~Hz}, 1 \mathrm{H}, \mathrm{CH} \beta), 2.63(\mathrm{dd}, J=15.2,4.2$ $\mathrm{Hz}, 1 \mathrm{H}, \mathrm{CH} \beta), 4.75\left(\mathrm{~m}, 3 \mathrm{H}, \mathrm{H \alpha}, \mathrm{NCH}_{2}\right), 6.89$ (d, $J=7.8 \mathrm{~Hz}, 1 \mathrm{H}$ aromatic), 7.00 (td, $J=7.5$, $0.6 \mathrm{~Hz}, 1 \mathrm{H}$ aromatic), 7.21 (td, $J=7.8,1.0 \mathrm{~Hz}, 1 \mathrm{H}$ aromatic), 7.29-7.43 (m, 5H aromatics), 7.68-7.78 (m, $2 \mathrm{H}$ aromatics), 7.89-7.93 (m, $1 \mathrm{H}$ aromatic), $8.42\left(\mathrm{br} \mathrm{s}, \mathrm{NH}_{3}{ }^{+}, \mathrm{OH}\right), 8.85(\mathrm{t}, J=$ $5.4 \mathrm{~Hz}, 1 \mathrm{H}, \mathrm{NH}), 10.31$ (s, 1H, NH oxindole). ${ }^{13} \mathrm{C}$ NMR $\left(75.5 \mathrm{MHz}, \mathrm{CD}_{3} \mathrm{OD}\right) \delta 39.08\left(\mathrm{CH}_{2}\right)$, $42.48\left(\mathrm{CH}_{2}\right), 50.86(\mathrm{CH}), 75.67(\mathrm{C}), 111.68(\mathrm{CH}), 124.04(\mathrm{CH}), 124.22(\mathrm{CH}), 124.67(\mathrm{CH})$, $123.36(\mathrm{CH}), 126.86(\mathrm{CH}), 127.26(\mathrm{CH}), 127.40(\mathrm{CH}), 129.39(\mathrm{CH}), 129.73(\mathrm{CH}), 131.13$ (CH), 132.45 (C), 132.70 (C), 134.11 (C), 135.17 (C), 141.86 (C), 170.21 (CO), 180.70 (CO). HRMS (ESI) calcd for $\mathrm{C}_{22} \mathrm{H}_{21} \mathrm{~N}_{3} \mathrm{O}_{3} \mathrm{Na}[\mathrm{M}+\mathrm{Na}]^{+}:$398.1475, found 398.1476.

4.1.1.8. (S)-2-Amino-N-benzhydryl-3-((R)-3-hydroxy-2-oxoindolin-3-yl)propanamide $\quad$ 6e: According to the general procedure described above, spirolactone $9 \mathbf{a}(233 \mathrm{mg}$, ca $0.62 \mathrm{mmol}$ based on a 70:30 ratio of $\mathrm{H}$ - and $\mathrm{Br}$-oxindole starting material) and benzhydrylamine $(130 \mu \mathrm{L}$, $0.73 \mathrm{mmol})$ were reacted overnight. Purification by chromatography over silica gel $(8 \mathrm{~g}$, eluent $50 \%$ of AcOEt in $\mathrm{CH}_{2} \mathrm{Cl}_{2}$ then $80 \%$ AcOEt in $\mathrm{CH}_{2} \mathrm{Cl}_{2}$ ) afforded an orange amorphous solid (189 mg) that was hydrogenated according to the general procedure. Product $\mathbf{6 e}$, hydrochloride was obtained as a white solid (148 mg, 19\% from Z-Trp).

${ }^{1} \mathrm{H}$ NMR (300 MHz, DMSO-d 6 ) $\delta 2.07$ (dd, $\left.J=13.5,3.0 \mathrm{~Hz}, 1 \mathrm{H}, \mathrm{CH} \beta\right), 2.26(\mathrm{dd}, J=9.0,3.0$ $\mathrm{Hz}, 1 \mathrm{H}, \mathrm{CH} \beta$ ), 3.97 (s, 1H, OH), 4.22 (ddd, $J=18.0,15.0,1.5 \mathrm{~Hz}, 2 \mathrm{H}, \mathrm{NCH}_{2}$ ), 4.55 (br s, $1 \mathrm{H}$, $\mathrm{H \alpha}), 6.07\left(\mathrm{~d}, J=9.0 \mathrm{~Hz}, 1 \mathrm{H}, \mathrm{CH}(\mathrm{Ph})_{2}\right), 6.87(\mathrm{~d}, J=6.0 \mathrm{~Hz}, 1 \mathrm{H}$ aromatic), $6.93(\mathrm{~m}, 1 \mathrm{H}$ aromatic), $7.02(\mathrm{td}, J=7.5,1.0 \mathrm{~Hz}, 1 \mathrm{H}$ aromatic), 7.17-7.37 (m, $11 \mathrm{H}$ aromatic), 8.08 (br s, $\left.3 \mathrm{H}, \mathrm{NH}_{3}{ }^{+}\right), 9.3(\mathrm{~d}, J=9.0 \mathrm{~Hz}, 1 \mathrm{H}, \mathrm{NH}), 10.58$ (s, 1H, NH oxindole). ${ }^{13} \mathrm{C}$ NMR $(75.5 \mathrm{MHz}$, $\left.\mathrm{CD}_{3} \mathrm{OD}\right) \delta 38.97\left(\mathrm{CH}_{2}\right), 50.86(\mathrm{CH}), 58.61(\mathrm{CH}), 75.66(\mathrm{C}), 111.68(\mathrm{CH}), 124.06(\mathrm{CH})$, $124.67(\mathrm{CH}), 128.51(\mathrm{CH}), 128.59(\mathrm{CH}), 129.18(\mathrm{CH}), 129.56(\mathrm{CH}), 129.6(\mathrm{CH}), 129.89$ (CH), $131.18(\mathrm{CH}), 132.83$ (C), 141.98 (C), 142.32 (C), 142.42 (C), 169.09 (CO), 180.63 (CO). HRMS (ESI) calcd for $\mathrm{C}_{24} \mathrm{H}_{23} \mathrm{~N}_{3} \mathrm{O}_{3} \mathrm{Na}[\mathrm{M}+\mathrm{Na}]^{+}$: 424.1632, found 424.1630. 
4.1.1.9. (S)-N-([1,1'-Biphenyl]-4-ylmethyl)-2-amino-3-((R)-3-hydroxy-2-oxoindolin-3-yl) propanamide 6f: According to the general procedure described above, spirolactone 9a (261 mg, ca 0.69 mmol based on a 70:30 ratio of $\mathrm{H}$ - and Br-oxindole starting material) and 4phenylbenzylamine $(151 \mathrm{mg}, 0.82 \mathrm{mmol})$ were reacted overnight. Purification by chromatography over silica gel (20 g, eluent $30 \%$ of AcOEt in $\mathrm{CH}_{2} \mathrm{Cl}_{2}$ ) afforded an orange amorphous solid (300 mg) that was hydrogenated according to the general procedure. Product 6f, trifluoroacetate salt was obtained as a white solid (291 mg, 30\% from Z-Trp).

${ }^{1} \mathrm{H}$ NMR $\left(300 \mathrm{MHz}, \mathrm{CD}_{3} \mathrm{OD}\right) \delta 2.12(\mathrm{dd}, J=15.0,3.0 \mathrm{~Hz}, 1 \mathrm{H}, \mathrm{CH} \beta), 2.22(\mathrm{dd}, J=15.3,10.8$ $\mathrm{Hz}, 1 \mathrm{H}, \mathrm{CH} \beta), 4.34-4.38\left(\mathrm{~m}, 2 \mathrm{H}, \mathrm{CH}_{2}\right), 4.71(\mathrm{dd}, J=10.8,3.0 \mathrm{~Hz}, 1 \mathrm{H}, \mathrm{H \alpha}), 6.93(\mathrm{~d}, J=7.8$ $\mathrm{Hz}, 1 \mathrm{H}$ aromatic), 7.02 (td, $J=7.5,3.0 \mathrm{~Hz}, 1 \mathrm{H}$ aromatic), 7.22-7.32 (m, 7H aromatics), 7.457.49 ( $\mathrm{m}, 4 \mathrm{H}$ aromatics), 8.32 (br s, $\left.3 \mathrm{H}, \mathrm{NH}_{3}{ }^{+}\right), 8.79$ (t, $\left.J=6.0 \mathrm{~Hz}, 1 \mathrm{H}, \mathrm{NHCO}\right), 10.21$ (s, NH oxindole). ${ }^{13} \mathrm{C}$ NMR (75.5 MHz, $\left.\mathrm{CD}_{3} \mathrm{OD}\right) \delta 38.98\left(\mathrm{CH}_{2}\right), 44.04\left(\mathrm{CH}_{2}\right), 50.08(\mathrm{CH}), 75.59$ (C), $111.66(\mathrm{CH}), 124.03(\mathrm{CH}), 124.72(\mathrm{CH}), 127.77(\mathrm{CH}), 128.04(\mathrm{CH}), 128.28(\mathrm{CH})$, $129.14(\mathrm{CH}), 129.76(\mathrm{CH}), 131.14(\mathrm{CH}), 132.70(\mathrm{C}), 138.23(\mathrm{C}), 141.44(\mathrm{C}), 141.78(\mathrm{C})$, 141.92 (C), 169.73 (CO), 180.56 (CO). HRMS (ESI) calcd for $\mathrm{C}_{24} \mathrm{H}_{24} \mathrm{~N}_{3} \mathrm{O}_{3}[\mathrm{M}+\mathrm{H}]^{+}$: 402.1812, found 402.1802 .

\subsubsection{0.}

(S)-2-Amino-3-((R)-3-hydroxy-2-oxoindolin-3-yl)-N-(4-isopropylbenzyl)

\section{propanamide 6g:}

According to the general procedure described above, spirolactone 9a (284 mg, ca $0.75 \mathrm{mmol}$ based on a 70:30 ratio of $\mathrm{H}$ - and Br-oxindole starting material) and 4-(isopropyl)benzylamine (132 mg, $0.89 \mathrm{mmol}$ ) were reacted overnight. Purification by chromatography over silica gel (11 g, eluent $40 \%$ of AcOEt in $\mathrm{CH}_{2} \mathrm{Cl}_{2}$ ) afforded an orange amorphous solid (299 $\mathrm{mg}$ ) that was hydrogenated according to the general procedure. Product $\mathbf{6 g}$, trifluoroacetate salt was obtained as a white solid (271 mg, 27\% from Z-Trp).

${ }^{1} \mathrm{H}$ NMR (300 MHz, CD $\left.3 \mathrm{OD}\right) \delta 1.15$ (s, 3H, $\mathrm{CH}_{3}$ ), 1.16 (s, 3H, $\left.\mathrm{CH}_{3}\right), 2.09$ (dd, $J=15.0,3.0$ $\mathrm{Hz}, 1 \mathrm{H}, \mathrm{CH} \beta$ ), 2.22 (dd, $J=15.3,10.8 \mathrm{~Hz}, 1 \mathrm{H}, \mathrm{CH} \beta$ ), 2.74-2.83 (m, 1H, CH), 4.22-4.33 (m, 2H, $\mathrm{CH}_{2}-\mathrm{NHCO}$ ), 4.68 (dd, $J=8.3,3.0 \mathrm{~Hz}, 1 \mathrm{H}, \mathrm{H \alpha}$ ), 6.92 (d, $J=7.5 \mathrm{~Hz}, 1 \mathrm{H}$ aromatic), 7.03 $(\mathrm{td}, J=7.5,1.0 \mathrm{~Hz}, 1 \mathrm{H}$ aromatic), 7.08-7.15 (m, $4 \mathrm{H}$ aromatics), $7.25(\mathrm{td}, J=7.8,1.2 \mathrm{~Hz}, 1 \mathrm{H}$ aromatic), 7.31-7.36 (m, 1H, aromatic), $8.30\left(\mathrm{br} \mathrm{s}, 4 \mathrm{H}, \mathrm{NH}_{3}{ }^{+}, \mathrm{OH}\right), 8.70(\mathrm{t}, J=6.0 \mathrm{~Hz}, 1 \mathrm{H}$, NHCO), 10.26 (s, NH oxindole1H). ${ }^{13} \mathrm{C}$ NMR (75.5 MHz, CD $\left.\mathrm{OD}\right) \delta 24.36\left(\mathrm{CH}_{3}\right), 34.93$ $(\mathrm{CH}), 39\left(\mathrm{CH}_{2}\right), 44.2\left(\mathrm{CH}_{2}\right), 50.84(\mathrm{CH}), 75.64(\mathrm{C}), 111.69(\mathrm{CH}), 124.04(\mathrm{CH}), 124.71(\mathrm{CH})$, $127.50(\mathrm{CH}), 127.74(\mathrm{CH}), 131.14(\mathrm{CH}), 132.68(\mathrm{C}), 136.45(\mathrm{C}), 141.90(\mathrm{C}), 149.27(\mathrm{C})$, 
$169.65(\mathrm{CO}), 180.61(\mathrm{CO})$. HRMS (ESI) calcd for $\mathrm{C}_{21} \mathrm{H}_{26} \mathrm{~N}_{3} \mathrm{O}_{3}[\mathrm{M}+\mathrm{H}]^{+}$: 368.1969, found 368.1968 .

\subsubsection{Methyl 3-((S)-2-amino-3-((R)-3-hydroxy-2-oxoindolin-3-yl)propanamido) propanoate $6 \mathbf{h}$ :}

According to the general procedure described above, spirolactone 9a $(284 \mathrm{mg}$, ca $0.75 \mathrm{mmol}$ based on a 70:30 ratio of $\mathrm{H}$ - and Br-oxindole starting material), $\beta$-alanine methyl ester, hydrochloride (134 mg, $0.96 \mathrm{mmol})$ and triethylamine $(300 \mu \mathrm{L}, 2.13 \mathrm{mmol})$ were reacted overnight. Purification by chromatography over silica gel $(8 \mathrm{~g}$, eluent $15 \%$ of AcOEt in $\mathrm{CH}_{2} \mathrm{Cl}_{2}$ ) afforded an orange amorphous solid $(213 \mathrm{mg})$ that was hydrogenated according to the general procedure. Product $\mathbf{6 h}$, trifluoroacetate salt was obtained as a white solid (191 mg, $21 \%$ from Z-Trp).

${ }^{1} \mathrm{H}$ NMR $\left(300 \mathrm{MHz}, \mathrm{CD}_{3} \mathrm{OD}\right) \delta 2.06(\mathrm{dd}, J=15.3,3.0 \mathrm{~Hz}, 1 \mathrm{H}), 2.45-2.55(\mathrm{~m}, 3 \mathrm{H}), 3.37-3.51$ (m, 2H), $3.61(\mathrm{~s}, 3 \mathrm{H}), 4.59$ (dd, $J=10.8,3.0 \mathrm{~Hz}, 1 \mathrm{H}), 6.94(\mathrm{~d}, J=7.5 \mathrm{~Hz}, 1 \mathrm{H}), 7.08$ (t, $J=7.5$ $\mathrm{Hz}, 1 \mathrm{H}), 7.29$ (t, $J=7.5 \mathrm{~Hz}, 1 \mathrm{H}), 7.36$ (d, $J=7.5 \mathrm{~Hz}, 1 \mathrm{H}) .{ }^{13} \mathrm{C}$ NMR $\left(75.5 \mathrm{MHz}, \mathrm{CD}_{3} \mathrm{OD}\right) \delta$ $34.30\left(\mathrm{CH}_{2}\right), 36.59\left(\mathrm{CH}_{2}\right), 39.13\left(\mathrm{CH}_{2}\right), 50.69(\mathrm{CH}), 52.21\left(\mathrm{CH}_{2}\right), 75.60,111.63(\mathrm{CH}), 124.05$ $(\mathrm{CH}), 124.70(\mathrm{CH}), 131.18(\mathrm{CH}), 132.85(\mathrm{C}), 142.02(\mathrm{C}), 169.95(\mathrm{C}), 173.65(\mathrm{C}), 180.68(\mathrm{C})$. HRMS (ESI) calcd for $\mathrm{C}_{15} \mathrm{H}_{19} \mathrm{~N}_{3} \mathrm{O}_{5} \mathrm{Na}[\mathrm{M}+\mathrm{Na}]^{+}: 344.1217$, found 344.1212.

\subsubsection{2. (S)-2-amino-3-((R)-3-hydroxy-2-oxoindolin-3-yl)-N-phenethylpropanamide $6 \mathbf{i}$ :}

According to the general procedure described above, spirolactone 9a (260 mg, ca $0.7 \mathrm{mmol}$ based on a 70:30 ratio of $\mathrm{H}$ - and Br-oxindole starting material) and phenethyl amine $(102 \mu \mathrm{L}$, $0.81 \mathrm{mmol})$ were reacted overnight. Purification by chromatography over silica gel (15 g, eluent $2 \%$ of $\mathrm{MeOH}$ in $\mathrm{CH}_{2} \mathrm{Cl}_{2}$ ) afforded an orange amorphous solid (300 mg) that was hydrogenated according to the general procedure. Product $\mathbf{6 i}$, trifluoroacetate salt was obtained as a white solid (241 mg, 28\% yield from Z-Trp).

${ }^{1} \mathrm{H}$ NMR (300 MHz, CD 3 OD) $\delta 1.72(\mathrm{dd}, J=15.5,3.0 \mathrm{~Hz}, 1 \mathrm{H}), 2.30(\mathrm{dd}, J=15.5,11.4 \mathrm{~Hz}$, $1 \mathrm{H}), 2.68-2.87(\mathrm{~m}, 2 \mathrm{H}), 3.28-3.37(\mathrm{~m}, 1 \mathrm{H}), 3.50-3.60(\mathrm{~m}, 1 \mathrm{H}), 4.50(\mathrm{dd}, J=11.4,3.0 \mathrm{~Hz}$, $1 \mathrm{H}), 6.94(\mathrm{~d}, J=7.5 \mathrm{~Hz}, 1 \mathrm{H}), 7.05-7.16(\mathrm{~m}, 6 \mathrm{H}), 7.31-7.34(\mathrm{~m}, 2 \mathrm{H}) .{ }^{13} \mathrm{C} \mathrm{NMR}(75.5 \mathrm{MHz}$, $\left.\mathrm{CD}_{3} \mathrm{OD}\right) \delta 34.64\left(\mathrm{CH}_{2}\right), 38.03\left(\mathrm{CH}_{2}\right), 40.44\left(\mathrm{CH}_{2}\right), 49.35(\mathrm{CH}), 74.28(\mathrm{C}), 110.35(\mathrm{CH})$, $122.70(\mathrm{CH}), 123.41(\mathrm{CH}), 126.04(\mathrm{CH}), 128.05(\mathrm{CH}), 128.51(\mathrm{CH}), 129.83(\mathrm{CH}), 131.42$ (C), 138.64 (C), 140.56 (C), 168.50 (C), 179.27 (C). HRMS (ESI) calcd for $\mathrm{C}_{19} \mathrm{H}_{21} \mathrm{~N}_{3} \mathrm{O}_{3} \mathrm{Na}$ $[\mathrm{M}+\mathrm{Na}]^{+}:$362.1475, found 362.1476 . 
4.1.1.13. (S)-2-amino-N-(2-cyclohexylethyl)-3-((R)-3-hydroxy-2-oxoindolin-3-yl)propanamide 6j:

According to the general procedure described above, spirolactone 9a (260 mg, ca $0.7 \mathrm{mmol}$ based on a 70:30 ratio of $\mathrm{H}$ - and $\mathrm{Br}$-oxindole starting material) and 2-cyclohexylethyl amine (103 mg, $0.81 \mathrm{mmol})$ were reacted overnight. Purification by chromatography over silica gel (15 g, eluent $2 \%$ of $\mathrm{MeOH}$ in $\mathrm{CH}_{2} \mathrm{Cl}_{2}$ ) afforded an orange amorphous solid (272 $\mathrm{mg}$ ) that was hydrogenated according to the general procedure. Product $\mathbf{6 j}$, trifluoroacetate salt was obtained as a white solid (208 mg, $24 \%$ yield from Z-Trp).

${ }^{1} \mathrm{H}$ NMR (300 MHz, CD $\left.3 \mathrm{OD}\right) \delta$ 0.85-0.96 (m, 2H), 1.13-1.41 (m, 6H), 1.68 (m, 5H), 2.06 (dd, $J=15.3,3.3 \mathrm{~Hz}, 1 \mathrm{H}), 2.51(\mathrm{dd}, J=15.3,11.1 \mathrm{~Hz}, 1 \mathrm{H}), 3.21(\mathrm{~m}, 2 \mathrm{H}), 4.59(\mathrm{dd}, J=11.1,3.3$ $\mathrm{Hz}, 1 \mathrm{H}), 6.95(\mathrm{~d}, J=7.8 \mathrm{~Hz}, 1 \mathrm{H}), 7.08$ (t, $J=7.5 \mathrm{~Hz}, 1 \mathrm{H}), 7.29$ (t, $J=7.8 \mathrm{~Hz}, 1 \mathrm{H}), 7.38$ (d, $J$ $=7.5 \mathrm{~Hz}, 1 \mathrm{H}) .{ }^{13} \mathrm{C}$ NMR $\left(75.5 \mathrm{MHz}, \mathrm{CD}_{3} \mathrm{OD}\right) \delta 27.25\left(\mathrm{CH}_{2}\right), 27.54\left(\mathrm{CH}_{2}\right), 34.18(\mathrm{CH}), 36.41$ $\left(\mathrm{CH}_{2}\right), 37.50\left(\mathrm{CH}_{2}\right), 38.50\left(\mathrm{CH}_{2}\right), 39.21\left(\mathrm{CH}_{2}\right), 50.76(\mathrm{CH}), 75.63(\mathrm{C}), 111.64(\mathrm{CH}), 124.02$ (CH), $124.68(\mathrm{CH}), 131.15(\mathrm{CH}), 132.81$ (C), 142.01 (C), 169.61 (C), 180.63 (C). HRMS (ESI) calcd for $\mathrm{C}_{19} \mathrm{H}_{27} \mathrm{~N}_{3} \mathrm{O}_{3} \mathrm{Na}[\mathrm{M}+\mathrm{Na}]^{+}: 368.1945$, found 368.1948 .

\subsubsection{4. (S)-2-Amino)-N-cyclohexylmethyl-3-((R)-3-hydroxy-2-oxoindolin-3-yl)propanamide} 6k:

According to the general procedure described above, spirolactone $9 \mathbf{a}(151 \mathrm{mg}, \mathrm{ca} 0.40 \mathrm{mmol}$ based on a 70:30 ratio of $\mathrm{H}$ - and Br-oxindole starting material) and cyclohexylmethylene amine (113.2 mg, $0.4 \mathrm{mmol}$ ) were reacted overnight. Purification by chromatography over silica gel (6 g, eluent $50 \%$ of AcOEt in $\left.\mathrm{CH}_{2} \mathrm{Cl}_{2}\right)$ afforded an orange amorphous solid (163 mg) that was hydrogenated according to the general procedure. Product $\mathbf{6 k}$, trifluoroacetate salt was obtained as a white solid (121 mg, 26\% yield from Z-Trp).

${ }^{1} \mathrm{H}$ NMR (300 MHz, CD $\left.\mathrm{OD}\right) \delta$ 0.85-0.97 (m, 2H), 1.19-1.26 (m, 3H), 1.46 (br s, 1H), 1.67$1.71(\mathrm{~m}, 5 \mathrm{H}), 2.06(\mathrm{dd}, J=15.3,3.0 \mathrm{~Hz}, 1 \mathrm{H}), 2.52(\mathrm{dd}, J=15.3,11.1 \mathrm{~Hz}, 1 \mathrm{H}), 3.03(\mathrm{~d}, J=$ $6.0 \mathrm{~Hz}, 2 \mathrm{H}), 4.62(\mathrm{dd}, J=11.1,2.7 \mathrm{~Hz}, 2 \mathrm{H}), 6.95(\mathrm{~d}, J=7.8 \mathrm{~Hz}, 1 \mathrm{H}), 7.10(\mathrm{td}, J=7.8,1.0$ $\mathrm{Hz}, 1 \mathrm{H}), 7.32(\mathrm{td}, J=7.8,1.5 \mathrm{~Hz}, 1 \mathrm{H}), 7.38(\mathrm{~d}, J=6.0 \mathrm{~Hz}, 1 \mathrm{H}) .{ }^{13} \mathrm{C}$ NMR $(75.5 \mathrm{MHz}$, $\left.\mathrm{CD}_{3} \mathrm{OD}\right) \delta 26.9\left(\mathrm{CH}_{2}\right), 27.5\left(\mathrm{CH}_{2}\right), 31.9\left(\mathrm{CH}_{2}\right), 32.0\left(\mathrm{CH}_{2}\right), 39.0(\mathrm{CH}), 39.3\left(\mathrm{CH}_{2}\right), 47.0$ $\left(\mathrm{CH}_{2}\right), 50.8(\mathrm{CH}), 75.7(\mathrm{C}), 111.7(\mathrm{CH}), 123.1(\mathrm{CH}), 124.8(\mathrm{CH}), 131.3(\mathrm{CH}), 133.0(\mathrm{C})$, $142.2(\mathrm{C}), 169.9(\mathrm{CO}), 180.8(\mathrm{CO})$. HRMS (ESI) calcd for $\mathrm{C}_{18} \mathrm{H}_{26} \mathrm{~N}_{3} \mathrm{O}_{3}[\mathrm{M}+\mathrm{H}]^{+}: 332.1969$, found 332.1972 .

4.1.1.15. (S)-2-Amino-3-((R)-3-hydroxy-2-oxoindolin-3-yl)-N-neopentylpropanamide 61: 
According to the general procedure described above, spirolactone 9a (250 mg, ca $0.66 \mathrm{mmol}$ based on a 70:30 ratio of $\mathrm{H}$ - and $\mathrm{Br}$-oxindole starting material) and tert-butylmethylene amine $(92 \mu \mathrm{L}, 0.78 \mathrm{mmol})$ were reacted overnight. Purification by chromatography over silica gel (8 $\mathrm{g}$, eluent $20 \%$ of AcOEt in $\mathrm{CH}_{2} \mathrm{Cl}_{2}$ ) afforded an orange amorphous solid (250 mg) that was hydrogenated according to the general procedure. Product 61, hydrochloride was obtained as a white solid (149 mg, 24\% from Z-Trp).

${ }^{1} \mathrm{H}$ NMR (300 MHz, DMSO-d 6 ) $\delta 0.80(\mathrm{~s}, 9 \mathrm{H}, t-\mathrm{Bu}), 2.03(\mathrm{dd}, J=14.7,3.9 \mathrm{~Hz}, 1 \mathrm{H}, \mathrm{CH} \beta)$, $2.22(\mathrm{dd}, J=14.7,10.2 \mathrm{~Hz}, 1 \mathrm{H}, \mathrm{CH} \beta), 2.81$ and $2.90\left(\mathrm{ABX}\right.$ system, $2 \mathrm{H}, J_{A X}=6.3 \mathrm{~Hz}, J_{B X}=$ $\left.6.3 \mathrm{~Hz}, J_{A B}=12.9 \mathrm{~Hz}, 2 \mathrm{H}, \mathrm{CH}_{2}-\mathrm{NHCO}\right), 4.36(\mathrm{dd}, J=10.2,2.1 \mathrm{~Hz}, 1 \mathrm{H}, \mathrm{H \alpha}), 6.88(\mathrm{~d}, J=7.8$ $\mathrm{Hz}, 1 \mathrm{H}$ aromatic), $7.02(\mathrm{td}, J=7.5,1.0 \mathrm{~Hz}, 1 \mathrm{H}$ aromatic), 7.24-7.38 (m, 2H aromatics), 7.77 (br s, $\left.\mathrm{NH}_{3}{ }^{+}, \mathrm{OH}, 4 \mathrm{H}\right), 8.23$ (t, $\left.J=6.0 \mathrm{~Hz}, 1 \mathrm{H}, \mathrm{NHCO}\right), 10.56$ (s, $1 \mathrm{H}, \mathrm{NH}$ oxindole). ${ }^{13} \mathrm{C}$ NMR (75.5 MHz, $\left.\mathrm{CD}_{3} \mathrm{OD}\right) \delta 26.20\left(\mathrm{CH}_{3}\right), 31.68(\mathrm{C}), 38.03\left(\mathrm{CH}_{2}\right), 49.43(\mathrm{CH} \alpha), 50.47\left(\mathrm{CH}_{2}\right), 74.26$ (C), $110.24(\mathrm{CH}), 122.70(\mathrm{CH}), 123.25(\mathrm{CH}), 129.81(\mathrm{CH}), 131.56(\mathrm{C}), 140.66(\mathrm{C}), 168.70$ (CO), 179.31 (CO). HRMS (ESI) calcd for $\mathrm{C}_{16} \mathrm{H}_{23} \mathrm{~N}_{3} \mathrm{O}_{3} \mathrm{Na}[\mathrm{M}+\mathrm{Na}]^{+}$: 328.1632, found 328.1632 .

\subsubsection{6. (2S)-N-(adamantan-1-yl)methyl)-2-amino-3-((R)-3-hydroxy-2-oxoindolin-3-} yl)propanamide $\mathbf{6 m :}$

According to the general procedure described above, spirolactone 9a (208 mg, ca $0.55 \mathrm{mmol}$ based on a 70:30 ratio of $\mathrm{H}$ - and Br-oxindole starting material) and adamantylmethylene amine $(140 \mu \mathrm{L}, 0.90 \mathrm{mmol})$ were reacted overnight. Purification by chromatography over silica gel ( $8 \mathrm{~g}$, eluent $15 \%$ of AcOEt in $\mathrm{CH}_{2} \mathrm{Cl}_{2}$ ) afforded an orange amorphous solid (240 mg) that was hydrogenated according to the general procedure. Product $6 \mathbf{m}$, trifluoroacetate salt was obtained as a white solid (150 mg, 20\% from Z-Trp).

${ }^{1} \mathrm{H}$ NMR (300 MHz, DMSO-d $\left.{ }_{6}\right) \delta 1.37-1.89$ (m, 15H, adamantyl), $2.02(\mathrm{~d}, J=3.9 \mathrm{~Hz}, 1 \mathrm{H}$, $\mathrm{CH} \beta$ ), 2.18-2.27 (m, 1H, CHß), 2.70-2.77 (m, 2H, $\left.\mathrm{CH}_{2}-\mathrm{NHCO}\right), 4.38$ (br s, $1 \mathrm{H}, \mathrm{H \alpha}$ ), 6.88 (d, $J=7.8 \mathrm{~Hz}, 1 \mathrm{H}$ aromatic), $7.02(\mathrm{td}, J=7.5,1 \mathrm{~Hz}, 1 \mathrm{H}$ aromatic), 7.24-7.32 (m, 2H aromatics), 8.02 (br s, $\left.\mathrm{NH}_{3}{ }^{+}, \mathrm{OH}\right), 8.16(\mathrm{t}, J=6 \mathrm{~Hz}, 1 \mathrm{H}, \mathrm{NH}), 10.57$ (s, $1 \mathrm{H}, \mathrm{NH}$ oxindole). ${ }^{13} \mathrm{C} \mathrm{NMR}$ (75.5 MHz, CD $\left.\mathrm{CD}_{3} \mathrm{OD}\right) \delta 29.61\left(\mathrm{CH}\right.$ adamantyl), $35.05(\mathrm{C}), 37.88\left(\mathrm{CH}_{2}\right), 39.36\left(\mathrm{CH}_{2}\right), 41.16$ $\left(\mathrm{CH}_{2}\right), 50.81(\mathrm{CH} \alpha), 52.35\left(\mathrm{CH}_{2}\right), 75.66(\mathrm{C}), 111.70(\mathrm{CH}), 124.06(\mathrm{CH}), 124.65(\mathrm{CH}), 131.16$ (CH), 132.85 (C), 141.98 (C), 160.61 (CO), 170.17 (CO), 180.65 (CO). HRMS (ESI) calcd for $\mathrm{C}_{22} \mathrm{H}_{29} \mathrm{~N}_{3} \mathrm{O}_{3} \mathrm{Na}[\mathrm{M}+\mathrm{Na}]^{+}$: 406.2101, found 406.2105. 
4.1.1.17.

(S)-2-Amino-N-methyl-3-((S)-3-hydroxy-2-oxoindolin-3-yl)propanamide

According to the general procedure described above, spirolactone 10a (243 mg, ca $0.64 \mathrm{mmol}$ based on a 70:30 ratio of $\mathrm{H}$ - and Br-oxindole starting material) and $2 \mathrm{M}$ methylamine in THF ( $2 \mathrm{~mL}, 4 \mathrm{mmol})$ were reacted for $3 \mathrm{~h}$. Purification by chromatography over silica gel $(8.1 \mathrm{~g}$, eluent $10 \%$ of AcOEt in $\mathrm{CH}_{2} \mathrm{Cl}_{2}$ then then $25 \%$ AcOEt in $\mathrm{CH}_{2} \mathrm{Cl}_{2}$ ) afforded an orange amorphous solid (189 mg). MPLC purification of a small sample $(20 \mathrm{mg})$ over reversed phase silica $(\mathrm{C} 18,5 \mathrm{~g}, 50 \% \mathrm{MeOH}$ in water) afforded after lyophilization, (S)-2benzyloxycarbonylamino- $N$-methyl-3-((S)-3-hydroxy-2-oxoindolin-3-yl)propanamide (9 mg, ${ }^{1} \mathrm{H}$ NMR (300 MHz, $\left.\mathrm{CDCl}_{3}\right) \delta$ 2.32-2.55 (m, 2H, $\left.\mathrm{CH}_{2} \beta\right), 4.50(\mathrm{~m}, 1 \mathrm{H}, \mathrm{H \alpha}), 4.88($ broad s, 3H, $\left.\mathrm{CH}_{2} \mathrm{Ph}+\mathrm{OH}\right), 5.80$ (broad, $\left.1 \mathrm{H}, \mathrm{NHZ}\right), 6.73-7.31(\mathrm{~m}, 9 \mathrm{H}$, aromatic $\mathrm{H}), 9.22(\mathrm{~s}, 1 \mathrm{H}, \mathrm{NH}) .{ }^{13} \mathrm{C}$ NMR (75.5 MHz, $\left.\mathrm{CDCl}_{3}\right) \delta 26.2\left(\mathrm{NCH}_{3}\right), 39.8,51.2,66.9\left(\mathrm{OCH}_{2} \mathrm{Ph}\right), 75.7\left(\mathrm{C}_{\gamma}\right), 110.5-140.6$ (aromatic C), $155.9(\mathrm{C}=\mathrm{O}), 172.4(\mathrm{C}=\mathrm{O}), 179.9(\mathrm{C}=\mathrm{O}) . \mathrm{R}_{\mathrm{f}}=0.27(\mathrm{RP} 18,50 \% \mathrm{MeOH}$ in water), HRMS (LSIMS) calcd for $\mathrm{C}_{20} \mathrm{H}_{22} \mathrm{~N}_{3} \mathrm{O}_{5}[\mathrm{M}+\mathrm{H}]^{+}: 384.1559$, found 384.1555) and $(S)-2-$ benzyloxycarbonylamino- $N$-methyl-3-(5-bromo-(S)-3-hydroxy-2-oxoindolin-3-

yl)propanamide $\left(5.5 \mathrm{mg},{ }^{1} \mathrm{H}\right.$ NMR $\left(300 \mathrm{MHz}, \mathrm{CDCl}_{3}\right) \delta 2.16-2.59\left(\mathrm{~m}, 2 \mathrm{H}, \mathrm{CH}_{2} \beta\right), 2.72(\mathrm{~s}$, $3 \mathrm{H}, \mathrm{NCH}_{3}$ ), 4.48 (broad s, 1H, $\mathrm{H \alpha}$ ), 4.90 (s, 2H, $\mathrm{CH}_{2} \mathrm{Ph}$ ), 5.84 (broad s, 1H, OH), 6.33 (broad , 1H, NH), 6.59-7.60 (m, 8H, aromatic H), 9.20 (broad s, $1 \mathrm{H}, \mathrm{NH}) . \mathrm{R}_{\mathrm{f}}=0.13(\mathrm{RP} 18,50 \%$ $\mathrm{MeOH}$ in water), HRMS (LSIMS) calcd for $\mathrm{C}_{20} \mathrm{H}_{21}{ }^{79} \mathrm{Br} \mathrm{N}_{3} \mathrm{O}_{5}[\mathrm{M}+\mathrm{H}]^{+}: 462.0665$, found 462.0669).

As above, hydrogenation of the mixture $(169 \mathrm{mg}$ ) afforded $\mathbf{7 a}, \mathrm{HCl}$ salt as a white solid (114 mg, $28 \%$ from Z-Trp).

${ }^{1} \mathrm{H}$ NMR $\left(200 \mathrm{MHz}, \mathrm{D}_{2} \mathrm{O}+\mathrm{HCl}\right) \delta 2.39\left(\mathrm{ABX}\right.$ system, $1 \mathrm{H}_{\mathrm{A}}, J_{A X}=7 \mathrm{~Hz}, J_{A B}=14.7 \mathrm{~Hz}$, $\mathrm{CH}_{2} \beta$ ), 2.55 (ABX system, $1 \mathrm{H}_{\mathrm{B}}, J_{B X}=7 \mathrm{~Hz}, J_{A B}=14.7 \mathrm{~Hz}, \mathrm{CH}_{2} \beta$ ), $2.69\left(\right.$ broad s, $3 \mathrm{H}, \mathrm{NCH}_{3}$ ), $4.13(\mathrm{t}, 1 \mathrm{H}, J=7 \mathrm{~Hz}, \mathrm{H} \alpha), 7.05\left(\mathrm{~d}, 1 \mathrm{H}, J=7.8 \mathrm{~Hz}, \mathrm{H}_{7}\right), 7.21\left(\mathrm{t}, 1 \mathrm{H}, J=7.8 \mathrm{~Hz}, \mathrm{H}_{5}\right), 7.33$ (t, $\left.1 \mathrm{H}, J=7.8 \mathrm{~Hz}, \mathrm{H}_{6}\right), 7.47\left(\mathrm{~d}, 1 \mathrm{H}, J=7.8 \mathrm{~Hz}, \mathrm{H}_{4}\right) .{ }^{13} \mathrm{C} \mathrm{NMR}\left(75.5 \mathrm{MHz}, \mathrm{D}_{2} \mathrm{O}+\mathrm{HCl}\right) \delta 26.5$ (Me), $37.7\left(\mathrm{CH}_{2}\right), 50.4(\mathrm{CH \alpha}), 75.1(\mathrm{C}), 112.1(\mathrm{CH}), 124.5(\mathrm{CH}), 124.8(\mathrm{CH}), 129.6(\mathrm{C})$, $131.5(\mathrm{CH}), 140.9(\mathrm{C}), 164.4(\mathrm{C}=\mathrm{O}), 169.6(\mathrm{C}=\mathrm{O}), 180.5(\mathrm{C}=\mathrm{O})$. HRMS (LSIMS) calcd for $\mathrm{C}_{12} \mathrm{H}_{16} \mathrm{~N}_{3} \mathrm{O}_{3}[\mathrm{M}+\mathrm{H}]^{+}:$250.1192, found 250.1196.

\subsubsection{8.}

(S)-2-Amino-N-benzyl-3-((S)-3-hydroxy-2-oxoindolin-3-yl)propanamide

7b: According to the general procedure described above, spirolactone 10a (351 $\mathrm{mg}$, ca $0.93 \mathrm{mmol}$ based on a 70:30 ratio of $\mathrm{H}$ - and Br-oxindole starting material) and benzylamine (120 $\mu \mathrm{L}$, $1.10 \mathrm{mmol})$ were reacted overnight. Purification by chromatography over silica gel $(8 \mathrm{~g}$, 
eluent $15 \%$ of AcOEt in $\mathrm{CH}_{2} \mathrm{Cl}_{2}$ ) afforded an orange amorphous solid (385 mg) that was hydrogenated according to the general procedure. Product $\mathbf{7 b}, \mathrm{HCl}$ salt was obtained as a white solid (290 mg, 39\% from Z-Trp).

${ }^{1} \mathrm{H}$ NMR (300 MHz, $\left.\mathrm{D}_{2} \mathrm{O}\right) \delta 2.32$ and $2.46\left(\mathrm{ABX}\right.$ system, $2 \mathrm{H}, J_{A X}=7.5 \mathrm{~Hz}, J_{B X}=6.2 \mathrm{~Hz}, J_{A B}$ $\left.=14.9 \mathrm{~Hz}, \mathrm{CH}_{2} \beta\right), 4.23(\mathrm{t}, 1 \mathrm{H}, J=6.3 \mathrm{~Hz}, \mathrm{CH} \alpha), 4.28\left(\operatorname{broad~s}, 2 \mathrm{H}, \mathrm{CH}_{2} \mathrm{Ph}\right), 6.93(\mathrm{~d}, 1 \mathrm{H}, J=$ $7.8 \mathrm{~Hz}), 7.13(\mathrm{t}, 2 \mathrm{H}, J=6.9 \mathrm{~Hz}), 7.23-7.42(\mathrm{~m}, 6 \mathrm{H}) .{ }^{13} \mathrm{C} \mathrm{NMR}\left(75.5 \mathrm{MHz}, \mathrm{D}_{2} \mathrm{O}\right) \delta 37.8\left(\mathrm{CH}_{2}\right)$, $44.1\left(\mathrm{CH}_{2}\right), 50.4(\mathrm{CH} \alpha), 75.1(\mathrm{C} \gamma), 112.1(\mathrm{CH}), 124.4(\mathrm{CH}), 124.7(\mathrm{CH}), 128.3(\mathrm{CH}), 128.4$ $(\mathrm{CH}), 129.5(\mathrm{CH}), 129.8(\mathrm{C}), 131.5(\mathrm{CH}), 137.7(\mathrm{C}), 140.8(\mathrm{C}), 158.5(\mathrm{C}=\mathrm{O}), 169.1(\mathrm{C}=\mathrm{O})$, $180.6(\mathrm{C}=\mathrm{O})$. HRMS (ESI) calcd for $\mathrm{C}_{18} \mathrm{H}_{20} \mathrm{~N}_{3} \mathrm{O}_{3}[\mathrm{M}+\mathrm{H}]^{+}:$326.1505, found 326.1512.

4.1.1.19. (S)-2-Benzyloxyamino-N-benzyl-3-((S)-3-hydroxy-1-methyl-2-oxoindolin-3yl)propanamide:

According to the general procedure described above, spirolactone 10b (1.60 g, $4.75 \mathrm{mmol})$ and benzylamine $(560 \mu \mathrm{L}, 5.12 \mathrm{mmol})$ were reacted overnight. Purification by chromatography over silica gel (60 g, eluent $10 \%$ of AcOEt in $\left.\mathrm{CH}_{2} \mathrm{Cl}_{2}\right)$ afforded $(S)$-2benzyloxyamino- $N$-benzyl-3-((S)-3-hydroxy-1-methyl-2-oxoindolin-3-yl)propanamide as a beige solid (1.54 g, 69\%). Mp 56-59 ${ }^{\circ} \mathrm{C} .{ }^{1} \mathrm{H} \mathrm{NMR}\left(300 \mathrm{MHz}, \mathrm{CDCl}_{3}\right) \delta 2.18(\mathrm{dd}, J=14.7,7.2$ $\mathrm{Hz}, 1 \mathrm{H}), 2.56(\mathrm{dd}, J=14.8,6.8 \mathrm{~Hz}, 1 \mathrm{H}), 3.11(\mathrm{~s}, 3 \mathrm{H}), 4.40(\mathrm{~m}, 2 \mathrm{H}), 4.69(\mathrm{~m}, 1 \mathrm{H}), 5.01(\mathrm{~m}$, 2H), 5.90 (br s, 1H), 6.77 (d, $J=7.7 \mathrm{~Hz}, 1 \mathrm{H}), 7.05$ (t, $J=7.4 \mathrm{~Hz}, 1 \mathrm{H}), 7.17-7.36(\mathrm{~m}, 14 \mathrm{H})$. ${ }^{13} \mathrm{C}$ NMR $\left(75.5 \mathrm{MHz}, \mathrm{CDCl}_{3}\right) \delta 26.01\left(\mathrm{CH}_{3}\right), 39.70\left(\mathrm{CH}_{2}\right), 43.40\left(\mathrm{CH}_{2}\right), 51.23(\mathrm{CH}), 66.75$ $\left(\mathrm{CH}_{2}\right), 74.91(\mathrm{C}), 108.47(\mathrm{CH}), 123.23(\mathrm{CH}), 123.77(\mathrm{CH}), 127.11(\mathrm{CH}), 127.40(\mathrm{CH}), 127.86$ $(\mathrm{CH}), 127.93(\mathrm{CH}), 128.28(\mathrm{CH}), 128.39(\mathrm{CH}), 129.46(\mathrm{CH}), 130.49(\mathrm{C}), 135.98(\mathrm{C}), 137.68$ (C), 142.43 (C), 155.89 (C), 171.93 (C), 177.47 (C). HRMS (ESI) calcd for $\mathrm{C}_{27} \mathrm{H}_{27} \mathrm{~N}_{3} \mathrm{O}_{5} \mathrm{Na}$ $\left[(\mathrm{M}+\mathrm{Na})^{+}\right]$496.1843, found 496.1842. $R_{f}\left(2 / 3 \mathrm{AcOEt} / \mathrm{CH}_{2} \mathrm{Cl}_{2}\right)$ 0.28.

\subsubsection{0. (S)-2-Amino-N-benzyl-3-((S)-3-hydroxy-1-methyl-2-oxoindolin-3-yl)propanamide}

7c: Hydrogenation of (S)-2-benzyloxyamino- $N$-benzyl-3-( $(S)-3$-hydroxy-1-methyl-2oxoindolin-3-yl)propanamide $(972 \mathrm{mg}, 2.05 \mathrm{mmol}$ ) according to the general procedure afforded 7c as a white solid (697 mg, quantitative, 29\% from Z-L-methyl tryptophan). ${ }^{1} \mathrm{H}$ NMR (300 MHz, DMSO-d $)_{6} \delta 1.85(\mathrm{~m}, 2 \mathrm{H}), 3.09$ (s, 3H), $3.71(\mathrm{dd}, J=8.1,5.4 \mathrm{~Hz}, 1 \mathrm{H}), 4.24$ (s, 2H), $6.99(\mathrm{~d}, J=7.8 \mathrm{~Hz}, 1 \mathrm{H}), 7.05(\mathrm{t}, J=7.5 \mathrm{~Hz}, 1 \mathrm{H}), 7.22-7.30(\mathrm{~m}, 6 \mathrm{H}), 7.42$ (d, $J=7.5$ $\mathrm{Hz}, 1 \mathrm{H}), 8.42$ (br s, 1H). 


\subsubsection{Lactams 10 and 11}

Lactam10: ${ }^{1} \mathrm{H}$ NMR (400 MHz, DMSO-d 6 ) $\delta 2.06(\mathrm{dd}, J=8.8,12.0 \mathrm{~Hz}, 1 \mathrm{H}, \mathrm{H} \beta), 2.60(\mathrm{~d}, J=$ $4.6 \mathrm{~Hz}, 3 \mathrm{H}, \mathrm{Me}), 2.77$ (dd, $J=12.3,6.1 \mathrm{~Hz}, 1 \mathrm{H}, \mathrm{H} \beta$ ), 3.62 (dd, $J=8.8,6.2 \mathrm{~Hz}, 1 \mathrm{H}, \mathrm{H \alpha}$ ), 5.25 (s, 2H, $\mathrm{NH}_{2}$ ), 6.10 (s, $\left.1 \mathrm{H}, \mathrm{OH}\right), 6.50$ (ddd, $\left.J=8.6,7.3,1.3 \mathrm{~Hz}, 1 \mathrm{H}\right), 6.69$ (dd, $J=8.0,1.2 \mathrm{~Hz}$ ), $6.82(\mathrm{dd}, J=7.7,1.6 \mathrm{~Hz}, 1 \mathrm{H}), 7.00(\mathrm{ddd}, J=8.7,7.3,1.6 \mathrm{~Hz}, 1 \mathrm{H}), 8.01(\mathrm{q}, J=4.6 \mathrm{~Hz}, 1 \mathrm{H})$, 8.31(br s, 1H, NH).

Lactam 11: ${ }^{1} \mathrm{H}$ NMR (400 MHz, DMSO-d 6 ) $\delta 2.31$ (dd, $J=13.5,5.7 \mathrm{~Hz}, 1 \mathrm{H}, \mathrm{H} \beta$ trans to $\mathrm{H} \alpha$ ), $2.52(\mathrm{~m}, 4 \mathrm{H}, \mathrm{H} \beta$ cis to $\mathrm{H} \alpha$ and $\mathrm{Me}$ ), 4.06 ( dd, J = 7.5, $5.7 \mathrm{~Hz}, 1 \mathrm{H}, \mathrm{H} \alpha), 5.05$ (s, 2H, $\left.\mathrm{NH}_{2}\right), 6.10(\mathrm{~s}, 1 \mathrm{H}, \mathrm{OH}), 6.48\left(\mathrm{ddd}, J=8.1,7.3,1.3 \mathrm{~Hz}, 1 \mathrm{H}, \mathrm{H}^{2}\right), 6.61(\mathrm{dd}, J=8.0,1.2 \mathrm{~Hz}, 1 \mathrm{H}$, $\left.\mathrm{H}^{4}\right), 6.94\left(\mathrm{ddd}, J=8.8,7.3,1.6 \mathrm{~Hz}, 1 \mathrm{H}, \mathrm{H}^{3}\right), 7.13\left(\mathrm{dd}, J=7.7,1.6 \mathrm{~Hz}, 1 \mathrm{H}, \mathrm{H}^{1}\right), 7.94(\mathrm{q}, J=$ $4.6 \mathrm{~Hz}, 1 \mathrm{H}, \mathrm{NH}$ amide), 8.24 (br s, 1H, NH lactam). ${ }^{13} \mathrm{C}$ NMR (DMSO, $\left.100 \mathrm{MHz}\right) \delta 25.5$ $\left(\mathrm{CH}_{3}\right), 39.4\left(\mathrm{CH}_{2}\right), 52.64(\mathrm{CH}), 115.2(\mathrm{CH}), 115.8(\mathrm{CH}), 125.2(\mathrm{C}), 126.7(\mathrm{CH}), 127.7(\mathrm{CH})$, 146.0 (C), 171.9 (CO amide), 176.4 (CO lactam).

\subsubsection{Synthesis of tripeptides 1-2 and dipeptides 5}

4.1.3.1. General procedure for the convergent synthesis of tripeptide 1a: A mixture of BocTyr(Bn)-Ala-OSu (278.1 mg, $0.515 \mathrm{mmol}$ prepared from $13\left(\mathrm{R}^{3}=\mathrm{Me}\right)$ [16], DCC and HOSu according to the literature [52]) and oxidized tryptophan $\mathbf{6 b}, \mathrm{HCl}(152.3 \mathrm{mg}, 0.421 \mathrm{mmol})$ in dry DMF $(0.7 \mathrm{~mL})$, triethylamine $(60 \mu \mathrm{l}, 0.43 \mathrm{mmol})$ and dry $\mathrm{CH}_{2} \mathrm{Cl}_{2}(1.3 \mathrm{~mL})$ was stirred at room temperature for two days. After evaporation of the solvent under high vacuum and chromatography of the residue over silica gel $\left(3 \% \mathrm{MeOH}\right.$ in $\left.\mathrm{CH}_{2} \mathrm{Cl}_{2}\right)$, tripeptide 1a was afforded as a white solid (155.7 $\mathrm{mg}, 49 \%)$. Characterization datas of 1a were previously published [17]. $R_{f}\left(5 / 95 \mathrm{MeOH} / \mathrm{CH}_{2} \mathrm{Cl}_{2}\right)$ 0.49. HPLC (column 1): $t_{\mathrm{R}}=27.2 \mathrm{~min}$, area percent $>99 \%$ at $254 \mathrm{~nm}$.

4.1.3.2. General procedure for the linear synthesis of tripeptide 1a: To a solution of oxidized tryptophan $\mathrm{HCl}, 6 \mathbf{b}(1.38 \mathrm{~g}, 3.83 \mathrm{mmol})$ and commercial Z-Ala-OSu (1.23 g, $3.83 \mathrm{mmol})$ in dry $\mathrm{CH}_{2} \mathrm{Cl}_{2}(25 \mathrm{~mL})$ was added triethylamine $(840 \mu \mathrm{L}, 6 \mathrm{mmol})$. The mixture was stirred overnight at room temperature. The mixture was washed by water. The aqueous phase was extracted three times with $\mathrm{CH}_{2} \mathrm{Cl}_{2}$. The combined organic phases were dried over sodium sulfate and then concentrated under reduced pressure. After chromatography of the residue over silica gel (60 g, 40\% AcOEt in $\left.\mathrm{CH}_{2} \mathrm{Cl}_{2}\right)$, Z-dipeptide 5a was afforded as a white solid $(1.80 \mathrm{~g}, 88 \%) .{ }^{1} \mathrm{H}$ NMR (500 MHz, DMSO-d 6$) \delta 1.19(\mathrm{~d}, J=7.2 \mathrm{~Hz}, 3 \mathrm{H}), 2.18(\mathrm{dd}, J=13.9$, 
$9.0 \mathrm{~Hz}, 1 \mathrm{H}), 2.45-2.50(\mathrm{~m}, 1 \mathrm{H}), 3.83-3.90(\mathrm{~m}, 1 \mathrm{H}), 4.11(\mathrm{dd}, J=15.3,5.5 \mathrm{~Hz}, 1 \mathrm{H}), 4.16(\mathrm{td}, J$ $=8.6,3.6 \mathrm{~Hz}, 1 \mathrm{H}), 4.25(\mathrm{dd}, J=15.3,6.4 \mathrm{~Hz}, 1 \mathrm{H}), 4.87(\mathrm{~d}, J=12.6 \mathrm{~Hz}, 1 \mathrm{H}), 4.98(\mathrm{~d}, J=12.6$ $\mathrm{Hz}, 1 \mathrm{H}), 6.01(\mathrm{~s}, 1 \mathrm{H}), 6.75(\mathrm{~d}, J=7.7 \mathrm{~Hz}, 1 \mathrm{H}), 6.94(\mathrm{t}, J=7.4 \mathrm{~Hz}, 1 \mathrm{H}), 7.16-7.37$ (m, 12H), $7.47(\mathrm{~d}, J=5.8 \mathrm{~Hz}, 1 \mathrm{H}), 7.91-7.96(\mathrm{~m}, 2 \mathrm{H}), 10.08(\mathrm{~s}, 1 \mathrm{H}) .{ }^{13} \mathrm{C} \mathrm{NMR}(125 \mathrm{MHz}$, DMSO-d 6 ) $\delta$ 17.3, 38.6, 42.0, 49.1, 50.9, 65.5, 74.3, 109.5, 121.4, 124.4, 126.5, 126.8, 127.0, 127.1, 127.7, $128.0,128.2,128.9,131.0,136.7,139.1,141.8,156.2,171.0,171.9,178.9$. A mixture of the Z-dipeptide 5a (1.80 g, $3.40 \mathrm{mmol})$ and $10 \%$ palladium on charcoal (542 $\mathrm{mg}$ ) in methanol $(20 \mathrm{~mL})$ was stirred overnight at room temperature under $\mathrm{H}_{2}$ atmosphere. After filtration through celite, the filtrate was concentrated under reduced pressure to afford the deprotected dipeptide as a white solid (1.46 g, quantitative). ${ }^{1} \mathrm{H}$ NMR $\left(300 \mathrm{MHz}, \mathrm{CD}_{3} \mathrm{OD}+\mathrm{HCl}\right) \delta 1.44$ (d, $J=7.2 \mathrm{~Hz}, 3 \mathrm{H}), 2.31(\mathrm{dd}, J=14.4,7.5 \mathrm{~Hz}, 1 \mathrm{H}), 2.50(\mathrm{dd}, J=14.4,5.1 \mathrm{~Hz}, 1 \mathrm{H}), 3.87(\mathrm{q}, J=$ $7.2 \mathrm{~Hz}, 1 \mathrm{H}), 4.09$ and $4.30\left(\mathrm{AB}\right.$ system, $\left.J_{A B}=15.3 \mathrm{~Hz}, 2 \mathrm{H}\right), 4.43(\mathrm{dd}, J=7.5,5.1 \mathrm{~Hz}, 1 \mathrm{H})$, $6.91(\mathrm{~d}, J=7.5 \mathrm{~Hz}, 1 \mathrm{H}), 7.06(\mathrm{t}, J=7.5 \mathrm{~Hz}, 1 \mathrm{H}), 7.21-7.37(\mathrm{~m}, 7 \mathrm{H})$. A mixture of the deprotected dipeptide (1.46 g, $3.68 \mathrm{mmol})$, commercial Boc-Tyr(Bn)-OSu (1.85 g, 3.96 $\mathrm{mmol})$ and triethylamine $(690 \mu \mathrm{L}, 4.95 \mathrm{mmol})$ in dry $\mathrm{CH}_{2} \mathrm{Cl}_{2}(25 \mathrm{~mL})$ was stirred overnight at room temperature. After dilution by $\mathrm{CH}_{2} \mathrm{Cl}_{2}$, the mixture was washed with water. The aqueous phase was extracted three times with $\mathrm{CH}_{2} \mathrm{Cl}_{2}$. The combined organic phases were dried over sodium sulfate and then concentrated under reduced pressure. After chromatography of the residue over silica gel (88 g, 50\% AcOEt in $\mathrm{CH}_{2} \mathrm{Cl}_{2}$ ), tripeptide 1a was afforded as a white solid $(2.00 \mathrm{~g}, 73 \%)$. The overall yield from oxidized tryptophan $\mathbf{6 b}$ was $64 \%$. Characterization datas of 1 a were previously published [17].

4.1.3.3. Tripeptide 1b: It was prepared by the convergent synthesis according to the general procedure starting from Boc-Tyr(Bn)-Ala-OSu (159.3 mg, $0.295 \mathrm{mmol})$ and $6 \mathbf{a}(78.1 \mathrm{mg}$, $0.313 \mathrm{mmol})$ in DMF (0.3 mL). Tripeptide $\mathbf{1 b}$ was afforded as a white solid (63 $\mathrm{mg}, 32 \%)$. Characterization datas of $\mathbf{1 b}$ were previously published [17].

4.1.3.4. Tripeptide 1c: It was prepared by the convergent synthesis according to the general procedure starting from Boc-Tyr(Bn)-Ala-OSu (1.00 g, $1.85 \mathrm{mmol})$ and $6 \mathbf{c}(0.691 \mathrm{~g}, 2.04$ $\mathrm{mmol})$ in $\mathrm{CH}_{2} \mathrm{Cl}_{2}(20 \mathrm{~mL})$. Tripeptide $1 \mathrm{c}$ was afforded as a white solid $(0.789 \mathrm{~g}, 56 \%)$.

${ }^{1} \mathrm{H}$ NMR (300 MHz, DMSO-d 6 ) $\delta 1.13(\mathrm{~d}, J=7.2 \mathrm{~Hz}, 3 \mathrm{H}), 1.27(\mathrm{~s}, 9 \mathrm{H}), 2.20(\mathrm{~m} \mathrm{1H}), 2.60$ (m, 1H), $2.90(\mathrm{~m}, 1 \mathrm{H}), 2.98(\mathrm{~s}, 3 \mathrm{H}), 3.93(\mathrm{~m}, 1 \mathrm{H}), 4.09-4.30(\mathrm{~m}, 4 \mathrm{H}), 5.05(\mathrm{~s}, 2 \mathrm{H}), 6.07(\mathrm{~s}$, $1 \mathrm{H})$, 6.85-7.04 (m, 5H), 7.13-7.43 (m, 14H), 7.87-7.94 (m, 3H). ${ }^{13} \mathrm{C}$ NMR $(75.5 \mathrm{MHz}$, DMSO-d $\left.{ }_{6}\right) \delta 18.11\left(\mathrm{CH}_{3}\right), 25.71\left(\mathrm{CH}_{3}\right), 28.11\left(\mathrm{CH}_{3}\right), 36.23\left(\mathrm{CH}_{2}\right), 38.72\left(\mathrm{CH}_{2}\right), 42.12\left(\mathrm{CH}_{2}\right)$, 
$48.45(\mathrm{CH}), 49.17(\mathrm{CH}), 55.87(\mathrm{CH}), 69.12\left(\mathrm{CH}_{2}\right), 74.00(\mathrm{C}), 78.13(\mathrm{C}), 108.30(\mathrm{CH}), 114.33$ $(\mathrm{CH}), 122.16(\mathrm{CH}), 123.90(\mathrm{CH}), 126.61(\mathrm{CH}), 126.91(\mathrm{CH}), 127.54(\mathrm{CH}), 127.69(\mathrm{CH})$, $128.09(\mathrm{CH}), 128.35(\mathrm{CH}), 129.17(\mathrm{CH}), 130.15(\mathrm{CH}), 130.27(\mathrm{C}), 137.22(\mathrm{C}), 139.16(\mathrm{C})$, 143.43 (C), 155.33 (C), 156.85 (C), 170.62 (C), 171.43 (C), 171.63 (C), 176.82 (C). HRMS (ESI) calcd for $\mathrm{C}_{43} \mathrm{H}_{49} \mathrm{~N}_{5} \mathrm{O}_{8} \mathrm{Na}\left[(\mathrm{M}+\mathrm{Na})^{+}\right]$786.3473, found 786.3470. $R_{f}(\mathrm{AcOEt})$ 0.44.

4.1.3.5. Tripeptide 1d: A mixture of tripeptide $1 \mathrm{a}(26 \mathrm{mg}, 0.035 \mathrm{mmol})$ and $10 \%$ palladium on charcoal $(5 \mathrm{mg})$ in $\mathrm{MeOH}(1 \mathrm{~mL})$ was hydrogenated at atmospheric pressure overnight. After filtration over a pad of celite, the filtrate was concentrated and the resulting residue was washed with ether to afford $1 \mathbf{d}$ as a white solid $(22.7 \mathrm{mg}, 99 \%)$. Characterization datas of $\mathbf{1 d}$ were previously published [17].

4.1.3.6. Tripeptide 1e: Tripeptide 1a $(34.29 \mathrm{mg}, 0.0457 \mathrm{mmol})$ was dissolved in $\mathrm{MeOH}$ $(0.1 \mathrm{~mL})$ and treated at $0{ }^{\circ} \mathrm{C}$ for $30 \mathrm{~min}$ with anhydrous $12 \mathrm{M} \mathrm{HCl}$ in $\mathrm{MeOH}(0.2 \mathrm{~mL}, 2.4$ mmol). The resulting mixture was then concentrated in vacuo. Purification by MPLC over RP silica (C18, MeOH/0.005 $\mathrm{M}$ aqueous $\mathrm{HCl}$ 40/60) afforded tripeptide 1e (13.0 mg, 41\%). Characterization datas of 1e were previously published [17].

4.1.3.7. Tripeptide 1f: It was prepared by the convergent synthesis according to the general procedure starting from Boc-Tyr(Bn)-Ala-OSu (231 mg, $0.428 \mathrm{mmol})$ and $6 \mathbf{d}, \mathrm{HCl}$ salt (216.5 $\mathrm{mg}, 0.435 \mathrm{mmol})$ in $\mathrm{CH}_{2} \mathrm{Cl}_{2}(1.5 \mathrm{~mL})$. Tripeptide $\mathbf{1 f}$ was afforded as a white solid (123.5 $\mathrm{mg}$, $36 \%$ yield). It was also prepared by the linear synthesis according to the general procedure. Intermediate Z-dipeptide was obtained as a white solid (214 mg, 77\%) from oxidized tryptophan, $\mathrm{HCl}$ salt 6d (236 mg, $0.483 \mathrm{mmol})$ and Z-Ala-OSu (156 mg, $0.49 \mathrm{mmol}) .{ }^{1} \mathrm{H}$ NMR $\left(300 \mathrm{MHz}, \mathrm{CDCl}_{3}\right) \delta 1.22(\mathrm{~d}, J=7.2 \mathrm{~Hz}, 3 \mathrm{H}), 2.36(\mathrm{dd}, J=16.5,4.2 \mathrm{~Hz}, 1 \mathrm{H}), 2.59(\mathrm{dd}, J=$ 16.5, 6.6 Hz, 1H), $4.21(\mathrm{q}, J=7.2 \mathrm{~Hz}, 1 \mathrm{H}), 4.64(\mathrm{~m}, 1 \mathrm{H}), 4.80-5.01(\mathrm{~m}, 4 \mathrm{H}), 5.42(\mathrm{~s}, 1 \mathrm{H})$, $5.45(\mathrm{~d}, J=7.2 \mathrm{~Hz}, 1 \mathrm{H}), 6.59$ (d, $J=7.8 \mathrm{~Hz}, 1 \mathrm{H}), 7.02-7.49$ (m, 13H), 7.69-7.94 (m, 5H). Hydrogenation and then coupling with Boc-Tyr(Bn)-OSu (133 mg, $0.290 \mathrm{mmol})$ afforded tripeptide $\mathbf{1 f}$ as a white solid (142 $\mathrm{mg}, 48 \%$ ). The overall yield from oxidized tryptophan $\mathbf{6 d}$ was $37 \%$.

${ }^{1} \mathrm{H}$ NMR (500 MHz, DMSO-d 6 ) $\delta 1.14$ (d, $J=7.0 \mathrm{~Hz}, 3 \mathrm{H}, \mathrm{CH}_{3}$ ), 1.29 (s, 9H, Boc), 2.08 (dd, $J$ $=14.5,3.0 \mathrm{~Hz}, 1 \mathrm{H}, \mathrm{CH} \beta), 2.46(\mathrm{dd}, J=14.5,3.5 \mathrm{~Hz}, 1 \mathrm{H}, \mathrm{CH} \beta), 2.59(\mathrm{dd}, J=14.5,9.0 \mathrm{~Hz}$, $1 \mathrm{H}, \mathrm{CH} \beta), 2.93(\mathrm{dd}, J=15.0,4.5 \mathrm{~Hz}, 1 \mathrm{H}), 4.06-4.13\left(\mathrm{~m}, 2 \mathrm{H}, \mathrm{NCH}_{2}\right), 4.23-4.28(\mathrm{~m}, 1 \mathrm{H}$, $\mathrm{CH \alpha}), 4.57(\mathrm{dd}, J=15.0,5.5 \mathrm{~Hz}, 1 \mathrm{H}), 4.71(\mathrm{dd}, J=15.0,6.0 \mathrm{~Hz}, 1 \mathrm{H}), 5.05\left(\mathrm{~s}, 2 \mathrm{H}, \mathrm{OCH}_{2}\right)$, 
$6.01(\mathrm{~s}, 1 \mathrm{H}, \mathrm{OH}), 6.77(\mathrm{~d}, J=7.5 \mathrm{~Hz}, 1 \mathrm{H}), 6.87-6.95$ (m, 4H aromatic), 7.13-7.55 (m, 14H), $7.83(\mathrm{dd}, J=17.0,7.5 \mathrm{~Hz}, 1 \mathrm{H}), 7.92-7.94(\mathrm{~m}, 1 \mathrm{H}), 7.97-8.02(\mathrm{~m}, 2 \mathrm{H}), 10.10(\mathrm{~s}, 1 \mathrm{H}, \mathrm{NH}$ oxindole). ${ }^{13} \mathrm{C}$ NMR $\left(75.5 \mathrm{MHz}, \mathrm{CDCl}_{3}\right) \delta 17.08\left(\mathrm{CH}_{3}\right), 28.73\left(\mathrm{CH}_{3}\right), 30.77\left(\mathrm{CH}_{2}\right), 37.83$ $\left(\mathrm{CH}_{2}\right), 42.25\left(\mathrm{CH}_{2}\right), 51.26(\mathrm{CH}), 51.69(\mathrm{CH}), 57.41(\mathrm{CH}), 70.90\left(\mathrm{CH}_{2}\right), 76.37(\mathrm{C}), 80.89(\mathrm{C})$, $114.42(\mathrm{CH}), 115.82(\mathrm{CH}), 123.86(\mathrm{CH}), 124.45(\mathrm{CH}), 125.50(\mathrm{CH}), 126.45(\mathrm{CH}), 126.81$ $(\mathrm{CH}), 126.94(\mathrm{CH}), 127.36(\mathrm{CH}), 128.54(\mathrm{CH}), 128.80(\mathrm{CH}), 129.12(\mathrm{CH}), 129.46(\mathrm{CH})$, $129.70(\mathrm{C}), 130.53(\mathrm{CH}), 130.91(\mathrm{CH}), 131.33(\mathrm{CH}), 131.76(\mathrm{C}), 132.92(\mathrm{C}), 134.66(\mathrm{C})$, 135.20 (C), 138.79 (C), 142.92 (C), 157.87 (CO), 159.01 (C), 172.99 (CO), 174.67 (CO), $175.16(\mathrm{CO}), 181.50(\mathrm{CO})$. HRMS (ESI) calcd for $\mathrm{C}_{46} \mathrm{H}_{49} \mathrm{~N}_{5} \mathrm{O}_{8} \mathrm{Na}[\mathrm{M}+\mathrm{Na}]^{+}$822.3473, found 822.3474. $R_{f}\left(5 / 95 \mathrm{MeOH} / \mathrm{CH}_{2} \mathrm{Cl}_{2}\right)$ 0.21. HPLC (column 1): $t_{\mathrm{R}}=29.9 \mathrm{~min}$, area percent $98 \%$ at $254 \mathrm{~nm}$.

4.1.3.8. Tripeptide 1g: It was prepared by the convergent synthesis according to the general procedure starting from Boc-Tyr(Bn)-Ala-OSu (112.4 mg, $0.21 \mathrm{mmol})$ and $6 \mathbf{6 e}, \mathrm{HCl}$ salt $(99.7$ $\mathrm{mg}, 0.19 \mathrm{mmol})$ in $\mathrm{CH}_{2} \mathrm{Cl}_{2}(0.3 \mathrm{~mL})$. Tripeptide $1 \mathrm{~g}$ was afforded as a white solid $(67.5 \mathrm{mg}$, $42 \%$ yield).

${ }^{1} \mathrm{H}$ NMR (500 MHz, DMSO-d 6 ) $\delta 1.16$ (d, $J=7.0 \mathrm{~Hz}, 3 \mathrm{H}, \mathrm{CH}_{3}$ ), 1.29 (s, 9H, Boc), 2.10 (dd, $J$ $=15.0,4.5 \mathrm{~Hz}, 1 \mathrm{H}, \mathrm{CH} \beta), 2.39(\mathrm{dd}, J=15.0,4.5 \mathrm{~Hz}, 1 \mathrm{H}, \mathrm{CH} \beta), 2.92(\mathrm{dd}, J=10.5,4.5 \mathrm{~Hz}$, $1 \mathrm{H}), 4.09-4.15\left(\mathrm{~m}, 3 \mathrm{H}, \mathrm{NCH}_{2}, \mathrm{CH}\right), 4.24-4.29(\mathrm{~m}, 1 \mathrm{H}, \mathrm{CH} \alpha), 5.05\left(\mathrm{~s}, 2 \mathrm{H}, \mathrm{OCH}_{2}\right), 6.01(\mathrm{~d}, J=$ $\left.8.5 \mathrm{~Hz}, 1 \mathrm{H}, \mathrm{CH}(\mathrm{Ph})_{2}\right), 6.05$ (s, 1H, OH), 6.76 (d, $J=8.0 \mathrm{~Hz}, 1 \mathrm{H}$ aromatic), 6.85-6.93 (m, 4H aromatics), 7.13-7.44 (m, $18 \mathrm{H}$ aromatics, $1 \mathrm{NH}), 7.89(\mathrm{~d}, J=7.5 \mathrm{~Hz}, 1 \mathrm{H}, \mathrm{NH}), 8.00(\mathrm{~d}, J=9.0$ $\mathrm{Hz}, 1 \mathrm{H}, \mathrm{NH}), 8.17$ (d, $\left.J=9.0 \mathrm{~Hz}, 1 \mathrm{H}, \mathrm{NH}-\mathrm{CH}(\mathrm{Ph})_{2}\right), 10.08$ (s, 1H, NH oxindole). NMR signal attribution resulted from HMBC and HSQC experiments. ${ }^{1} \mathrm{H}$ NMR $\left(300 \mathrm{MHz}, \mathrm{CDCl}_{3}\right)$ $\delta 1.25\left(\mathrm{~d}, J=7.2 \mathrm{~Hz}, 3 \mathrm{H}, \mathrm{CH}_{3}\right), 1.37$ (s, 9H, Boc), 2.40 (br s, $\left.1 \mathrm{H}, \mathrm{H}^{4}\right), 2.54-2.56\left(\mathrm{~m}, 1 \mathrm{H}, \mathrm{H}^{4}\right)$, $2.73\left(\mathrm{~m}, 1 \mathrm{H}, \mathrm{H}^{20}\right), 2.96\left(\mathrm{~m}, 1 \mathrm{H}, \mathrm{H}^{20}\right), 4.35\left(\mathrm{~m}, 2 \mathrm{H}, \mathrm{H}^{15}, \mathrm{H}^{11}\right), 4.57\left(\mathrm{~m}, 1 \mathrm{H}, \mathrm{H}^{5}\right), 4.98(\mathrm{~s}, 2 \mathrm{H}$, $\left.\mathrm{H}^{22}\right), 5.04\left(\mathrm{~m}, 1 \mathrm{H}, \mathrm{H}^{16}\right), 5.38(\mathrm{br} \mathrm{s}, 1 \mathrm{H}, \mathrm{OH}), 6.21\left(\mathrm{~d}, J=8.4 \mathrm{~Hz}, 1 \mathrm{H}, \mathrm{H}^{8}\right), 6.72(\mathrm{~d}, J=7.8 \mathrm{~Hz}$, $1 \mathrm{H}$ aromatic), $6.86(\mathrm{~d}, J=8.7 \mathrm{~Hz}, 1 \mathrm{H}$ aromatic), 6.98-7.42 (m, 21 $\mathrm{H}$ aromatics, $\mathrm{NH}), 7.68(\mathrm{~d}, J$ $\left.=6.0 \mathrm{~Hz}, 1 \mathrm{H}, \mathrm{H}^{7}\right), 7.81\left(\mathrm{~d}, J=7.8 \mathrm{~Hz}, 1 \mathrm{H}, \mathrm{H}^{9}\right), 9.27\left(\mathrm{~s}, 1 \mathrm{H}, \mathrm{H}^{1}\right) \cdot{ }^{13} \mathrm{C} \mathrm{NMR}(125.77 \mathrm{MHz}$, $\left.\mathrm{CDCl}_{3}\right) \delta 17.67\left(\mathrm{C}^{12}\right), 28.37\left(\mathrm{C}^{19}\right), 37.23\left(\mathrm{C}^{20}\right), 39.30\left(\mathrm{C}^{4}\right), 49.88\left(\mathrm{C}^{11}, \mathrm{C}^{5}\right), 55.85\left(\mathrm{C}^{15}\right), 55.17$ $\left(\mathrm{C}^{8}\right), 77.03\left(\mathrm{C}^{22}\right), 75.48\left(\mathrm{C}^{3}\right), 80.86\left(\mathrm{C}^{18}\right), 110.76(\mathrm{CH}), 115.07(\mathrm{CH}), 123.49(\mathrm{CH}), 124.34$ $(\mathrm{CH}), 127.46(\mathrm{CH}), 127.52(\mathrm{CH}), 127.59(\mathrm{CH}), 127.79(\mathrm{CH}), 128.08(\mathrm{CH}), 128.6(\mathrm{CH})$, $128.67(\mathrm{CH}), 128.71(\mathrm{CH}), 129.98(\mathrm{CH}), 130.44(\mathrm{CH}), 137.01\left(\mathrm{C}^{23}\right), 140.59(\mathrm{C}), 141.22(\mathrm{C})$, $141.48(\mathrm{C}), 156.00\left(\mathrm{C}^{17}\right), 157.85\left(\mathrm{C}^{21}\right), 170.59\left(\mathrm{C}^{6}\right), 172.42\left(\mathrm{C}^{14}\right), 172.67\left(\mathrm{C}^{10}\right), 180.78\left(\mathrm{C}^{2}\right)$. 
HRMS (ESI) calcd for $\mathrm{C}_{48} \mathrm{H}_{51} \mathrm{~N}_{5} \mathrm{O}_{8} \mathrm{Na}[\mathrm{M}+\mathrm{Na}]^{+}$848.3630, found 848.3631. $R_{f}(1 / 9$ $\mathrm{MeOH} / \mathrm{CH}_{2} \mathrm{Cl}_{2}$ ) 0.36. HPLC (column 1): $t_{\mathrm{R}}=31.24$ min, area percent $94 \%$ at $254 \mathrm{~nm}$.

4.1.3.9. Tripeptide $\mathbf{1 h}$ : It was prepared by the linear synthesis according to the general procedure. Intermediate Z-dipeptide was obtained as a white solid (149 mg, 60\%) from oxidized tryptophan, TFA salt $6 \mathbf{f}(211 \mathrm{mg}, 0.41 \mathrm{mmol})$ and Z-Ala-OSu (156 mg, 0.49 mmol). ${ }^{1} \mathrm{H}$ NMR $\left(300 \mathrm{MHz}, \mathrm{CDCl}_{3}\right) \delta 1.38(\mathrm{~d}, J=6.9 \mathrm{~Hz}, 3 \mathrm{H}), 2.32-2.38(\mathrm{~m}, 1 \mathrm{H}), 2.64(\mathrm{dd}, J$ $=15.6,6.3 \mathrm{~Hz}, 1 \mathrm{H}), 3.17(\mathrm{dd}, J=12.9,6.6 \mathrm{~Hz}, 1 \mathrm{H}), 4.28(\mathrm{t}, J=7.2 \mathrm{~Hz}, 1 \mathrm{H}), 4.35-4.61(\mathrm{~m}$, 2H), 4.72-4.78 (m, 1H), 5.06 (br s, 2H), 5.44-5.50 (m, 1H), 6.72 (t, $J=8.5 \mathrm{~Hz}, 1 \mathrm{H}), 7.06-7.26$ $(\mathrm{m}, 4 \mathrm{H}), 7.33-7.58(\mathrm{~m}, 13 \mathrm{H}), 7.78-7.88(\mathrm{~m}, 2 \mathrm{H})$. Deprotection of the $\mathrm{Z}$ group afforded a white solid (117 mg, quantitative). ${ }^{1} \mathrm{H}$ NMR (300 MHz, $\left.\mathrm{CD}_{3} \mathrm{OD}\right) \delta 1.44(\mathrm{~d}, J=7.2 \mathrm{~Hz}, 3 \mathrm{H}), 2.35$ (dd, $J=14.5,6.9 \mathrm{~Hz}, 1 \mathrm{H}), 2.53$ (dd, $J=14.4,5.1 \mathrm{~Hz}, 1 \mathrm{H}), 3.79$ (br s, 1H), 4.15-4.45 (m, 3H), $6.92(\mathrm{~d}, J=7.5 \mathrm{~Hz}, 1 \mathrm{H}), 7.09(\mathrm{td}, J=7.8,1.0 \mathrm{~Hz}, 1 \mathrm{H}), 7.27-7.45(\mathrm{~m}, 7 \mathrm{H}), 7.54-7.60(\mathrm{~m}, 4 \mathrm{H})$. Coupling with Boc-Tyr(Bn)-OSu (116 mg, $0.25 \mathrm{mmol})$ afforded tripeptide $\mathbf{1 h}$ as a white solid (118 mg, 58\%). The overall yield from oxidized tryptophan $\mathbf{6 f}$ was $35 \%$.

${ }^{1} \mathrm{H}$ NMR (500 MHz, DMSO-d 6 ) $\delta 1.20$ (d, $J=7.0 \mathrm{~Hz}, 3 \mathrm{H}, \mathrm{CH}_{3}$ ), 1.29 (s, 9H, Boc), 2.11 (dd, $J$ $=15.0,10.0 \mathrm{~Hz}, 1 \mathrm{H}, \mathrm{CH} \beta), 2.44(\mathrm{dd}, J=15.0,5.0 \mathrm{~Hz}, 1 \mathrm{H}, \mathrm{CH} \beta), 2.58-2.61(\mathrm{~m}, 1 \mathrm{H}, \mathrm{CH}), 2.95$ (dd, $J=15.0,5.0 \mathrm{~Hz}, 1 \mathrm{H}), 4.07-4.24\left(\mathrm{~m}, 4 \mathrm{H}, \mathrm{NCH}_{2}, \mathrm{CH}_{2}\right), 4.29$ (dd, $J=15.0,7.0 \mathrm{~Hz}, 1 \mathrm{H}$, $\mathrm{CH \alpha}), 5.04\left(\mathrm{~s}, 2 \mathrm{H}, \mathrm{OCH}_{2}\right), 6.02(\mathrm{~s}, 1 \mathrm{H}, \mathrm{OH}), 6.77$ (d, $J=7.5 \mathrm{~Hz}, 1 \mathrm{H}$ aromatic), 6.87-6.95 (m, $4 \mathrm{H}$ aromatics), 7.14-7.45 (m, 13H aromatics, $1 \mathrm{NH}), 7.56$ (d, $J=7.5 \mathrm{~Hz}, 2 \mathrm{H}$ aromatics), 7.61 (d, $J=8.0 \mathrm{~Hz}, 2 \mathrm{H}$ aromatics), $7.84(\mathrm{~d}, J=8.5 \mathrm{~Hz}, 1 \mathrm{H}, 1 \mathrm{NH}), 7.96(\mathrm{t}, J=5.5 \mathrm{~Hz} 1 \mathrm{H}, \mathrm{NH}), 8.05$ (d, $J=7.0 \mathrm{~Hz}, 1 \mathrm{H}, \mathrm{NH}), 10.11$ (s, 1H, NH oxindole). ${ }^{13} \mathrm{C}$ NMR $\left(75.5 \mathrm{MHz}, \mathrm{DMSO}_{\mathrm{d}}\right) \delta$ $17.59\left(\mathrm{CH}_{3}\right), 28.13\left(\mathrm{CH}_{3}\right), 30.38\left(\mathrm{CH}_{2}\right), 36.23\left(\mathrm{CH}_{2}\right), 41.89\left(\mathrm{CH}_{2}\right), 48.98(\mathrm{CH}), 49.10(\mathrm{CH})$, $55.78(\mathrm{CH}), 69.11\left(\mathrm{CH}_{2}\right), 74.26(\mathrm{C}), 78.09(\mathrm{C}), 109.66(\mathrm{CH}), 114.29(\mathrm{CH}), 121.48(\mathrm{CH})$, $124.45(\mathrm{CH}), 126.45(\mathrm{CH}), 126.53(\mathrm{CH}), 127.25(\mathrm{CH}), 127.59(\mathrm{CH}), 127.72(\mathrm{CH}), 127.93$ $(\mathrm{CH}), 128.37(\mathrm{CH}), 128.86(\mathrm{CH}), 129.98(\mathrm{CH}), 130.16(\mathrm{CH}), 131.02(\mathrm{C}), 132.58(\mathrm{C}), 137.22$ (C), 138.53 (C), 138.58 (C), 139.97 (C), 141.76 (C), 155.35 (C), 156.83 (CO), 170.95 (CO), $171.61(\mathrm{CO}), 172.23(\mathrm{CO}), 179.00(\mathrm{CO})$. HRMS (ESI) calcd for $\mathrm{C}_{48} \mathrm{H}_{51} \mathrm{~N}_{5} \mathrm{O}_{8} \mathrm{Na}[\mathrm{M}+\mathrm{Na}]^{+}$ 848.3630, found 848.3632. $R_{f}\left(1 / 4 \mathrm{MeOH} / \mathrm{CH}_{2} \mathrm{Cl}_{2}\right)$ 0.57. HPLC (column 1): $t_{\mathrm{R}}=31.7 \mathrm{~min}$, area percent $98 \%$ at $254 \mathrm{~nm}$.

4.1.3.10. Tripeptide 1i: It was prepared by the linear synthesis according to the general procedure. Intermediate Z-dipeptide was obtained as a white solid (249 $\mathrm{mg}, 78 \%$ ) from oxidized tryptophan, TFA salt $\mathbf{6 g}$ (267 mg, $0.55 \mathrm{mmol})$ and Z-Ala-OSu (195 mg, $0.61 \mathrm{mmol})$. 
${ }^{1} \mathrm{H}$ NMR $\left(300 \mathrm{MHz}, \mathrm{CDCl}_{3}\right) \delta 1.20(\mathrm{~s}, 3 \mathrm{H}), 1.23(\mathrm{~s}, 3 \mathrm{H}), 1.36(\mathrm{~d}, J=7.2 \mathrm{~Hz}, 3 \mathrm{H}), 2.31-2.37$ (m, 1H), $2.61(\mathrm{dd}, J=15.0,6.0 \mathrm{~Hz}, 1 \mathrm{H}), 2.87(\mathrm{~m}, 1 \mathrm{H}), 4.25-4.45(\mathrm{~m}, 2 \mathrm{H}), 4.70$ (br s, 1H), $5.07(\mathrm{~s}, 1 \mathrm{H}), 5.44-5.54(\mathrm{~m}, 2 \mathrm{H}), 6.70(\mathrm{~d}, J=6.5 \mathrm{~Hz}, 1 \mathrm{H}), 7.06-7.25(\mathrm{~m}, 8 \mathrm{H}), 7.35-7.38(\mathrm{~m}$, $3 \mathrm{H}), 7.75$ (br d, 2H), 7.87 (br s, 1H). Deprotection of the dipeptide afforded a white solid (188 $\mathrm{mg}, 98 \%) .{ }^{1} \mathrm{H} \mathrm{NMR}\left(300 \mathrm{MHz}, \mathrm{CD}_{3} \mathrm{OD}\right) \delta 1.22$ (br s, 6H), 1.38 (d, $\left.J=6.3 \mathrm{~Hz}, 3 \mathrm{H}\right), 2.34-2.46$ (m, 1H), 2.52-2.56 (m, 1H), 2.84-2.88 (m, 1H), 3.77 (br s, 1H), 4.10-4.40 (m, 3H), 6.94-7.42 (m, 9H). Coupling with Boc-Tyr(Bn)-OSu (211 mg, $0.45 \mathrm{mmol})$ afforded tripeptide $\mathbf{1 i}$ as a white solid (285 mg, 83\%). The overall yield from oxidized tryptophan $\mathbf{6 g}$ was $63 \%$.

${ }^{1} \mathrm{H}$ NMR (500 MHz, DMSO-d $)_{6} \delta 1.14$ (s, 3H, $\mathrm{CH}_{3}$ ), 1.15 (s, 3H, $\left.\mathrm{CH}_{3}\right), 1.17$ (d, J = 7.0 Hz, $3 \mathrm{H}, \mathrm{CH}_{3}$ ), 1.29 (s, 9H, Boc), 2.07 (dd, $J=15.0,8.5 \mathrm{~Hz}, 1 \mathrm{H}, \mathrm{CH} \beta$ ), 2.42 (dd, $J=15.0,5.0 \mathrm{~Hz}$, $1 \mathrm{H}, \mathrm{CH} \beta), 2.58-2.62(\mathrm{~m}, 1 \mathrm{H}, \mathrm{CH}), 2.79-2.85\left(\mathrm{~m}, 1 \mathrm{H}, \mathrm{CH}\left(\mathrm{CH}_{3}\right)_{2}\right), 2.95(\mathrm{dd}, J=15.0,5.0 \mathrm{~Hz}$, $1 \mathrm{H})$, 4.07-4.21 (m, 5H, $\left.\mathrm{NCH}_{2}, \mathrm{CH}_{2}, \mathrm{CH \alpha}\right), 5.05$ (s, 2H, $\left.\mathrm{OCH}_{2}\right), 6.01(\mathrm{~s}, 1 \mathrm{H}, \mathrm{OH}), 6.77$ (d, $J=$ $7.5 \mathrm{~Hz}, 1 \mathrm{H}$ aromatic), 6.89-6.94 (m, $4 \mathrm{H}$ aromatics), 7.10-7.44 (m, 12H aromatics, $1 \mathrm{NH}), 7.80$ $(\mathrm{d}, J=8.0 \mathrm{~Hz}, 1 \mathrm{H}, 1 \mathrm{NH}), 7.87(\mathrm{t}, J=6.0 \mathrm{~Hz}, 1 \mathrm{H}, \mathrm{NH}), 8.03(\mathrm{~d}, J=7.0 \mathrm{~Hz}, 1 \mathrm{H}, \mathrm{NH}), 10.10$ (s, $1 \mathrm{H}, \mathrm{NH}$ oxindole). ${ }^{13} \mathrm{C} \mathrm{NMR}\left(75.5 \mathrm{MHz}, \mathrm{CDCl}_{3}\right) \delta 17.64\left(\mathrm{CH}_{3}\right), 22.04\left(\mathrm{CH}_{3}\right), 28.34\left(\mathrm{CH}_{3}\right)$, 29.76, $33.79(\mathrm{CH}), 37.29\left(\mathrm{CH}_{2}\right), 39.48\left(\mathrm{CH}_{2}\right), 43.33\left(\mathrm{CH}_{2}\right), 49.86(\mathrm{CH}), 55.89(\mathrm{CH}), 69.98$ $\left(\mathrm{CH}_{2}\right), 75.49(\mathrm{C}), 80.67(\mathrm{C}), 110.79(\mathrm{CH}), 115.00(\mathrm{CH}), 123.32(\mathrm{CH}), 124.32(\mathrm{CH}), 126.65$ $(\mathrm{CH}), 127.53(\mathrm{CH}), 127.67(\mathrm{CH}), 128.00(\mathrm{CH}), 128.62(\mathrm{CH}), 129.91(\mathrm{CH}), 130.42(\mathrm{CH})$, 130.62 (C), 135.38 (C), 137.04 (C), 140.77 (C), 147.93 (C), 148.03 (C), 156.00 (CO), 157.8 (C), 157.89 (CO), 171.42 (CO), 172.60 (CO), 180.68 (CO). HRMS (ESI) calcd for $\mathrm{C}_{45} \mathrm{H}_{53} \mathrm{~N}_{5} \mathrm{O}_{8} \mathrm{Na}[\mathrm{M}+\mathrm{Na}]^{+}$814.3786, found 814.3782. $R_{f}$ (1/9 $\left.\mathrm{MeOH} / \mathrm{CH}_{2} \mathrm{Cl}_{2}\right)$ 0.77. HPLC (column 1 ): $t_{\mathrm{R}}=31.8 \mathrm{~min}$, area percent $>99 \%$ at $254 \mathrm{~nm}$.

4.1.3.11. Tripeptide 1j: It was prepared by the linear synthesis according to the general procedure. Intermediate Z-dipeptide was obtained as a white solid $(80.1 \mathrm{mg}, 69 \%)$ from oxidized tryptophan, TFA salt $\mathbf{6 h}(95.1 \mathrm{mg}, 0.218 \mathrm{mmol})$ and Z-Ala-OSu $(79.4 \mathrm{mg}, 0.248$ mmol). ${ }^{1} \mathrm{H}$ NMR (300 MHz, $\left.\mathrm{CDCl}_{3}\right) \delta 1.34(\mathrm{~d}, J=6.0 \mathrm{~Hz}, 3 \mathrm{H}), 2.46(\mathrm{~m}, 4 \mathrm{H}), 3.39$ (m, 2H), $3.62(\mathrm{~s}, 3 \mathrm{H}), 4.25(\mathrm{~m}, 1 \mathrm{H}), 4.45(\mathrm{~m}, 1 \mathrm{H}), 5.10(\mathrm{~s}, 2 \mathrm{H}), 5.91(\mathrm{~d}, J=8.0 \mathrm{~Hz}, 1 \mathrm{H}), 6.64(\mathrm{~d}, J=7.8$ $\mathrm{Hz}, 1 \mathrm{H}), 7.03(\mathrm{t}, J=7.8 \mathrm{~Hz}, 1 \mathrm{H}), 7.16(\mathrm{~m}, 2 \mathrm{H}), 7.36-7.38(\mathrm{~m}, 6 \mathrm{H}), 7.78(\mathrm{~d}, J=7.8 \mathrm{~Hz}, 1 \mathrm{H})$, 8.88 (br s, 1H). ${ }^{13} \mathrm{C}$ NMR (75.5 MHz, $\left.\mathrm{CDCl}_{3}\right) \delta: 18.15(\mathrm{CH}), 33.56\left(\mathrm{CH}_{2}\right), 35.24\left(\mathrm{CH}_{2}\right), 39.58$ $\left(\mathrm{CH}_{2}\right), 49.51(\mathrm{CH}), 50.86(\mathrm{CH}), 51.81\left(\mathrm{CH}_{3}\right), 67.09\left(\mathrm{CH}_{2}\right), 75.25(\mathrm{C}), 110.60(\mathrm{CH}), 123.31$ $(\mathrm{CH}), 124.22(\mathrm{CH}), 127.94(\mathrm{CH}), 128.21(\mathrm{CH}), 128.57(\mathrm{CH}), 129.88(\mathrm{CH}), 130.25(\mathrm{CH})$, 136.13 (C), 140.51 (C), 156.55 (C), 171.40 (C), 172.61 (C), 173.04 (C), 180.41 (C). Deprotection of the dipeptide afforded a white solid (56.9 mg, 95\%). Coupling with Boc- 
Tyr(Bn)-OSu (75.5 mg, $0.161 \mathrm{mmol})$ afforded tripeptide $\mathbf{1 j}$ as a white solid $(81.2 \mathrm{mg}, 75 \%)$. The overall yield from oxidized tryptophan $\mathbf{6 h}$ was $49 \%$.

${ }^{1} \mathrm{H}$ NMR (300 MHz, CD 3 OD) $\delta 1.36(\mathrm{~m}, 12 \mathrm{H}), 2.41(\mathrm{dd}, J=9.6,14.1 \mathrm{~Hz}, 1 \mathrm{H}), 2.64-2.78(\mathrm{~m}$, 4H), 3.09 (dd, $J=4.8,13.8 \mathrm{~Hz}, 1 \mathrm{H}), 4.17-4.39$ (m, 4H), $4.56(\mathrm{~m}, 1 \mathrm{H}), 5.04$ (s, 2H), 6.83-6.91 $(\mathrm{m}, 2 \mathrm{H}), 7.01-7.43(\mathrm{~m}, 11 \mathrm{H}) .{ }^{13} \mathrm{C} \mathrm{NMR}\left(75.5 \mathrm{MHz}, \mathrm{CDCl}_{3}\right) \delta 17.6\left(\mathrm{CH}_{3}\right), 28.2\left(\mathrm{CH}_{3}\right), 29.7$ $\left(\mathrm{CH}_{2}\right), 33.6\left(\mathrm{CH}_{2}\right), 35.3\left(\mathrm{CH}_{2}\right), 39.6\left(\mathrm{CH}_{2}\right), 49.6(\mathrm{CH}), 49.7(\mathrm{CH}), 51.8\left(\mathrm{CH}_{3}\right), 55.9(\mathrm{CH})$, $70.0\left(\mathrm{CH}_{2}\right), 75.3(\mathrm{C}), 80.7(\mathrm{C}), 110.6(\mathrm{CH}), 115.0(\mathrm{CH}), 123.3(\mathrm{CH}), 124.2(\mathrm{CH}), 127.4(\mathrm{CH})$, $127.9(\mathrm{CH}), 128.5(\mathrm{CH}), 128.7(\mathrm{C}), 129.8(\mathrm{CH}), 130.4(\mathrm{CH}), 130.5(\mathrm{C}), 136.9(\mathrm{C}), 140.6(\mathrm{C})$, 155.9 (C), 157.8 (C), 171.4 (C), 172.3 (C), 172.5 (C), 180.6 (C). HRMS (ESI) calcd for $\mathrm{C}_{39} \mathrm{H}_{47} \mathrm{~N}_{5} \mathrm{O}_{10} \mathrm{Na}\left[(\mathrm{M}+\mathrm{Na})^{+}\right]$768.3215, found 768.3219. $R_{f}(1 / 9 \mathrm{MeOH} / \mathrm{AcOEt})$ 0.54. UPLC (column 2): $t_{\mathrm{R}}=17.1 \mathrm{~min}$, area percent $>99 \%$ at $254 \mathrm{~nm}$.

4.1.3.12. Tripeptide 1k: To a solution of tripeptide $\mathbf{1 j}(50.1 \mathrm{mg}, 0.0671 \mathrm{mmol})$ in THF $(0.5$ $\mathrm{ml}$ ) was added dropwise a $1 \mathrm{M}$ aqueous $\mathrm{LiOH}(150 \mu \mathrm{L}, 0.15 \mathrm{mmol})$. The mixture was stirred at room temperature for $24 \mathrm{~h}$. The solvent was concentrated in vacuo and the residue was dissolved in $1 \mathrm{M}$ hydrochloric acid $(0.5 \mathrm{~mL})$ and AcOEt $(10 \mathrm{~mL})$. The organic phase was dried over sodium sulfate and concentrated in vacuo to afford tripeptide $\mathbf{1 k}$ as a white solid (49 mg, quantitative).

${ }^{1} \mathrm{H}$ NMR (300 MHz, DMSO-d 6 ) $\delta 1.24(\mathrm{~m}, 12 \mathrm{H}), 2.03(\mathrm{dd}, J=8.6,14.2 \mathrm{~Hz}, 1 \mathrm{H}), 2.28(\mathrm{~m})$, $2.52(\mathrm{~m}), 2.96(\mathrm{~m}), 3.16(\mathrm{~m}), 3.34(\mathrm{~m}, 3 \mathrm{H}), 2.14(\mathrm{~s}, 2 \mathrm{H}), 5.99(\mathrm{~s}, 1 \mathrm{H}), 6.76(\mathrm{~d}, J=7.8 \mathrm{~Hz}$, $1 \mathrm{H}), 6.90-7.42(\mathrm{~m}, 14 \mathrm{H}), 7.75(\mathrm{~d}, J=7.8 \mathrm{~Hz}, 1 \mathrm{H}), 8.02$ (d, $J=7.8 \mathrm{~Hz}, 1 \mathrm{H}), 10.08(\mathrm{~s}, 1 \mathrm{H})$. HRMS (ESI) calcd for $\mathrm{C}_{38} \mathrm{H}_{45} \mathrm{~N}_{5} \mathrm{O}_{10} \mathrm{Na}\left[(\mathrm{M}+\mathrm{Na})^{+}\right]$754.3059, found 754.3062. UPLC (column $2): t_{\mathrm{R}}=17.4 \mathrm{~min}$, area percent $70 \%$ at $254 \mathrm{~nm}$.

4.1.3.13. Tripeptide 11: It was prepared by the linear synthesis according to the general procedure. Intermediate Z-dipeptide was obtained as a white solid (164 mg, 60\%) from oxidized tryptophan, TFA salt $6 \mathbf{i}(240 \mathrm{mg}, 0.53 \mathrm{mmol})$ and Z-Ala-OSu (160 mg, $0.50 \mathrm{mmol})$. ${ }^{1} \mathrm{H}$ NMR $\left(300 \mathrm{MHz}, \mathrm{CD}_{3} \mathrm{OD}\right) \delta 1.36(\mathrm{~d}, J=8.7 \mathrm{~Hz}, 3 \mathrm{H}), 2.42(\mathrm{~m}, 1 \mathrm{H}), 2.52(\mathrm{~m}, 1 \mathrm{H}), 2.74(\mathrm{~m}$, 2H), $3.30(\mathrm{~m}, 2 \mathrm{H}), 3.99$ (q, $J=8.7 \mathrm{~Hz}, 1 \mathrm{H}), 4.12(\mathrm{~m}, 1 \mathrm{H}), 5.16(\mathrm{~s}, 2 \mathrm{H}), 6.82$ (d, J = $7.8 \mathrm{~Hz}$, $1 \mathrm{H}), 7.07(\mathrm{t}, J=7.8,1 \mathrm{H}), 7.23-7.38(\mathrm{~m}, 12 \mathrm{H})$. Deprotection of the dipeptide $(67.5 \mathrm{mg}, 0.124$ mmol) afforded a white solid (50.9 mg, quantitative). ${ }^{1} \mathrm{H}$ NMR (300 MHz, $\left.\mathrm{CD}_{3} \mathrm{OD}\right) \delta 1.22(\mathrm{~d}$, $J=6.9 \mathrm{~Hz}, 3 \mathrm{H}), 2.28-2.45(\mathrm{~m}, 2 \mathrm{H}), 2.72(\mathrm{t}, J=7.2 \mathrm{~Hz}, 2 \mathrm{H}), 3.40(\mathrm{~m}, 1 \mathrm{H}), 4.11(\mathrm{dd}, J=9.3$, $3.6 \mathrm{~Hz}, 1 \mathrm{H}), 6.85(\mathrm{~d}, J=7.8 \mathrm{~Hz}, 1 \mathrm{H}), 7.06(\mathrm{t}, J=7.5 \mathrm{~Hz}, 1 \mathrm{H}), 7.15-7.30(\mathrm{~m}, 6 \mathrm{H}), 7.33(\mathrm{~d}, J=$ 
$7.5 \mathrm{~Hz}, 1 \mathrm{H})$. Coupling with Boc-Tyr(Bn)-OSu (59 mg, $0.124 \mathrm{mmol})$ afforded tripeptide $\mathbf{1 l}$ as a white solid (65 mg, 68\%). The overall yield from oxidized tryptophan $6 \mathbf{i}$ was $41 \%$.

${ }^{1} \mathrm{H}$ NMR (300 MHz, $\left.\mathrm{CD}_{3} \mathrm{COCD}_{3}\right) \delta 1.34(\mathrm{~m}, 12 \mathrm{H}), 2.32(\mathrm{dd}, J=8.1 \mathrm{~Hz}, 14.4 \mathrm{~Hz}, 1 \mathrm{H}), 2.64$ $(\mathrm{dd}, J=3.6,14.4 \mathrm{~Hz}, 1 \mathrm{H}), 2.79(\mathrm{t}, J=6.9 \mathrm{~Hz}, 2 \mathrm{H}), 2.91(\mathrm{dd}, J=9.3,13.8 \mathrm{~Hz}, 1 \mathrm{H}), 3.18(\mathrm{dd}, J$ $=4.8,14.1 \mathrm{~Hz}, 1 \mathrm{H}), 3.41$ and $3.36\left(\mathrm{AB}\right.$ system, $\left.J_{A B}=12 \mathrm{~Hz}, 2 \mathrm{H}\right), 4.28-4.48(\mathrm{~m}, 3 \mathrm{H}), 5.07(\mathrm{~s}$, 2H), 5.74 (br s, 1H), 6.25, 6.86-7.02 (m, 4H), 7.14-7.56 (m, 16H), $7.79(\mathrm{~d}, J=5.7 \mathrm{~Hz}, 1 \mathrm{H})$, $9.50(\mathrm{~s}, 1 \mathrm{H}) .{ }^{13} \mathrm{C} \mathrm{NMR}\left(75.5 \mathrm{MHz}, \mathrm{CD}_{3} \mathrm{COCD}_{3}\right) \delta 17.54\left(\mathrm{CH}_{3}\right), 28.60\left(\mathrm{CH}_{3}\right), 36.13\left(\mathrm{CH}_{2}\right)$, $37.56\left(\mathrm{CH}_{2}\right), 40.71\left(\mathrm{CH}_{2}\right), 41.70\left(\mathrm{CH}_{2}\right), 50.24(\mathrm{CH}), 50.70(\mathrm{CH}), 57.07(\mathrm{CH}), 70.36\left(\mathrm{CH}_{2}\right)$, $75.60(\mathrm{C}), 79.83(\mathrm{C}), 110.94(\mathrm{CH}), 115.48(\mathrm{CH}), 123.06(\mathrm{CH}), 125.13(\mathrm{CH}), 126.90(\mathrm{CH})$, $128.34(\mathrm{CH}), 128.50(\mathrm{CH}), 129.16(\mathrm{CH}), 129.20(\mathrm{CH}), 129.59(\mathrm{CH}), 130.19(\mathrm{CH}), 130.65$ (C), $131.24(\mathrm{CH}), 132.01(\mathrm{C}), 138.47$ (C), 140.32 (C), 142.40 (C), 156.76 (C), 158.53 (C), 172.06 (C), 172.68 (C), 173.72 (C), 180.37 (C). HRMS (ESI) calcd for $\mathrm{C}_{43} \mathrm{H}_{49} \mathrm{~N}_{5} \mathrm{O}_{8} \mathrm{Na}$ $[\mathrm{M}+\mathrm{Na}]^{+} 786.3473$, found 789.3484. $R_{f}\left(5 / 95 \mathrm{MeOH} / \mathrm{CH}_{2} \mathrm{Cl}_{2}\right)$ 0.31. UPLC (column 2): $t_{\mathrm{R}}=$ $20.9 \mathrm{~min}$, area percent $92 \%$ at $254 \mathrm{~nm}$.

4.1.3.14. Tripeptide 1m: It was prepared by the linear synthesis according to the general procedure. Intermediate Z-dipeptide was obtained as a white solid (166 mg, 73\%) from oxidized tryptophan, TFA salt $\mathbf{6 j}$ (200 mg, $0.44 \mathrm{mmol})$ and Z-Ala-OSu (132 mg, $0.41 \mathrm{mmol})$. ${ }^{1} \mathrm{H}$ NMR (300 MHz, CD $\left.{ }_{3} \mathrm{OD}\right) \delta 0.91(\mathrm{~m}, 2 \mathrm{H}), 1.18-1.39(\mathrm{~m}, 9 \mathrm{H}), 1.70(\mathrm{~m}, 5 \mathrm{H}), 2.40(\mathrm{t}, J=$ $12.0 \mathrm{~Hz}, 1 \mathrm{H}), 2.62$ (d, $J=15 \mathrm{~Hz}, 1 \mathrm{H}), 3.08-3.15(\mathrm{~m}, 2 \mathrm{H}), 5.15(\mathrm{~s}, 2 \mathrm{H}), 6.83$ (d, $J=7.8 \mathrm{~Hz}$, $1 \mathrm{H}), 7.07$ (t, $J=7.8,1 \mathrm{H}), 7.26-7.39(\mathrm{~m}, 7 \mathrm{H})$. Deprotection of the dippetide (58.2 mg, 0.105 mmol) afforded a white solid (44.1 mg, 96\%). ${ }^{1} \mathrm{H}$ NMR (300 MHz, $\left.\mathrm{CD}_{3} \mathrm{OD}\right) \delta 0.91(\mathrm{~m}, 2 \mathrm{H})$, $1.18-1.35(\mathrm{~m}, 9 \mathrm{H}), 1.70(\mathrm{~m}, 5 \mathrm{H}), 2.36(\mathrm{dd}, J=14.1,9.3 \mathrm{~Hz}, 1 \mathrm{H}), 2.50(\mathrm{dd}, J=14.1,3.9 \mathrm{~Hz}$, $1 \mathrm{H}), 3.01-3.17(\mathrm{~m}, 2 \mathrm{H}), 4.13(\mathrm{dd}, J=9.3,3.9 \mathrm{~Hz}, 1 \mathrm{H}), 6.86(\mathrm{~d}, J=7.8 \mathrm{~Hz}, 1 \mathrm{H}), 7.06(\mathrm{t}, J=$ $7.5 \mathrm{~Hz}, 1 \mathrm{H}), 7.26$ (t, $J=7.8 \mathrm{~Hz}, 1 \mathrm{H}$ ), 7.36 (d, $J=7.5 \mathrm{~Hz}, 1 \mathrm{H})$. Coupling with Boc-Tyr(Bn)$\mathrm{OH}(40.3 \mathrm{mg}, 0.108 \mathrm{mmol})$ using $\mathrm{EDC}, \mathrm{HCl}(24.5 \mathrm{mg}, 0.127 \mathrm{mmol})$ and $\mathrm{HOBt}(21.1 \mathrm{mg}$, $0.137 \mathrm{mmol}$ ) afforded tripeptide $\mathbf{1 m}$ as a white solid $(45.3 \mathrm{mg}, 56 \%)$. The overall yield from oxidized tryptophan $\mathbf{6 j}$ was $39 \%$.

${ }^{1} \mathrm{H}$ NMR $\left(300 \mathrm{MHz}, \mathrm{CD}_{3} \mathrm{COCD}_{3}\right) \delta 0.90(\mathrm{~m}, 3 \mathrm{H}), 1.12-1.42(\mathrm{~m}, 17 \mathrm{H}), 1.60-1.76(\mathrm{~m}, 5 \mathrm{H})$, $2.19(\mathrm{dd}, J=7.8 \mathrm{~Hz}, 14.7 \mathrm{~Hz}, 1 \mathrm{H}), 2.66(\mathrm{dd}, J=4.8 \mathrm{~Hz}, 14.7 \mathrm{~Hz}, 1 \mathrm{H}), 2.91$ (dd, $J=9.0 \mathrm{~Hz}$, $14.1 \mathrm{~Hz}, 1 \mathrm{H}), 3.12-3.26(\mathrm{~m}, 3 \mathrm{H}), 4.17-4.46(\mathrm{~m}, 3 \mathrm{H}), 5.09$ (s, 2H), 5.77 (s, 1H), $6.16(\mathrm{~d}, J=$ $6.9 \mathrm{~Hz}, 1 \mathrm{H}), 6.85(\mathrm{~d}, J=7.8 \mathrm{~Hz}, 1 \mathrm{H}), 6.94(\mathrm{~d}, J=8.7 \mathrm{~Hz}, 2 \mathrm{H}), 7.00$ (t, $J=7.5 \mathrm{~Hz}, 1 \mathrm{H}), 7.12-$ $7.49(\mathrm{~m}, 11 \mathrm{H}), 7.66(\mathrm{~d}, J=5.7 \mathrm{~Hz}, 1 \mathrm{H}), 9.29(\mathrm{~s}, 1 \mathrm{H}) .{ }^{13} \mathrm{C} \mathrm{NMR}\left(75.5 \mathrm{MHz}, \mathrm{CD}_{3} \mathrm{COCD}_{3}\right) \delta$ $17.49\left(\mathrm{CH}_{3}\right), 26.93\left(\mathrm{CH}_{2}\right), 27.26\left(\mathrm{CH}_{2}\right), 28.61\left(\mathrm{CH}_{3}\right), 33.77\left(\mathrm{CH}_{2}\right), 33.91\left(\mathrm{CH}_{2}\right), 35.74(\mathrm{CH})$, 
$37.48\left(\mathrm{CH}_{2}\right), 37.89\left(\mathrm{CH}_{2}\right), 40.93\left(\mathrm{CH}_{2}\right), 50.32(\mathrm{CH}), 51.02(\mathrm{CH}), 57.34(\mathrm{CH}), 70.39\left(\mathrm{CH}_{2}\right)$, $75.66(\mathrm{C}), 79.90(\mathrm{C}), 110.93(\mathrm{CH}), 115.51(\mathrm{CH}), 123.02(\mathrm{CH}), 125.15(\mathrm{CH}), 128.36(\mathrm{CH})$, $128.53(\mathrm{CH}), 129.22(\mathrm{CH}), 130.14(\mathrm{CH}), 130.56(\mathrm{C}), 131.23(\mathrm{CH}), 132.23(\mathrm{C}), 138.50(\mathrm{C})$, 142.54 (C), 156.85 (C), 158.59 (C), 172.07 (C), 172.64 (C), 173.84 (C), 180.44 (C). HRMS (ESI) calcd for $\mathrm{C}_{43} \mathrm{H}_{55} \mathrm{~N}_{5} \mathrm{O}_{8} \mathrm{Na}[\mathrm{M}+\mathrm{Na}]^{+} 792.3943$, found 792.3944. $R_{f}\left(1 / 9 \mathrm{MeOH} / \mathrm{CH}_{2} \mathrm{Cl}_{2}\right)$ 0.50. UPLC (column 2): $t_{\mathrm{R}}=23.9 \mathrm{~min}$, area percent $99 \%$ at $254 \mathrm{~nm}$.

4.1.3.15. Tripeptide 1n: It was prepared by the linear synthesis according to the general procedure. Intermediate Z-dipeptide was obtained as a white solid (88 $\mathrm{mg}, 63 \%$ ) from oxidized tryptophan, TFA salt $6 \mathbf{k}(116 \mathrm{mg}, 0.26 \mathrm{mmol})$ and Z-Ala-OSu $(83 \mathrm{mg}, 0.26 \mathrm{mmol})$. ${ }^{1} \mathrm{H}$ NMR (300 MHz, $\left.\mathrm{CDCl}_{3}\right) \delta$ 0.88-0.92 (m, 3H), 1.17-1.20 (m, $\left.1 \mathrm{H}\right), 1.42(\mathrm{~d}, J=8.7 \mathrm{~Hz}, 3 \mathrm{H})$, 1.60-1.69 (m, 8H), 2.28-2.32 (m, 1H), $2.58(\mathrm{dd}, J=15.0,4.8 \mathrm{~Hz}, 1 \mathrm{H}), 3.03-3.07(\mathrm{~m}, 2 \mathrm{H})$, 4.29-4.34 (m, 1H), 4.71 (br s, 1H), 5.16 (s, 2H), 5.42 (br s, 1H), 6.74 (d, J=7.8 Hz, 1H), 6.89 (m, 1H), $7.10(\mathrm{td}, J=7.8,1.0 \mathrm{~Hz}, 1 \mathrm{H}), 7.23(\mathrm{~d}, J=6.0 \mathrm{~Hz}, 1 \mathrm{H}), 7.36-7.38(\mathrm{~m}, 6 \mathrm{H}), 7.83$ (br s, $1 \mathrm{H})$. Deprotection of the dippetide afforded a white solid $(62 \mathrm{mg}, 97 \%) .{ }^{1} \mathrm{H}$ NMR $(300 \mathrm{MHz}$, $\left.\mathrm{CD}_{3} \mathrm{OD}\right) \delta$ 0.88-0.92 (m, 3H), 1.13-1.17 (m, 2H), $1.40(\mathrm{~d}, J=6.0 \mathrm{~Hz}, 3 \mathrm{H}), 1.64-1.68(\mathrm{~m}, 8 \mathrm{H})$, 2.35-2.44 (m, 2H), 3.03 (br s, 2H), 3.69 (br s, 1H), 4.81 (br s, 1H), 6.85-7.10 (m, 3H), 7.23 (d, $J=8.1 \mathrm{~Hz}, 1 \mathrm{H}), 7.35$ (d, $J=6.9 \mathrm{~Hz}, 1 \mathrm{H}), 8.62$ (br s, 1H). Coupling with Boc-Tyr(Bn)-OSu (73 $\mathrm{mg}, 0.16 \mathrm{mmol}$ ) afforded tripeptide $1 \mathrm{n}$ as a white solid $(65 \mathrm{mg}, 57 \%)$. The overall yield from oxidized tryptophan $\mathbf{6 k}$ was $35 \%$.

${ }^{1} \mathrm{H}$ NMR $\left(300 \mathrm{MHz}, \mathrm{CDCl}_{3}\right) \delta$ 0.89-0.94 (m, 3H), 1.18-1.23 (m, 1H), $1.40(\mathrm{~s}, 9 \mathrm{H}), 1.68-1.73$ (m, 9H), 2.46 (br s, 2H), 2.98-3.12 (m, 4H), 4.40-4.47 (m, 2H), 4.61-4.63 (m, 1H), 4.98 (br s, $1 \mathrm{H}), 5.04(\mathrm{~s}, 2 \mathrm{H}), 5.79(\mathrm{br} \mathrm{s}, 1 \mathrm{H}), 6.79-6.93(\mathrm{~m}, 5 \mathrm{H}), 7.05-7.15(\mathrm{~m}, 3 \mathrm{H}), 7.32(\mathrm{td}, J=7.8,1.2$ $\mathrm{Hz}, 1 \mathrm{H}), 7.33-7.44(\mathrm{~m}, 6 \mathrm{H}), 7.79(\mathrm{~d}, J=6.0 \mathrm{~Hz}, 1 \mathrm{H}), 8.40$ (br s, $1 \mathrm{H}) .{ }^{13} \mathrm{C} \mathrm{NMR}(75.5 \mathrm{MHz}$, $\left.\mathrm{CD}_{3} \mathrm{OD}\right) \delta 15.84\left(\mathrm{CH}_{3}\right), 25.61\left(\mathrm{CH}_{2}\right), 26.14\left(\mathrm{CH}_{2}\right), 27.41\left(\mathrm{CH}_{3}\right), 30.50\left(\mathrm{CH}_{2}\right), 36.53\left(\mathrm{CH}_{2}\right)$, $37.47(\mathrm{CH}), 38.40\left(\mathrm{CH}_{2}\right), 45.61\left(\mathrm{CH}_{2}\right), 49.78(\mathrm{CH}), 50.23(\mathrm{CH}), 56.38(\mathrm{CH}), 69.62\left(\mathrm{CH}_{2}\right)$, $75.00(\mathrm{C}), 79.64(\mathrm{C}), 110.09(\mathrm{CH}), 114.61(\mathrm{CH}), 122.49(\mathrm{CH}), 124.11(\mathrm{CH}), 127.15(\mathrm{CH})$, $127.44(\mathrm{CH}), 128.10(\mathrm{CH}), 129.29(\mathrm{C}), 129.54(\mathrm{CH}), 130.02(\mathrm{CH}), 130.35(\mathrm{C}), 137.38(\mathrm{C})$, 141.48 (C), 156.63 (C),157.73 (C), 171.71 (C), 173.09 (C), 173.75 (C), 180.14 (C). HRMS (ESI) calcd for $\mathrm{C}_{42} \mathrm{H}_{53} \mathrm{~N}_{5} \mathrm{O}_{8} \mathrm{Na}[\mathrm{M}+\mathrm{Na}]^{+}$778.3786, found 778.3787. $R_{f}\left(1 / 9 \mathrm{MeOH} / \mathrm{CH}_{2} \mathrm{Cl}_{2}\right)$ 0.48. UPLC (column 2): $t_{\mathrm{R}}=22.4 \mathrm{~min}$, area percent $92 \%$ at $254 \mathrm{~nm}$.

4.1.3.16. Tripeptide 1o: It was prepared by the convergent synthesis according to the general procedure starting from Boc-Tyr(Bn)-Ala-OSu (228 mg, $0.42 \mathrm{mmol})$ and $\mathbf{6 1}, \mathrm{HCl}$ salt (149 
$\mathrm{mg}, 0.44 \mathrm{mmol})$ in $\mathrm{CH}_{2} \mathrm{Cl}_{2}(1.5 \mathrm{~mL})$. Tripeptide 10 was afforded as a white solid $(224 \mathrm{mg}$, $73 \%$ yield).

${ }^{1} \mathrm{H}$ NMR (500 MHz, DMSO-d 6 ) $\delta 0.78(\mathrm{~s}, 9 \mathrm{H}, t-\mathrm{Bu}), 1.20\left(\mathrm{~d}, J=7.0 \mathrm{~Hz}, 3 \mathrm{H}, \mathrm{CH}_{3}\right), 1.30(\mathrm{~s}$, 9H, Boc), 2.04 (dd, $J=14.5,4.0 \mathrm{~Hz}, 1 \mathrm{H}, \mathrm{CH} \beta$ ), 2.35 (dd, $J=14.0,4.0 \mathrm{~Hz}, 1 \mathrm{H}, \mathrm{CH} \beta$ ), 2.66$2.84\left(\mathrm{~m}, 3 \mathrm{H}, \mathrm{CH}_{2}, \mathrm{CH}\right), 2.95(\mathrm{dd}, J=15.0,4.0 \mathrm{~Hz}, 1 \mathrm{H}, \mathrm{CH}), 4.09-4.21\left(\mathrm{~m}, 3 \mathrm{H}, \mathrm{NCH}_{2}, \mathrm{CH} \alpha\right)$, $5.05\left(\mathrm{~s}, 2 \mathrm{H}, \mathrm{OCH}_{2}\right), 6.04(\mathrm{~s}, 1 \mathrm{H}, \mathrm{OH}), 6.77(\mathrm{~d}, J=7.5 \mathrm{~Hz}, 1 \mathrm{H}$ aromatic), 6.90-6.96 (m, 4H aromatics), 7.13-7.44 (m, $8 \mathrm{H}$ aromatics, $2 \mathrm{NH}), 7.83(\mathrm{~d}, J=8.5 \mathrm{~Hz}, 1 \mathrm{H}, \mathrm{NH}), 7.99(\mathrm{~d}, J=8.0$ $\mathrm{Hz}, 1 \mathrm{H}, \mathrm{NH}), 10.08$ (s, 1H, NH oxindole). ${ }^{13} \mathrm{C} \mathrm{NMR}\left(75.5 \mathrm{MHz}, \mathrm{CDCl}_{3}\right) \delta 18.14\left(\mathrm{CH}_{3}\right), 27.28$ $\left(\mathrm{CH}_{3}\right), 28.38\left(\mathrm{CH}_{3}\right), 32.18(\mathrm{C}), 37.36\left(\mathrm{CH}_{2}\right), 39.71\left(\mathrm{CH}_{2}\right), 49.57(\mathrm{CH}), 50.01(\mathrm{CH}), 50.87$ $\left(\mathrm{CH}_{2}\right), 56.04(\mathrm{CH}), 70.06\left(\mathrm{CH}_{2}\right), 75.46(\mathrm{C}), 80.88(\mathrm{C}), 110.82(\mathrm{CH}), 115.12(\mathrm{CH}), 123.44$ $(\mathrm{CH}), 124.32(\mathrm{CH}), 127.53(\mathrm{C}), 127.57(\mathrm{CH}), 128.06(\mathrm{CH}), 128.67(\mathrm{CH}), 129.95(\mathrm{CH})$, $130.50(\mathrm{CH}), 130.70(\mathrm{C}), 137.05$ (C), 140.76 (C), 156.05 (CO), 157.9 (C), 171.59 (CO), 172.22 (CO), 172.60 (CO), 180.92 (CO). HRMS (ESI) calcd for $\mathrm{C}_{40} \mathrm{H}_{51} \mathrm{~N}_{5} \mathrm{O}_{8} \mathrm{Na}[\mathrm{M}+\mathrm{Na}]^{+}$ 752.3629, found 752.3631. $R_{f}\left(1 / 9 \mathrm{MeOH} / \mathrm{CH}_{2} \mathrm{Cl}_{2}\right)$ 0.37. HPLC (column 1): $t_{\mathrm{R}}=28.9 \mathrm{~min}$, area percent $>99 \%$ at $254 \mathrm{~nm}$.

4.1.3.17. Tripeptide 1p: It was prepared by the convergent synthesis according to the general procedure starting from Boc-Tyr(Bn)-Ala-OSu (162 mg, $0.300 \mathrm{mmol})$ and $\mathbf{6 m}$, TFA salt (151 $\mathrm{mg}, 0.303 \mathrm{mmol})$ in $\mathrm{CH}_{2} \mathrm{Cl}_{2}(1.5 \mathrm{~mL})$. Tripeptide 1p was afforded as a white solid (140 mg, $58 \%$ yield).

${ }^{1} \mathrm{H}$ NMR (500 MHz, DMSO-d 6 ) $\delta 1.21\left(\mathrm{~d}, J=7.0 \mathrm{~Hz}, 3 \mathrm{H}, \mathrm{CH}_{3}\right), 1.30$ (s, 9H, Boc), 1.36-1.88 (m, 15H, adamantyl), $2.04(\mathrm{dd}, J=14.0,5.0 \mathrm{~Hz}, 1 \mathrm{H}, \mathrm{CH}), 2.36(\mathrm{dd}, J=14.0,5.0 \mathrm{~Hz}, 1 \mathrm{H}$, $\mathrm{CH} \beta$ ), 2.63-2.74 (m, 3H, $\left.\mathrm{CH}_{2}, \mathrm{CH}\right), 2.96$ (dd, $\left.J=13.5,4.5 \mathrm{~Hz}, 1 \mathrm{H}, \mathrm{CH}\right), 4.09-4.19$ (m, 3H, $\left.\mathrm{NCH}_{2}, \mathrm{CH} \alpha\right), 5.05$ (s, 2H, $\left.\mathrm{OCH}_{2}\right), 6.03(\mathrm{~s}, 1 \mathrm{H}, \mathrm{OH}), 6.76$ (d, J=8.0 Hz, 1H aromatic), 6.91$6.95(\mathrm{~m}, 4 \mathrm{H}$ aromatics), 7.14-7.44 (m, 8H aromatics, 2NH), $7.82(\mathrm{~d}, J=9.5 \mathrm{~Hz}, 1 \mathrm{H}, \mathrm{NH})$, $8.00(\mathrm{~d}, J=8.0 \mathrm{~Hz}, 1 \mathrm{H}, \mathrm{NH}), 10.06\left(\mathrm{~s}, 1 \mathrm{H}, \mathrm{NH}\right.$ oxindole) ${ }^{13} \mathrm{C} \mathrm{NMR}\left(75.5 \mathrm{MHz}, \mathrm{CDCl}_{3}\right) \delta$ $18.14\left(\mathrm{CH}_{3}\right), 28.26\left(\mathrm{CH}_{3}\right), 28.38\left(\mathrm{CH}_{3}\right), 33.94(\mathrm{C}), 36.96\left(\mathrm{CH}_{2}\right), 37.33\left(\mathrm{CH}_{2}\right), 39.80\left(\mathrm{CH}_{2}\right)$, $40.11\left(\mathrm{CH}_{2}\right), 49.58(\mathrm{CH}), 49.94(\mathrm{CH}), 51.26\left(\mathrm{CH}_{2}\right), 56.03(\mathrm{CH}), 70.04\left(\mathrm{CH}_{2}\right), 75.43(\mathrm{C})$, $80.90(\mathrm{C}), 110.77(\mathrm{CH}), 115.11(\mathrm{CH}), 123.45(\mathrm{CH}), 124.35(\mathrm{CH}), 127.53(\mathrm{C}), 127.58(\mathrm{CH})$, $128.07(\mathrm{CH}), 128.67(\mathrm{CH}), 129.93(\mathrm{CH}), 130.48(\mathrm{CH}), 130.75(\mathrm{C}), 137.02(\mathrm{C}), 140.71(\mathrm{C})$, 156.05 (CO), 157.91 (C), 171.65 (CO), 172.22 (CO), 172.52 (CO), 180.94 (CO). HRMS (ESI) calcd for $\mathrm{C}_{46} \mathrm{H}_{57} \mathrm{~N}_{5} \mathrm{O}_{8} \mathrm{Na}[\mathrm{M}+\mathrm{Na}]^{+}$830.4099, found 830.4101. $R_{f}\left(1 / 9 \mathrm{MeOH} / \mathrm{CH}_{2} \mathrm{Cl}_{2}\right)$ 0.51 . HPLC (column 1): $t_{\mathrm{R}}=34.5 \mathrm{~min}$, area percent $>99 \%$ at $254 \mathrm{~nm}$. 
4.1.3.18. Tripeptide 1q: It was prepared by the convergent synthesis according to the general procedure starting from Boc-Tyr(Bn)-D-Ala-OSu $(77.9 \mathrm{mg}, 0.144 \mathrm{mmol})$ and $\mathbf{6 b}(38.4 \mathrm{mg}$, $0.118 \mathrm{mmol})$ in DMF $(0.2 \mathrm{~mL})$ and $\mathrm{CH}_{2} \mathrm{Cl}_{2}(0.4 \mathrm{~mL})$. Tripeptide 1q was afforded as a white solid $(67.4 \mathrm{mg}, 76 \%)$.

${ }^{1} \mathrm{H}$ NMR (300 MHz, DMSO-d $\left.{ }_{6}\right) \delta 1.16\left(\mathrm{~d}, J=7 \mathrm{~Hz}, 3 \mathrm{H}, \mathrm{CH}_{3}\right.$ ), 1.27 (s, 9H, Boc), 2.07 (dd, $J$ $=10 \mathrm{~Hz}, J=13.9 \mathrm{~Hz}, 1 \mathrm{H}), 2.5-2.8(\mathrm{~m}, 3 \mathrm{H}), 4.06-4.27(\mathrm{~m}, 5 \mathrm{H}), 5.05(\mathrm{~s}, 2 \mathrm{H}), 6.02(\mathrm{~s}, 1 \mathrm{H}, \mathrm{OH})$, $6.75(\mathrm{~d}, J=7.6 \mathrm{~Hz}, 1 \mathrm{H}), 6.87-7.00(\mathrm{~m}, 4 \mathrm{H}), 7.09-7.43(\mathrm{~m}, 14 \mathrm{H}), 8.08(\mathrm{~m}, 3 \mathrm{H}), 10.10(\mathrm{~s}, 1 \mathrm{H}$, $\mathrm{NH}$ oxindole). ${ }^{13} \mathrm{C} \mathrm{NMR}\left(75.5 \mathrm{MHz}, \mathrm{CDCl}_{3}\right) \delta 17.6\left(\mathrm{CH}_{3}\right), 28.2\left(\mathrm{CH}_{3}\right), 38.0\left(\mathrm{CH}_{2}\right), 39.0$ $\left(\mathrm{CH}_{2}\right), 43.5\left(\mathrm{NCH}_{2} \mathrm{Ph}\right), 49.7(\mathrm{CH}), 50.2(\mathrm{CH}), 55.5(\mathrm{CH}), 69.9\left(\mathrm{CH}_{2}\right), 75.3(\mathrm{C}), 80.4(\mathrm{C})$, $110.6(\mathrm{CH}), 114.9(\mathrm{CH}), 123.3(\mathrm{CH}), 124.2(\mathrm{CH}), 127.3(\mathrm{CH}), 127.4(\mathrm{CH}), 127.5(\mathrm{CH}), 127.9$ $(\mathrm{CH}), 128.5(\mathrm{CH}), 128.7(\mathrm{C}), 129.8(\mathrm{CH}), 130.3(\mathrm{CH}), 130.8(\mathrm{C}), 136.9(\mathrm{C}), 137.9(\mathrm{C}), 140.4$ (C), 155.7 (C), 157.7 (C), 171.5 (C), 171.9 (C), 173.1 (C), 180.6 (C). HRMS (ESI) calcd for $\mathrm{C}_{42} \mathrm{H}_{47} \mathrm{~N}_{5} \mathrm{O}_{8} \mathrm{Na}\left[(\mathrm{M}+\mathrm{Na})^{+}\right]$772.3322, found 772.3328. $R_{f}\left(1 / 9 \mathrm{MeOH} / \mathrm{CH}_{2} \mathrm{Cl}_{2}\right)$ 0.40. HPLC (column 2): $t_{\mathrm{R}}=20.4 \mathrm{~min}$, area percent $>99 \%$ at $254 \mathrm{~nm}$.

4.1.3.19. Tripeptide 1r: It was prepared by the convergent synthesis according to the general procedure starting from Boc-Tyr(Bn)-Gly-OH [16] (34.9 mg, $0.0813 \mathrm{mmol})$, EDC, HCl (19.5 $\mathrm{mg}, 0.101 \mathrm{mmol}), \mathrm{HOBt}(13.6 \mathrm{mg}, 0.089 \mathrm{mmol}), \mathrm{Et}_{3} \mathrm{~N}(15 \mu \mathrm{L}, 0.10 \mathrm{mmol})$ and $6 \mathbf{b}$, TFA salt (41.8 mg, $0.0855 \mathrm{mmol})$ in $\mathrm{CH}_{2} \mathrm{Cl}_{2}(1.4 \mathrm{~mL})$. Tripeptide $\mathbf{1 r}$ was afforded as a white solid (35.9 mg, 55\%).

${ }^{1} \mathrm{H}$ NMR (300 MHz, CD $\left.3 \mathrm{OD}\right) \delta 1.35(\mathrm{~s}, 9 \mathrm{H}), 2.40(\mathrm{dd}, J=14.1,8.4 \mathrm{~Hz}, 1 \mathrm{H}), 2.65-2.79(\mathrm{~m}$, $2 \mathrm{H}), 3.05(\mathrm{dd}, J=14.1,8.4 \mathrm{~Hz}, 1 \mathrm{H}), 3.72$ and 3.81 (AB system, $\left.J_{A B}=16.5 \mathrm{~Hz}, 2 \mathrm{H}\right), 4.21-4.41$ $(\mathrm{m}, 4 \mathrm{H}), 5.04(\mathrm{~s}, 2 \mathrm{H}), 6.85-6.93(\mathrm{~m}, 3 \mathrm{H}), 7.05-7.41(\mathrm{~m}, 15 \mathrm{H}) .{ }^{13} \mathrm{C} \mathrm{NMR}\left(75.5 \mathrm{MHz}, \mathrm{CD}_{3} \mathrm{OD}\right)$

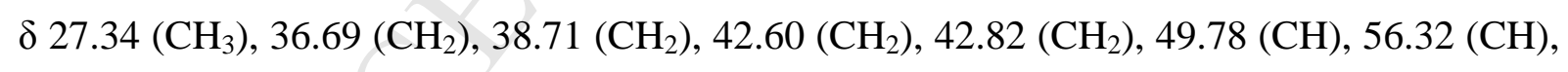
$69.59\left(\mathrm{CH}_{2}\right), 74.99(\mathrm{C}), 79.47(\mathrm{C}), 110.12(\mathrm{CH}), 114.53(\mathrm{CH}), 122.45(\mathrm{CH}), 124.03(\mathrm{CH})$, $126.69(\mathrm{CH}), 127.03(\mathrm{CH}), 127.11(\mathrm{CH}), 129.41(\mathrm{C}), 127.41(\mathrm{CH}), 128.05(\mathrm{CH}), 129.56$ (CH), $129.99(\mathrm{CH}), 130.25$ (C), 137.42 (C), 138.26 (C), 141.52 (C), 156.46 (C), 157.68 (C), 169.90, (C), 171.82 (C), 173.92 (C), 180.20 (C). HRMS (ESI) calcd for $\mathrm{C}_{41} \mathrm{H}_{45} \mathrm{~N}_{5} \mathrm{O}_{8} \mathrm{Na}$ $[\mathrm{M}+\mathrm{Na}]^{+} 758.3160$, found 758.3165. $R_{f}(\mathrm{AcOEt})$ 0.38. UPLC (column 2): $t_{\mathrm{R}}=19.9 \mathrm{~min}$, area percent $92 \%$ at $254 \mathrm{~nm}$.

4.1.3.20. Tripeptide 1s: It was prepared by the linear synthesis according to the general procedure. Intermediate Z-dipeptide 5c was obtained as a white solid (79.6 $\mathrm{mg}, 56 \%$ ) by coupling of oxidized tryptophan, TFA salt $\mathbf{6 b}(121 \mathrm{mg}, 0.248 \mathrm{mmol})$ and Z-Asn-OH (71.62 
$\mathrm{mg}, 0.269 \mathrm{mmol})$ in the presence of EDC $(59.7 \mathrm{mg}, 0.311 \mathrm{mmol}), \mathrm{HOBt}(46.5 \mathrm{mg}, 0.304$ mmol) and $\mathrm{Et}_{3} \mathrm{~N}(50 \mu \mathrm{L}, 0.355 \mathrm{mmol})$ [52]. ${ }^{1} \mathrm{H} \mathrm{NMR}\left(300 \mathrm{MHz}, \mathrm{CD}_{3} \mathrm{OD}\right) \delta 2.39$ (dd, $J=$ 14.1, 8.4 Hz, 1H), 2.61-2.80 (m, 3H), 3.74 (br s, 1H), 4.23-4.36 (m, 3H), 6.89 (d, J=8.1 Hz, 1H), $7.06(\mathrm{t}, J=8.1 \mathrm{~Hz}, 1 \mathrm{H}), 7.19-7.29(\mathrm{~m}, 6 \mathrm{H}), 7.38(\mathrm{~d}, J=8.1 \mathrm{~Hz}, 1 \mathrm{H}) .{ }^{13} \mathrm{C}$ NMR $(75.5$

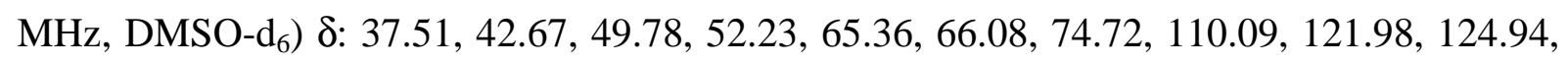
$127.01,127.37,128.16,128.52$, 128.79, 129.37, 131.63, 137.28, 139.71, 142.10, 156.39, 171.01, 171.64, 172.26, 178.50. Deprotection of $\mathbf{5 c}(61.5 \mathrm{mg}, 0.107 \mathrm{mmol})$ afforded a white solid (47.1 mg, 100\%). Coupling with Boc-Tyr(Bn)-OSu (55.25 mg, $0.118 \mathrm{mmol}$ ) afforded tripeptide $1 \mathrm{~s}$ as a white solid $(48.0 \mathrm{mg}, 56 \%)$. The overall yield from oxidized tryptophan $\mathbf{6 b}$ was $31 \%$.

${ }^{1} \mathrm{H}$ NMR $\left(300 \mathrm{MHz}, \mathrm{CD}_{3} \mathrm{OD}\right) \delta 1.35(\mathrm{~m}, 9 \mathrm{H}), 2.40(\mathrm{dd}, J=14.2,9.6 \mathrm{~Hz}, 1 \mathrm{H}), 2.64-2.84(\mathrm{~m}$, 4H), $3.09(\mathrm{dd}, J=14.2,5.0 \mathrm{~Hz}, 1 \mathrm{H}), 4.13-4.39(\mathrm{~m}, 4 \mathrm{H}), 4.57$ (t, $J=6.0 \mathrm{~Hz}), 5.05$ (s, 2H), 6.84 $(\mathrm{d}, J=7.7 \mathrm{~Hz}, 1 \mathrm{H}), 6.90(\mathrm{~d}, J=8.7 \mathrm{~Hz}, 2 \mathrm{H}), 7.04(\mathrm{t}, J=7.7 \mathrm{~Hz}, 1 \mathrm{H}), 7.14-7.45(\mathrm{~m}, 14 \mathrm{H}) .{ }^{13} \mathrm{C}$ NMR (75.5 MHz, CD $3 \mathrm{OD}) \delta 28.71\left(\mathrm{CH}_{3}\right), 37.26\left(\mathrm{CH}_{2}\right), 37.75\left(\mathrm{CH}_{2}\right), 39.54\left(\mathrm{CH}_{2}\right), 44.19$ $\left(\mathrm{CH}_{2}\right), 51.58(\mathrm{CH}), 51.87(\mathrm{CH}), 57.98(\mathrm{CH}), 71.02\left(\mathrm{CH}_{2}\right), 76.44(\mathrm{C}), 81.02(\mathrm{C}), 111.53(\mathrm{CH})$, $115.97(\mathrm{CH}), 123.87(\mathrm{CH}), 125.42(\mathrm{CH}), 128.02(\mathrm{CH}), 128.52(\mathrm{CH}), 128.53(\mathrm{CH}), 128.81$ $(\mathrm{CH}), 129.39(\mathrm{CH}), 129.47(\mathrm{CH}), 130.91(\mathrm{CH}), 131.40(\mathrm{CH}), 131.76(\mathrm{C}), 139.82(\mathrm{C}), 139.77$ (C), 142.87 (C), 159.09 (C), 172.53 (C), 173.16 (C), 174.66 (C), 174.88 (C), 179.64 (C), 181.53 (C). HRMS (ESI) calcd for $\mathrm{C}_{43} \mathrm{H}_{48} \mathrm{~N}_{6} \mathrm{O}_{9} \mathrm{Na}[\mathrm{M}+\mathrm{Na}]^{+}$815.3375, found 815.3383. $R_{f}$ $(1 / 9 \mathrm{MeOH} / \mathrm{AcOEt})$ 0.47. UPLC (column 2): $t_{\mathrm{R}}=19.0 \mathrm{~min}$, area percent $>99 \%$ at $254 \mathrm{~nm}$.

4.1.3.21. Tripeptide 1t: It was prepared by the linear synthesis according to the general procedure. Intermediate Z-dipeptide $\mathbf{5 b}$ was obtained as a white solid (54.0 $\mathrm{mg}, 85 \%)$ by coupling of oxidized tryptophan, TFA salt $\mathbf{6 b}(50.0 \mathrm{mg}, 0.114 \mathrm{mmol})$ and commercial Z-LThr-OSu (41.8 mg, $0.119 \mathrm{mmol}) .{ }^{1} \mathrm{H}$ NMR (300 MHz, DMSO) $\delta 0.99$ (d, $\left.J=6.3 \mathrm{~Hz}, 3 \mathrm{H}\right)$, $2.05(\mathrm{dd}, J=14.7,8.7 \mathrm{~Hz}, 1 \mathrm{H}), 2.44(\mathrm{dd}, J=14.7,3.9 \mathrm{~Hz}, 1 \mathrm{H}), 3.87-3.98$ (m, 2H), 4.09-4.23 $(\mathrm{m}, 2 \mathrm{H}), 4.29-4.35(\mathrm{~m}, 1 \mathrm{H}), 4.94-5.08(\mathrm{~m}, 3 \mathrm{H}), 6.02(\mathrm{~s}, 1 \mathrm{H}), 6.74(\mathrm{~d}, J=7.5 \mathrm{~Hz}, 1 \mathrm{H}), 6.87-$ $6.94(\mathrm{~m}, 2 \mathrm{H}), 7.14-7.37(\mathrm{~m}, 12 \mathrm{H}), 7.97(\mathrm{~d}, J=8.1 \mathrm{~Hz}, 1 \mathrm{H}), 8.05(\mathrm{t}, J=6.0 \mathrm{~Hz}, 1 \mathrm{H}), 10.12$ (s, 1H). ${ }^{13} \mathrm{C}$ NMR $\left(75.5 \mathrm{MHz}, \mathrm{CDCl}_{3}\right) \delta 18.50\left(\mathrm{CH}_{3}\right), 38.93\left(\mathrm{CH}_{2}\right), 43.65\left(\mathrm{CH}_{2}\right), 50.10(\mathrm{CH})$, $60.19(\mathrm{CH}), 67.32(\mathrm{CH}), 67.41\left(\mathrm{CH}_{2}\right), 75.78(\mathrm{C}), 110.88(\mathrm{CH}), 123.44(\mathrm{CH}), 124.22(\mathrm{CH})$, $127.38(\mathrm{CH}), 127.75(\mathrm{CH}), 128.07(\mathrm{CH}), 128.33(\mathrm{CH}), 128.61(\mathrm{CH}), 128.65(\mathrm{CH}), 129.95$ (CH), 130.58 (C), 136.08 (C), 137.88 (C), 140.46 (C), 157.11 (C), 170.92 (C), 171.34 (C), 180.53 (C). Deprotection of $\mathbf{5 b}(48.0 \mathrm{mg}, 0.0856 \mathrm{mmol})$ afforded a white solid $(37 \mathrm{mg}$, $100 \%) .{ }^{1} \mathrm{H}$ NMR $\left(300 \mathrm{MHz}, \mathrm{CD}_{3} \mathrm{OD}\right) \delta 1.18(\mathrm{~d}, J=6.3 \mathrm{~Hz}, 3 \mathrm{H}), 2.34(\mathrm{dd}, J=14.1,6.9 \mathrm{~Hz}$, 
1H), $2.54(\mathrm{dd}, J=14.1,5.7 \mathrm{~Hz}, 1 \mathrm{H}), 3.62(\mathrm{~d}, J=6.3 \mathrm{~Hz}, 1 \mathrm{H}), 4.03(\mathrm{q}, J=6.3 \mathrm{~Hz}, 1 \mathrm{H}), 4.08$ and $4.29\left(\mathrm{AB}\right.$ system, $\left.J_{A B}=15.0 \mathrm{~Hz}, 2 \mathrm{H}\right), 4.47(\mathrm{dd}, J=6.9,5.7 \mathrm{~Hz}, 1 \mathrm{H}), 6.91(\mathrm{~d}, J=7.8 \mathrm{~Hz}$, 1H), $7.08(\mathrm{t}, J=7.5 \mathrm{~Hz}, 1 \mathrm{H})$, 7.20-7.40 (m, 7H). Coupling with Boc-Tyr(Bn)-OSu (40.6 mg, $0.0866 \mathrm{mmol})$ afforded tripeptide $1 \mathrm{t}$ as a white solid $(21 \mathrm{mg}, 31 \%)$. The overall yield from oxidized tryptophan $\mathbf{6 b}$ was $26 \%$.

${ }^{1} \mathrm{H}$ NMR (300 MHz, DMSO) $\delta 0.98(\mathrm{~d}, J=6.3 \mathrm{~Hz}, 3 \mathrm{H}), 1.31(\mathrm{~s}, 9 \mathrm{H}), 2.04$ (dd, $J=14.7,9.6$ $\mathrm{Hz}, 1 \mathrm{H}), 2.38$ (m, 1H), $2.64(\mathrm{~m}, 1 \mathrm{H}), 2.95$ (dd, $J=15.3,3.9 \mathrm{~Hz}, 1 \mathrm{H}), 3.98-4.38(\mathrm{~m}, 5 \mathrm{H}), 5.06$ (s, 2H), $5.11(\mathrm{~d}, J=6.3 \mathrm{~Hz}, 1 \mathrm{H}), 6.04(\mathrm{~s}, 1 \mathrm{H}), 6.76(\mathrm{~d}, J=7.8 \mathrm{~Hz}, 1 \mathrm{H}), 6.89-7.45(\mathrm{~m}, 15 \mathrm{H})$, 7.05-7.41 (m, 17H), 7.65 (d, $J=7.8 \mathrm{~Hz}, 1 \mathrm{H}), 7.88(\mathrm{~d}, J=8.4 \mathrm{~Hz}, 1 \mathrm{H}), 8.12(\mathrm{~m}, 1 \mathrm{H}), 10.17$ (s, 1H). ${ }^{13} \mathrm{C}$ NMR $\left(75.5 \mathrm{MHz}, \mathrm{CD}_{3} \mathrm{COCD}_{3}\right) \delta 20.11\left(\mathrm{CH}_{3}\right), 28.57\left(\mathrm{CH}_{3}\right), 36.85\left(\mathrm{CH}_{2}\right), 40.43$ $\left(\mathrm{CH}_{2}\right), 43.56\left(\mathrm{CH}_{2}\right), 50.09(\mathrm{CH})$, 57.67, 60.11, 67.04, 70. $42\left(\mathrm{CH}_{2}\right), 75.93(\mathrm{C}), 80.35(\mathrm{C})$, $110.97(\mathrm{CH}), 115.57(\mathrm{CH}), 123.24(\mathrm{CH}), 125.17(\mathrm{CH}), 127.62(\mathrm{CH}), 128.25(\mathrm{CH}), 128.36$ $(\mathrm{CH}), 128.55(\mathrm{CH}), 129.07(\mathrm{CH}), 129.25(\mathrm{CH}), 130.33(\mathrm{C}), 131.20(\mathrm{CH}), 132.05(\mathrm{CH})$, 138.54 (C), 140.04 (C), 142.49 (C), 157.16 (C), 158.65 (C), 170.80 (C), 171.86 (C), 173.85 (C), 180.39 (C), 209.96 (C). HRMS (ESI) calcd for $\mathrm{C}_{43} \mathrm{H}_{49} \mathrm{~N}_{5} \mathrm{O}_{9} \mathrm{Na}[\mathrm{M}+\mathrm{Na}]^{+} 802.3422$, found 802.3429. $R_{f}(\mathrm{AcOEt}) 0.19$. UPLC (column 2): $t_{\mathrm{R}}=19.9 \mathrm{~min}$, area percent $96 \%$ at $254 \mathrm{~nm}$.

4.1.3.22. Tripeptide 1u: It was prepared by the convergent synthesis according to the general procedure starting from Boc-Tyr(Bn)-Lys(Boc)-OSu [16] (236.7 mg, $0.340 \mathrm{mmol}$ ) and oxidized tryptophan $\mathbf{6 b}(118.0 \mathrm{mg}, 0.363 \mathrm{mmol})$ in $\mathrm{DMF}(0.7 \mathrm{~mL})$ and $\mathrm{CH}_{2} \mathrm{Cl}_{2}(1.3 \mathrm{~mL})$. A first crop of $\mathbf{1} \mathbf{u}$ precipitated in $\mathrm{CH}_{2} \mathrm{Cl}_{2}$ as a white solid (54.0 mg, 18\%) before chromatography. A second fraction was afforded as a white solid after chromatography (39.6 $\mathrm{mg}, 13 \% ; 31 \%$ overall yield).

${ }^{1} \mathrm{H}$ NMR (300 MHz, DMSO-d 6 ) $\delta$ 1.05-1.57 (m, 24H), $2.01(\mathrm{dd}, J=8.3,14.1 \mathrm{~Hz}, 1 \mathrm{H}), 2.39$ (dd, $J=14.1,4.3 \mathrm{~Hz}, 1 \mathrm{H}), 2.67(\mathrm{~m}, 1 \mathrm{H}), 2.88(\mathrm{~m}, 3 \mathrm{H}), 4.08-4.35(\mathrm{~m}, 5 \mathrm{H}), 5.05(\mathrm{~s}, 2 \mathrm{H}), 6.02$ $(\mathrm{s}, 1 \mathrm{H}, \mathrm{OH}), 6.74-6.94(\mathrm{~m}, 6 \mathrm{H}), 7.16-7.45(\mathrm{~m}, 14 \mathrm{H}), 7.93(\mathrm{~m}, 3 \mathrm{H}), 10.12(\mathrm{~s}, 1 \mathrm{H}, \mathrm{NH}) .{ }^{13} \mathrm{C}$ NMR (125.5 MHz, CD $3 \mathrm{OD}) \delta 24.3\left(\mathrm{CH}_{2}\right), 28.8\left(\mathrm{CH}_{3}\right), 28.9\left(\mathrm{CH}_{3}\right), 30.5\left(\mathrm{CH}_{2}\right), 32.0\left(\mathrm{CH}_{2}\right)$, $37.9\left(\mathrm{CH}_{2}\right), 39.7\left(\mathrm{CH}_{2}\right), 41.1\left(\mathrm{CH}_{2}\right), 44.1\left(\mathrm{CH}_{2}\right), 51.3(\mathrm{CH}), 55.6(\mathrm{CH}), 57.6(\mathrm{CH}), 71.0$ $\left(\mathrm{CH}_{2}\right), 76.4(\mathrm{C}), 79.9(\mathrm{C}), 80.9(\mathrm{C}), 111.5(\mathrm{CH}), 116.0(\mathrm{CH}), 123.9(\mathrm{CH}), 125.6(\mathrm{CH}), 128.2$ $(\mathrm{CH}), 128.6(\mathrm{CH}), 128.7(\mathrm{CH}), 128.9(\mathrm{CH}), 129.5(\mathrm{CH}), 130.8(\mathrm{C}), 131.0(\mathrm{CH}), 131.4(\mathrm{CH})$, 131.9 (C), 138.9 (C), 139.7 (C), 142.9 (C), 158.0 (C), 158.6 (C), 159.1 (C), 173.2 (C), 173.9 (C), $175.3(\mathrm{C}), 181.6(\mathrm{C})$. HRMS (ESI) calcd for $\mathrm{C}_{50} \mathrm{H}_{62} \mathrm{~N}_{6} \mathrm{O}_{10} \mathrm{Na}\left[(\mathrm{M}+\mathrm{Na})^{+}\right]$929.4420, found 929.4424. $R_{f}\left(1 / 9 \mathrm{MeOH} / \mathrm{CH}_{2} \mathrm{Cl}_{2}\right)$ 0.50. UPLC (column 2$): t_{\mathrm{R}}=22.5 \mathrm{~min}$, area percent $>99 \%$ at $254 \mathrm{~nm}$. 
4.1.3.23. Tripeptide 1v: Tripeptide 1u (43.33 mg, $0.0478 \mathrm{mmol}$ ) was dissolved in $\mathrm{MeOH}$ $(0.1 \mathrm{~mL})$ and treated with anhydrous $6 \mathrm{M} \mathrm{HCl}$ in $\mathrm{MeOH}(0.15 \mathrm{~mL}, 0.9 \mathrm{mmol})$ at $0{ }^{\circ} \mathrm{C}$ for 10 min and then $10 \mathrm{~min}$ at room temperature. The resulting mixture was then concentrated in vacuo to afford tripeptide $\mathbf{1 v}$ (37 $\mathrm{mg}$, quantitative).

${ }^{1} \mathrm{H}$ NMR (500 MHz, D $\left.2 \mathrm{O}\right) \delta 1.05$ (m, 1H, CH Lys), 1.12 (m, 1H, CH Lys), 1.43 (m, 2H, $\mathrm{CH}_{2}$ Lys), 1.53 (m, 2H, $\mathrm{CH}_{2}$ Lys), 2.39 (dd, $J=6.5 \mathrm{~Hz}, J=13.8 \mathrm{~Hz}, 1 \mathrm{H}, \mathrm{CH}$ oxidized Trp), 2.58 $(\mathrm{dd}, J=7.4 \mathrm{~Hz}, J=13.8 \mathrm{~Hz}, 1 \mathrm{H}, \mathrm{CH}$ oxidized $\operatorname{Trp}), 2.64\left(\mathrm{~m}, 2 \mathrm{H}, \mathrm{CH}_{2} \mathrm{~N}\right.$ Lys), 3.03 (dd, $J=$ $\left.2.3 \mathrm{~Hz}, J=7.1 \mathrm{~Hz}, 2 \mathrm{H}, \mathrm{CH}_{2} \mathrm{Tyr}\right), 3.80$ (d, $\left.J=15.4 \mathrm{~Hz}, 1 \mathrm{H}, \mathrm{COCHN}\right), 3.97$ (m, 2H, COCHN and $\mathrm{CH} \alpha$ oxidized Trp), 4.12 (m, 2H, CH $\alpha$ Lys and Tyr), 5.03 (s, 2H, OCH $\mathrm{H}_{2} \mathrm{Ph}$ ), 6.90 (m, 3H, $\mathrm{CH}$ ar), 7.07 (m, 5H, CH ar), 7.23-7.37 (m, 10H, CH ar). $\left.{ }^{13} \mathrm{C} \mathrm{NMR} \mathrm{(125.5} \mathrm{MHz,} \mathrm{D}_{2} \mathrm{O}\right) \delta 21.8$ $\left(\mathrm{CH}_{2}\right), 26.2\left(\mathrm{CH}_{2}\right), 30.5\left(\mathrm{CH}_{2}\right), 35.9\left(\mathrm{CH}_{2}\right), 37.3\left(\mathrm{CH}_{2}\right), 39.0\left(\mathrm{CH}_{2}\right), 43.0\left(\mathrm{CH}_{2}\right), 50.1(\mathrm{CH})$, $53.1(\mathrm{CH}), 54.1(\mathrm{CH}), 70.3\left(\mathrm{CH}_{2}\right), 75.0(\mathrm{C}), 123.6(\mathrm{CH}), 124.7(\mathrm{CH}), 126.4(\mathrm{CH}), 126.9$ $(\mathrm{CH}), 127.3(\mathrm{CH}), 128.1(\mathrm{CH}), 128.3(\mathrm{CH}), 128.4(\mathrm{CH}), 128.6(\mathrm{CH}), 128.8(\mathrm{C}), 128.9(\mathrm{CH})$, $130.7(\mathrm{CH}), 130.8$ (C), 136.4 (C), 137.5 (C), 140.6 (C), 157.5 (C), 168.7 (C), 171.5 (C), 171.8 (C), 180.0 (C). HRMS (ESI) calcd for $\mathrm{C}_{40} \mathrm{H}_{47} \mathrm{~N}_{6} \mathrm{O}_{6}\left[(\mathrm{M}+\mathrm{H})^{+}\right]$707.3552, found 707.3556. UPLC (column 2): $t_{\mathrm{R}}=10.9 \mathrm{~min}$, area percent $89 \%$ at $254 \mathrm{~nm}$.

4.1.3.24. Tripeptide 2a: It was prepared by the convergent synthesis according to the general procedure starting from Boc-Tyr(Bn)-Ala-OSu (105.6 mg, $0.195 \mathrm{mmol}$ ) and oxidized tryptophan $7 \mathbf{b}(65.4 \mathrm{mg}, 0.201 \mathrm{mmol})$ in DMF $(0.3 \mathrm{~mL})$ and $\mathrm{CH}_{2} \mathrm{Cl}_{2}(0.5 \mathrm{~mL})$. Tripeptide $\mathbf{2 a}$ was afforded as a white solid (76.13 mg, 52\%). Characterization datas of 2 a were previously published [17].

4.1.3.25. Tripeptide $\mathbf{2 b}$ : It was prepared by the convergent synthesis according to the general procedure starting from Boc-Tyr(Bn)-Ala-OSu (115 mg, $0.213 \mathrm{mmol})$ and 7a $(66.1 \mathrm{mg}, 0.265$ mmol, containing $10 \%$ 6a). Tripeptide $2 \mathbf{b}$ was afforded as a white solid (59.5 mg, 42\%) which contained $10 \% \mathbf{1 b}$. Characterization datas of $\mathbf{2} \mathbf{b}$ were previously published [17].

4.1.3.26. Tripeptide 2c: It was prepared by the convergent synthesis according to the general procedure starting from Boc-Tyr(Bn)-Ala-OSu (1.00 g, $1.85 \mathrm{mmol})$ and 7c (0.690 g, 2.03 mmol) in $\mathrm{CH}_{2} \mathrm{Cl}_{2}(20 \mathrm{~mL})$. Tripeptide $2 \mathrm{c}$ was afforded as a white solid (0.890 g, 63\%). 
${ }^{1} \mathrm{H}$ NMR (300 MHz, DMSO-d $\left.{ }_{6}\right) \delta 1.07$ (d, $\left.J=7.2 \mathrm{~Hz}, 3 \mathrm{H}\right), 1.29(\mathrm{~s}, 9 \mathrm{H}), 2.15-2.32(\mathrm{~m}, 2 \mathrm{H})$, $2.61(\mathrm{dd}, J=13.8,10.8 \mathrm{~Hz}, 1 \mathrm{H}), 2.96(\mathrm{dd}, J=13.8,3.9 \mathrm{~Hz}, 1 \mathrm{H}), 3.03$ (s, 3H), 3.81 (q, $J=6.6$ $\mathrm{Hz}, 1 \mathrm{H}), 4.07-4.29(\mathrm{~m}, 4 \mathrm{H}), 5.05(\mathrm{~s}, 2 \mathrm{H}), 6.15(\mathrm{~s}, 1 \mathrm{H}), 6.82-7.01(\mathrm{~m}, 4 \mathrm{H}), 7.14-7.44(\mathrm{~m}, 15 \mathrm{H})$, 7.76-7.81 (m, 2H), 8.05 (br s 1H). ${ }^{13} \mathrm{C}$ NMR (75.5 MHz, DMSO-d 6 ) $\delta 18.07\left(\mathrm{CH}_{3}\right), 25.76$ $\left(\mathrm{CH}_{3}\right), 28.10\left(\mathrm{CH}_{3}\right), 36.29\left(\mathrm{CH}_{2}\right), 38.65\left(\mathrm{CH}_{2}\right), 42.13\left(\mathrm{CH}_{2}\right), 48.29(\mathrm{CH}), 49.50(\mathrm{CH}), 55.82$ $(\mathrm{CH}), 69.11\left(\mathrm{CH}_{2}\right), 74.31(\mathrm{C}), 78.12(\mathrm{C}), 108.37(\mathrm{CH}), 114.33(\mathrm{CH}), 122.05(\mathrm{CH}), 123.86$ $(\mathrm{CH}), 126.62(\mathrm{CH}), 126.94(\mathrm{CH}), 127.52(\mathrm{CH}), 127.68(\mathrm{CH}), 128.10(\mathrm{CH}), 128.34(\mathrm{CH})$, $129.03(\mathrm{CH}), 130.13(\mathrm{CH}), 130.34(\mathrm{C}), 130.74(\mathrm{C}), 137.22$ (C), 139.15 (C), 142.92 (C), 155.36 (C), 156.84 (C), 170.76 (C), 171.15 (C), 171.29 (C), 176.67 (C). HRMS (ESI) calcd for $\mathrm{C}_{43} \mathrm{H}_{49} \mathrm{~N}_{5} \mathrm{O}_{8} \mathrm{Na}\left[(\mathrm{M}+\mathrm{Na})^{+}\right]$786.3473, found 786.3472. $R_{f}(\mathrm{AcOEt})$ 0.33.

4.1.3.27. Dipeptide 5d: A mixture of the deprotected dipeptide obtained from 5a $59.24 \mathrm{mg}$, $0.149 \mathrm{mmol}), 3-\mathrm{PhO}-\mathrm{C}_{6} \mathrm{H}_{4}-\mathrm{CH}_{2}-\mathrm{CO}_{2} \mathrm{Su}(55.46 \mathrm{mg}, 0.1739 \mathrm{mmol})$ and triethylamine $(26 \mu \mathrm{L}$, $0.18 \mathrm{mmol})$ in dry $\mathrm{CH}_{2} \mathrm{Cl}_{2}(1.5 \mathrm{~mL})$ was stirred overnight at room temperature. After dilution by $\mathrm{CH}_{2} \mathrm{Cl}_{2}$, the mixture was washed with water. The aqueous phase was extracted three times with $\mathrm{CH}_{2} \mathrm{Cl}_{2}$. The combined organic phases were dried over sodium sulfate and then concentrated under reduced pressure. After chromatography of the residue over silica gel (15 $\mathrm{g}, 5 \% \mathrm{MeOH}$ in $\mathrm{CH}_{2} \mathrm{Cl}_{2}$ ), dipeptide $\mathbf{5 d}$ was afforded as a white solid (20.0 $\left.\mathrm{mg}, 23 \%\right)$.

${ }^{1} \mathrm{H}$ NMR (300 MHz, DMSO-d $\left.{ }_{6}\right) \delta 1.18\left(\mathrm{~d}, J=7.1 \mathrm{~Hz}, 3 \mathrm{H}, \mathrm{CH}_{3}\right), 2.11(\mathrm{dd}, J=14.1,9.2 \mathrm{~Hz}$, $1 \mathrm{H}, \mathrm{CH} \beta), 2.44(\mathrm{~m}, 1 \mathrm{H}, \mathrm{CH} \beta), 3.43$ and 3.50 (AB system, $\left.J_{A B}=14.6 \mathrm{~Hz}, 2 \mathrm{H}\right), 3.96-4.17(\mathrm{~m}$, $4 \mathrm{H}), 6.01(\mathrm{~s}, 1 \mathrm{H}, \mathrm{OH}), 6.72(\mathrm{~d}, J=7.6 \mathrm{~Hz}, 1 \mathrm{H}), 6.83-7.02(\mathrm{~m}, 6 \mathrm{H}), 7.10-7.44(\mathrm{~m}, 11 \mathrm{H}), 7.80-$ $7.86(\mathrm{~m}, 2 \mathrm{H}), 8.31(\mathrm{~d}, J=6.0 \mathrm{~Hz}, 1 \mathrm{H}, \mathrm{NH}), 10.06(\mathrm{~s}, 1 \mathrm{H}, \mathrm{NH}$ oxindole $) .{ }^{13} \mathrm{C}$ NMR $(75.5 \mathrm{MHz}$, $\left.\mathrm{CD}_{3} \mathrm{COCD}_{3}\right) \delta 17.41\left(\mathrm{CH}_{3}\right), 40.44\left(\mathrm{CH}_{2}\right), 43.08\left(\mathrm{CH}_{2}\right), 43.57\left(\mathrm{CH}_{2}\right), 50.53(\mathrm{CH}), 51.14(\mathrm{CH})$, $75.69(\mathrm{C}), 110.85(\mathrm{CH}), 117.76(\mathrm{CH}), 119.63(\mathrm{CH}), 120.68(\mathrm{CH}), 123.03(\mathrm{CH}), 124.14(\mathrm{CH})$, $125.08(\mathrm{CH}), 125.22(\mathrm{CH}), 127.56(\mathrm{CH}), 128.19(\mathrm{CH}), 129.06(\mathrm{CH}), 130.26(\mathrm{CH}), 130.60$ $(\mathrm{CH}), 130.74(\mathrm{CH}), 132.00(\mathrm{C}), 138.87$ (C), 140.18 (C), 142.69 (C), $158.14(\mathrm{C}), 172.07(\mathrm{C})$, 172.42 (C), 172.95 (C), 180.30 (C). HRMS (ESI) calcd for $\mathrm{C}_{35} \mathrm{H}_{34} \mathrm{~N}_{4} \mathrm{O}_{6} \mathrm{Na}\left[(\mathrm{M}+\mathrm{Na})^{+}\right]$ 629.2370, found 629.2373. $R_{f}\left(1 / 9 \mathrm{MeOH} / \mathrm{CH}_{2} \mathrm{Cl}_{2}\right)$ 0.63. UPLC (column 2): $t_{\mathrm{R}}=16.0 \mathrm{~min}$, area percent $>99 \%$ at $254 \mathrm{~nm}$.

4.1.3.28. Dipeptide 5e: A mixture of the deprotected dipeptide obtained from 5a (45.85 $\mathrm{mg}$, $0.115 \mathrm{mmol}$ ), 4-BnO- $\mathrm{C}_{6} \mathrm{H}_{4}-\mathrm{CO}_{2} \mathrm{Su}(42.96 \mathrm{mg}, 0.139 \mathrm{mmol})$ and triethylamine $(20 \mu \mathrm{L}, 0.14$ mmol) in dry $\mathrm{CH}_{2} \mathrm{Cl}_{2}(1 \mathrm{~mL})$ was stirred overnight at room temperature. After dilution by $\mathrm{CH}_{2} \mathrm{Cl}_{2}$, the mixture was washed with water. The aqueous phase was extracted three times 
with $\mathrm{CH}_{2} \mathrm{Cl}_{2}$. The combined organic phases were dried over sodium sulfate and then concentrated under reduced pressure. After chromatography of the residue over silica gel (12 g, 5\% MeOH in $\mathrm{CH}_{2} \mathrm{Cl}_{2}$ ), dipeptide 5 e was afforded as a white solid (21.7 mg, 31\%).

${ }^{1} \mathrm{H}$ NMR (300 MHz, DMSO-d 6 ) $\delta 1.32\left(\mathrm{~d}, J=7.2 \mathrm{~Hz}, 3 \mathrm{H}, \mathrm{CH}_{3}\right), 2.16(\mathrm{dd}, J=13.8,9.3 \mathrm{~Hz}$, $1 \mathrm{H}, \mathrm{CH} \beta), 2.50(1 \mathrm{H}, \mathrm{CH} \beta), 4.09-4.30\left(\mathrm{~m}, 4 \mathrm{H}, \mathrm{NCH}_{2}, \mathrm{CH} \alpha\right), 5.19\left(\mathrm{~s}, 2 \mathrm{H}, \mathrm{OCH}_{2}\right), 5.98(\mathrm{~s}, 1 \mathrm{H}$, $\mathrm{OH}), 6.76(\mathrm{~d}, J=7.8 \mathrm{~Hz}, 1 \mathrm{H}), 6.95(\mathrm{t}, J=7.5 \mathrm{~Hz}, 1 \mathrm{H}), 7.04(\mathrm{~d}, J=8.9 \mathrm{~Hz}, 2 \mathrm{H}), 7.16-7.48(\mathrm{~m}$, 12H), 7.83 (d, $J=8.9 \mathrm{~Hz}, 2 \mathrm{H}), 7.89$ (d, $J=8.4 \mathrm{~Hz}, 1 \mathrm{H}), 7.97$ (t, $J=6.0 \mathrm{~Hz}, 1 \mathrm{H}, \mathrm{NH}), 8.33$ (d, $J$ $=5.8 \mathrm{~Hz}, 1 \mathrm{H}, \mathrm{NH}), 10.10\left(\mathrm{~s}, 1 \mathrm{H}, \mathrm{NH}\right.$ oxindole) ${ }^{13} \mathrm{C} \mathrm{NMR}\left(75.5 \mathrm{MHz}, \mathrm{CD}_{3} \mathrm{COCD}_{3}\right) \delta 17.36$ $\left(\mathrm{CH}_{3}\right), 40.16\left(\mathrm{CH}_{2}\right), 43.59\left(\mathrm{CH}_{2}\right), 50.42(\mathrm{CH}), 51.87(\mathrm{CH}), 70.59\left(\mathrm{CH}_{2}\right), 75.76(\mathrm{C}), 110.83$ $(\mathrm{CH}), 115.25(\mathrm{CH}), 123.09(\mathrm{CH}), 125.18(\mathrm{CH}), 127.14(\mathrm{C}), 127.61(\mathrm{CH}), 128.29(\mathrm{CH})$, $128.45(\mathrm{CH}), 128.79(\mathrm{CH}), 129.09(\mathrm{CH}), 129.37(\mathrm{CH}), 130.27(\mathrm{CH}), 130.42(\mathrm{CH}), 132.01$ (C), 137.95 (C), 140.13 (C), 142.63 (C), 162.46 (C), 168.40 (C), 172.27 (C), 173.29 (C), 180.30 (C). HRMS (ESI) calcd for $\mathrm{C}_{35} \mathrm{H}_{34} \mathrm{~N}_{4} \mathrm{O}_{6} \mathrm{Na}\left[(\mathrm{M}+\mathrm{Na})^{+}\right]$629.2370, found 629.2377. $R_{f}$ $\left(1 / 9 \mathrm{MeOH} / \mathrm{CH}_{2} \mathrm{Cl}_{2}\right)$ 0.66. UPLC (column 2): $t_{\mathrm{R}}=15.7 \mathrm{~min}$, area percent $98 \%$ at $254 \mathrm{~nm}$.

4.1.3.29. Dipeptide 5f: A mixture of the deprotected dipeptide obtained from $\mathbf{5 b}(57 \mathrm{mg}$, $0.133 \mathrm{mmol}$ ), 4-BnO- $\mathrm{C}_{6} \mathrm{H}_{4}-\mathrm{CO}_{2} \mathrm{H}(33 \mathrm{mg}, 0.14 \mathrm{mmol}), \mathrm{EDC}, \mathrm{HCl}$ (35 mg, $\left.0.18 \mathrm{mmol}\right)$, $\mathrm{HOBt}, \mathrm{H}_{2} \mathrm{O}(25 \mathrm{mg}, 0.16 \mathrm{mmol})$ and triethylamine $(45 \mu \mathrm{L}, 0.33 \mathrm{mmol})$ in a mixture of dry $\mathrm{CH}_{2} \mathrm{Cl}_{2}(0.4 \mathrm{~mL})$ and DMF $(0.2 \mathrm{~mL})$ was stirred overnight at room temperature. After dilution by $\mathrm{CH}_{2} \mathrm{Cl}_{2}$, the mixture was washed with water. The aqueous phase was extracted three times with $\mathrm{CH}_{2} \mathrm{Cl}_{2}$. The combined organic phases were dried over sodium sulfate and then concentrated under reduced pressure. After chromatography of the residue over silica gel $(5 \mathrm{~g}$, AcOEt), dipeptide $\mathbf{5 f}$ was afforded as a white solid (60.9 mg, 72\%).

${ }^{1} \mathrm{H}$ NMR (300 MHz, DMSO-d 6 ) $\delta 1.07$ (d, $\left.J=6.3 \mathrm{~Hz}, 3 \mathrm{H}\right), 2.10(\mathrm{dd}, J=13.8,9.0 \mathrm{~Hz}, 1 \mathrm{H})$, $2.47(\mathrm{~m}, 1 \mathrm{H}), 4.09-4.32(\mathrm{~m}, 5 \mathrm{H}), 5.05(\mathrm{~d}, J=6.3 \mathrm{~Hz}, 1 \mathrm{H}), 5.20(\mathrm{~s}, 2 \mathrm{H}), 6.03(\mathrm{~s}, 1 \mathrm{H}), 6.76(\mathrm{~d}$, $J=7.8 \mathrm{~Hz}, 1 \mathrm{H}), 6.93(\mathrm{t}, J=7.5 \mathrm{~Hz}, 1 \mathrm{H}), 7.09(\mathrm{~d}, J=8.7 \mathrm{~Hz}, 2 \mathrm{H}), 7.17-7.49(\mathrm{~m}, 12 \mathrm{H}), 7.78$ $(\mathrm{d}, J=7.8 \mathrm{~Hz}, 1 \mathrm{H}), 7.84(\mathrm{~d}, J=8.7 \mathrm{~Hz}, 2 \mathrm{H}), 8.04(\mathrm{~d}, J=8.4 \mathrm{~Hz}, 1 \mathrm{H}), 10.13(\mathrm{~s}, 1 \mathrm{H}) .{ }^{13} \mathrm{C} \mathrm{NMR}$ (75.5 MHz, DMSO-d $)_{6} \delta 19.76\left(\mathrm{CH}_{3}\right), 38.41\left(\mathrm{CH}_{2}\right), 42.22\left(\mathrm{CH}_{2}\right), 49.13(\mathrm{CH}), 59.46(\mathrm{CH})$, $66.53(\mathrm{CH}), 69.34\left(\mathrm{CH}_{2}\right), 74.34(\mathrm{C}), 109.68(\mathrm{CH}), 114.37(\mathrm{CH}), 121.54(\mathrm{CH}), 124.49(\mathrm{CH})$, $126.39(\mathrm{C}), 126.63(\mathrm{CH}), 126.98(\mathrm{CH}), 127.73(\mathrm{CH}), 127.94(\mathrm{CH}), 128.15(\mathrm{CH}), 128.47$ (CH), $129.04(\mathrm{CH}), 129.36(\mathrm{CH}), 131.17(\mathrm{C}), 136.69$ (C), 139.12 (C), $141.74(\mathrm{C}), 160.83(\mathrm{C})$, 166.27 (C), 169.71 (C), 171.02 (C), 179.09 (C). HRMS (ESI) calcd for $\mathrm{C}_{36} \mathrm{H}_{36} \mathrm{~N}_{4} \mathrm{O}_{7} \mathrm{Na}$ $\left[(\mathrm{M}+\mathrm{Na})^{+}\right]$659.2476, found 659.2478. $R_{f}(\mathrm{AcOEt})$ 0.20. UPLC (column 2): $t_{\mathrm{R}}=15.7 \mathrm{~min}$, area percent $99 \%$ at $254 \mathrm{~nm}$. 


\subsection{Enzyme studies}

Purified human 20S constitutive proteasome cCP and 20S immunoproteasome iCP were obtained from Boston Biochem (Bio-Techne, Lille, France). The fluorogenic substrates Suc-LLVY-AMC (ChT-L activity, cCP and iCP), Z-LLE- $\beta$ NA (C-L activity, cCP) and BocLRR-AMC (T-L activity, cCP and iCP) were obtained from Bachem (Bubendorf, Switzerland) and Ac-PAL-AMC (C-L activity, iCP) from Boston Biochem (Bio-Techne, Lille, France).

Proteasome activities were determined by monitoring the hydrolysis of the appropriate substrate $\left(\lambda_{\mathrm{exc}}=360 \mathrm{~nm}\right.$ and $\lambda_{\mathrm{em}}=460 \mathrm{~nm}$ for AMC substrates; $\lambda_{\mathrm{exc}}=340 \mathrm{~nm}$ and $\lambda_{\mathrm{em}}=404$ $\mathrm{nm}$ for the $\beta \mathrm{NA}$ substrate). The enzyme-catalyzed fluorescence emission was followed for 45 min at $37^{\circ} \mathrm{C}$ in microplates using the FLUOstar Optima (BMG Labtech). The enzymes were either untreated (controls) or treated by various concentrations of the tested compounds. Before use, substrates and compounds were previously dissolved in DMSO. The percentage of this co-solvent was maintained equal to $2 \%(\mathrm{v} / \mathrm{v})$ in all experiments. In addition to DMSO, the buffers ( $\mathrm{pH} 8$ ) used to measure ChT-L and C-L activities contained $20 \mathrm{mM}$ Tris-HCl, 10\% glycerol, $0.01 \%$ (w/v) SDS, whereas SDS was replaced with $0.005 \%$ Triton X-100 (w/v) in the buffer used for T-L activity. The enzyme concentrations were $0.3 \mathrm{nM}$ in both cases; the substrate concentrations were $20 \mu \mathrm{M}$ for Suc-LLVY-AMC (ChT-L activity of cCP and iCP), $50 \mu \mathrm{M}$ for Z-LLE- $\beta$ NA (C-L activity of cCP), $50 \mu \mathrm{M}$ for Ac-PAL-AMC (C-L activity of iCP) and $50 \mu \mathrm{M}$ for Boc-LRR-AMC (T-L activity of $\mathrm{cCP}$ and $\mathrm{iCP}$ ). To determine the $\mathrm{IC}_{50}$ values (inhibitor concentration giving 50\% inhibition) the enzyme (cCP or iCP) and inhibitors (0.001-50 $\mu \mathrm{M})$ were incubated for $15 \mathrm{~min}$ before the measurement of the remaining activity. They were obtained by fitting the experimental data to eq 1 or eq 2 (n: Hill number), with $V_{0}$ being the initial rate of the control and $V i$ the initial rate in the presence of the tested compound at the concentration [I].

$$
\begin{gathered}
\text { \%Inhibition }=100 \times\left(1-\frac{V_{i}}{V_{0}}\right)=\frac{100 \times[I]}{I C_{50}+[I]} \quad(e q 1) \\
\% \text { Inhibition }=\frac{100 \times[I]^{n}}{I C_{50}^{n}+[I]^{n}}(\text { eq } 2)
\end{gathered}
$$

\subsection{Cellular assays}


Skin normal fibroblastic cells were purchased from Lonza (Basel, Switzerland), HuH7, Caco-2, MDA-MB-231, HCT116, PC3, HaCaT and NCI-H727 cancer cell lines were obtained from the ECACC collection (Porton, UK). Cells were grown according to ECACC recommendations in DMEM for HuH7, MDA-MB-231, HaCaT and fibroblast, in EMEM for CaCo-2, in McCoy's for HCT116 and in RPMI for PC3, NCI-H727 at $37^{\circ} \mathrm{C}$ and $5 \% \mathrm{CO}_{2}$. All culture media were added with $10 \%$ of FBS (fetal bovine serum), $1 \%$ of penicillinstreptomycin and $2 \mathrm{mM}$ glutamine. The proteasome inhibitor ONX-0914 was obtained from Boston Biochem.

Proteasome inhibitors were solubilized in DMSO at a concentration of $10 \mathrm{mM}$ (stock solutions) and diluted in culture medium to the desired final concentrations. The dose effect on cytotoxicity assays ( $\mathrm{IC}_{50}$ determination) were performed by increasing concentrations of each chemical (final well concentrations: $0.1 \mu \mathrm{M}-0.3 \mu \mathrm{M}-0.9 \mu \mathrm{M}-3 \mu \mathrm{M}-9 \mu \mathrm{M}-25$ $\mu \mathrm{M})$. Cells were plated in 96 wells (4000 cells/well). Twenty-four hours after seeding, cells were exposed to chemicals. After $48 \mathrm{~h}$ of treatment, cells were washed in PBS and fixed in cooled $90 \%$ ethanol $/ 5 \%$ acetic acid for $20 \mathrm{~min}$. Then, the nuclei were stained with Hoechst 33342 (B2261 Sigma). Image acquisition and analysis were performed using a Cellomics ArrayScan VTI/HCS Reader (ThermoScientific). The survival percentages were calculated as the number of cells after proteasome inhibitor treatment over the number of cells after DMSO treatment. The $\mathrm{EC}_{50}$ values (inhibitor concentrations leading to $50 \%$ survival) were determined from dose-response curves.

\section{Acknowledgement- Funding}

This work was supported by the Centre National de la Recherche Scientifique (CNRS), the University of Rennes 1 and the University Pierre et Marie Curie (UPMC-Sorbonne Universités).

\section{Conflict of interest}

All authors declare no conflict of interest.

\section{Appendix. Supplementary data}

Supplementary data (Figure S1, Figure S2, representative dose-response curves for tumor cell essays, general methods for chemistry, copies of ${ }^{1} \mathrm{H}$ and ${ }^{13} \mathrm{C}$ NMR spectra) related to this article can be found at https: 


\section{References}

[1] G.A. Collins, A.L. Goldberg, The logic of the 26S proteasome, Cell, 169 (2017) 792-806.

[2] P.M. Cromm, C.M. Crews, The proteasome in modern drug discovery: Second life of a highly valuable drug target, ACS Central Science, 3 (2017) 830-838.

[3] J. Adams, M. Kauffman, Development of the proteasome inhihitor Velcade((TM)) (Bortezomib), Cancer Investigation, 22 (2004) 304-311.

[4] J.J. Shah, E.A. Stadtmauer, R. Abonour, A.D. Cohen, W.I. Bensinger, C. Gasparetto, J.L. Kaufman, S. Lentzsch, D.T. Vogl, C.L. Gomes, N. Pascucci, D.D. Smith, R.Z. Orlowski, B.G. Durie, Carfilzomib, pomalidomide, and dexamethasone for relapsed or refractory myeloma, Blood, 126 (2015) 2284-2290.

[5] P. Moreau, T. Masszi, N. Grzasko, N.J. Bahlis, M. Hansson, L. Pour, I. Sandhu, P. Ganly, B.W. Baker, S.R. Jackson, A.M. Stoppa, D.R. Simpson, P. Gimsing, A. Palumbo, L. Garderet, M. Cavo, S. Kumar, C. Touzeau, F.K. Buadi, J.P. Laubach, D.T. Berg, J. Lin, A. Di Bacco, A.M. Hui, H. van de Velde, P.G. Richardson, Oral ixazomib, lenalidomide, and dexamethasone for multiple myeloma, N. Engl. J. Med., 374 (2016) 1621-1634.

[6] G. Lin, D. Li, L.P. de Carvalho, H. Deng, H. Tao, G. Vogt, K. Wu, J. Schneider, T. Chidawanyika, J.D. Warren, H. Li, C. Nathan, Inhibitors selective for mycobacterial versus human proteasomes, Nature, 461 (2009) 621-626.

[7] H. Li, C. Tsu, C. Blackburn, G. Li, P. Hales, L. Dick, M. Bogyo, Identification of potent and selective non-covalent inhibitors of the Plasmodium falciparum proteasome, J. Am. Chem. Soc., 136 (2014) 13562-13565.

[8] E. Genin, M. Reboud-Ravaux, J. Vidal, Proteasome inhibitors: recent advances and new perspective in medicinal chemistry., Curr. Top. Med. Chem., 10 (2010) 232-256.

[9] N. Micale, K. Scarbaci, V. Troiano, R. Ettari, S. Grasso, M. Zappala, Peptide-based proteasome inhibitors in anticancer drug design, Med. Res. Rev., 34 (2014) 1001-1069.

[10] Y. Koguchi, J. Kohno, M. Nishio, K. Takahashi, T. Okuda, T. Ohnuki, S. Komatsubara, TMC-95A, B, C, and D, novel proteasome inhibitors produced by Apiospora montagnei Sacc. TC 1093. Taxonomy, production, isolation, and biological activities, J. Antibiot. , 53 (2000) 105-109.

[11] M. Kaiser, M. Groll, C. Renner, R. Huber, L. Moroder, The core structure of TMC-95A is a promising lead for reversible proteasome inhibition, Angew. Chem. Int. Ed., 41 (2002) 780-783. 
[12] Z.-Q. Yang, B.H.B. Kwok, S. Lin, M.A. Koldobskiy, C.M. Crews, S.J. Danishefsky, Simplified synthetic TMC-95A/B analogues retain the potency of proteasome inhibitory activity, ChemBioChem, 4 (2003) 508-513.

[13] M. Kaiser, M. Groll, C. Siciliano, I. Assfalg-Machleidt, E. Weyher, J. Kohno, A.G. Milbradt, C. Renner, R. Huber, L. Moroder, Binding mode of TMC-95A analogues to eukaryotic 20S proteasome, ChemBioChem 5(2004) 1256-1266.

[14] M. Kaiser, A.G. Milbradt, C. Siciliano, I. Assfalg-Machleidt, W. Machleidt, M. Groll, C. Renner, L. Moroder, TMC-95A analogues with endocyclic biphenyl ether group as proteasome inhibitors, Chem. Biodiversity, 1 (2004) 161-173.

[15] M. Groll, M. Goetz, M. Kaiser, E. Weyher, L. Moroder, TMC-95-based inhibitor design provides evidence for the catalytic versatility of the proteasome, Chem. Biol., 13 (2006) 607614.

[16] N. Basse, S. Piguel, D. Papapostolou, A. Ferrier-Berthelot, N. Richy, M. Pagano, P. Sarthou, J. Sobczak-Thepot, M. Reboud-Ravaux, J. Vidal, Linear TMC-95-based proteasome inhibitors, J. Med. Chem., 50 (2007) 2842-2850.

[17] M. Groll, N. Gallastegui, X. Marechal, V. Le Ravalec, N. Basse, N. Richy, E. Genin, R. Huber, L. Moroder, J. Vidal, M. Reboud-Ravaux, 20S Proteasome inhibition: designing noncovalent linear peptide mimics of the natural product TMC-95A, ChemMedChem, 5 (2010) 1701-1705.

[18] P. Furet, P. Imbach, M. Noorani, J. Koeppler, K. Laumen, M. Lang, V. Guagnano, P. Fuerst, J. Roesel, J. Zimmermann, C. Garcia- Echeverria, Entry into a new class of potent proteasome inhibitors having high antiproliferative activity by structure-based design, J. Med. Chem., 47 (2004) 4810-4813.

[19] C. Blackburn, K.M. Gigstad, P. Hales, K. Garcia, M. Jones, F.J. Bruzzese, C. Barrett, J.X. Liu, T.A. Soucy, D.S. Sappal, N. Bump, E.J. Olhava, P. Fleming, L.R. Dick, C. Tsu, M.D. Sintchak, J.L. Blank, Characterization of a new series of non-covalent proteasome inhibitors with exquisite potency and selectivity for the 20S beta 5-subunit, Biochem. J., 430 (2010) 461-476.

[20] C. Blackburn, C. Barrett, J.L. Blank, F.J. Bruzzese, N. Bump, L.R. Dick, P. Fleming, K. Garcia, P. Hales, Z. Hu, M. Jones, J.X. Liu, D.S. Sappal, M.D. Sintchak, C. Tsu, K.M. Gigstad, Optimization of a series of dipeptides with a P3 threonine residue as non-covalent inhibitors of the chymotrypsin-like activity of the human $20 \mathrm{~S}$ proteasome, Bioorg. Med. Chem. Lett., 20 (2010) 6581-6586. 
[21] C. Blackburn, C. Barrett, J.L. Blank, F.J. Bruzzese, N. Bump, L.R. Dick, P. Fleming, K. Garcia, P. Hales, M. Jones, J.X. Liu, M. Nagayoshi, D.S. Sappal, M.D. Sintchak, C. Tsu, C. Xia, X. Zhou, K.M. Gigstad, Optimization of a series of dipeptides with a P3 [small beta]neopentyl asparagine residue as non-covalent inhibitors of the chymotrypsin-like activity of human 20S proteasome, MedChemComm, 3 (2012) 710-719.

[22] K. Xu, K. Wang, Y. Yang, D.-A. Yan, L. Huang, C.-H. Chen, Z. Xiao, Discovery of novel non-covalent inhibitors selective to the $\beta 5$-subunit of the human $20 \mathrm{~S}$ proteasome, Eur. J. Med. Chem., 98 (2015) 61-68.

[23] H.-C. Hsu, P.K. Singh, H. Fan, R. Wang, G. Sukenick, C. Nathan, G. Lin, H. Li, Structural basis for the species-selective binding of $N, C$-capped dipeptides to the Mycobacterium tuberculosis proteasome, Biochemistry, 56 (2017) 324-333.

[24] E. Sula Karreci, H. Fan, M. Uehara, A.B. Mihali, P.K. Singh, A.T. Kurdi, Z. Solhjou, L.V. Riella, I. Ghobrial, T. Laragione, S. Routray, J.P. Assaker, R. Wang, G. Sukenick, L. Shi, F.J. Barrat, C.F. Nathan, G. Lin, J. Azzi, Brief treatment with a highly selective immunoproteasome inhibitor promotes long-term cardiac allograft acceptance in mice, Proc. Natl. Acad. Sci. USA, 113 (2016) E8425-E8432.

[25] A. Bordessa, M. Keita, X. Marechal, L. Formicola, N. Lagarde, J. Rodrigo, G. Bernadat, C. Bauvais, J.L. Soulier, L. Dufau, T. Milcent, B. Crousse, M. Reboud-Ravaux, S. Ongeri, $\alpha-$ and $\beta$-Hydrazino acid-based pseudopeptides inhibit the chymotrypsin-like activity of the eukaryotic 20S proteasome, Eur. J. Med. Chem., 70 (2013) 505-524.

[26] P.K. Singh, H. Fan, X. Jiang, L. Shi, C.F. Nathan, G. Lin, Immunoproteasome beta5iSelective Dipeptidomimetic Inhibitors, ChemMedChem, 11 (2016) 2127-2131.

[27] J. Zhang, L. Gao, J. Xi, L. Sheng, Y. Zhao, L. Xu, Y. Shao, S. Liu, R. Zhuang, Y. Zhou, J. Li, Design, synthesis and biological evaluation of novel non-covalent piperidine-containing peptidyl proteasome inhibitors, Bioorg.Med. Chem., 24 (2016) 6206-6214.

[28] N. Basse, M. Montes, X. Marechal, L.X. Qin, M. Bouvier-Durand, E. Genin, J. Vidal, B.O. Villoutreix, M. Reboud-Ravaux, Novel organic proteasome inhibitors identified by virtual and in vitro screening, J. Med. Chem., 53 (2010) 509-513.

[29] P. Beck, M. Reboud-Ravaux, M. Groll, Identification of a $\beta 1 / \beta 2$-specific sulfonamide proteasome ligand by crystallographic screening, Angew. Chem. Int. Ed., 54 (2015) 1127511278.

[30] B.O. Villoutreix, A.M. Khatib, Y. Cheng, M.A. Miteva, X. Marechal, J. Vidal, M. Reboud-Ravaux, Blockade of the malignant phenotype by beta-subunit selective noncovalent inhibition of immuno- and constitutive proteasomes, Oncotarget, 8 (2017) 10437-10449. 
[31] S. Pundir, H.Y. Vu, V.R. Solomon, R. McClure, H. Lee, VR23: A quinoline-sulfonyl hybrid proteasome inhibitor that selectively kills cancer via cyclin e-mediated centrosome amplification, Cancer Res., 75 (2015) 4164-4175.

[32] N. Gallastegui, P. Beck, M. Arciniega, R. Huber, S. Hillebrand, M. Groll, Hydroxyureas as noncovalent proteasome inhibitors, Angew. Chem. Int. Ed. Engl., 51 (2012) 247-249.

[33] X. Maréchal, E. Genin, L. Qin, O. Sperandio, M. Montes, N. Basse, N. Richy, M.A. Miteva, M. Reboud-Ravaux, J. Vidal, B.O. Villoutreix, 1,2,4-oxadiazoles identified by virtual screening and their non-covalent inhibition of the human 20S proteasome, Curr. Med. Chem., 20 (2013) 2351-2362.

[34] Z. Miller, K.-S. Kim, D.-M. Lee, V. Kasam, S.E. Baek, K.H. Lee, Y.-Y. Zhang, L. Ao, K. Carmony, N.-R. Lee, S. Zhou, Q. Zhao, Y. Jang, H.-Y. Jeong, C.-G. Zhan, W. Lee, D.-E. Kim, K.B. Kim, Proteasome inhibitors with pyrazole scaffolds from structure-based virtual screening, J. Med. Chem., 58 (2015) 2036-2041.

[35] P. Beck, T.A. Lansdell, N.M. Hewlett, J.J. Tepe, M. Groll, Indolo-phakellins as beta5specific noncovalent proteasome inhibitors, Angew. Chem. Int. Ed. Engl., 54 (2015) 28302833.

[36] T.J. McDaniel, T.A. Lansdell, A.A. Dissanayake, L.M. Azevedo, J. Claes, A.L. Odom, J.J. Tepe, Substituted quinolines as noncovalent proteasome inhibitors, Bioorg. Med. Chem., 24 (2016) 2441-2450.

[37] I. Sosič, M. Gobec, B. Brus, D. Knez, M. Živec, J. Konc, S. Lešnik, M. Ogrizek, A. Obreza, D. Žigon, D. Janežič, I. Mlinarič-Raščan, S. Gobec, Nonpeptidic selective inhibitors of the chymotrypsin-like ( $\beta 5$ i) subunit of the immunoproteasome, Angew. Chem. Int. Ed., 55 (2016) 5745-5748.

[38] E.E. Manasanch, R.Z. Orlowski, Proteasome inhibitors in cancer therapy, Nat. Rev. Clin. Oncol., 14 (2017) 417-433.

[39] E.M. Huber, M. Basler, R. Schwab, W. Heinemeyer, C.J. Kirk, M. Groettrup, M. Groll, Immuno- and constitutive proteasome crystal structures reveal differences in substrate and inhibitor specificity, Cell, 148 (2012) 727-738.

[40] X. Maréchal, A. Pujol, N. Richy, E. Genin, N. Basse, M. Reboud-Ravaux, J. Vidal, Noncovalent inhibition of $20 \mathrm{~S}$ proteasome by pegylated dimerized inhibitors, Eur. J. Med. Chem., 52 (2012) 322-327.

[41] A. Desvergne, E. Genin, X. Maréchal, N. Gallastegui, L. Dufau, N. Richy, M. Groll, J. Vidal, M. Reboud-Ravaux, Dimerized linear mimics of a natural cyclopeptide (TMC-95A) 
are potent noncovalent inhibitors of the eukaryotic 20S proteasome, J. Med. Chem., 56 (2013) 3367-3378.

[42] A. Desvergne, Y. Cheng, S. Grosay-Gaudrel, X. Maréchal, M. Reboud-Ravaux, E. Genin, J. Vidal, Noncovalent fluorescent probes of human immuno- and constitutive proteasomes, J. Med. Chem., 57 (2014) 9211-9217.

[43] J. Schrader, F. Henneberg, R.A. Mata, K. Tittmann, T.R. Schneider, H. Stark, G. Bourenkov, A. Chari, The inhibition mechanism of human 20S proteasomes enables nextgeneration inhibitor design, Science, 353 (2016) 594-598.

[44] R.B. Labroo, V.M. Labroo, M.M. King, L.A. Cohen, An improved synthesis of dioxindole-3-propionic acid and some transformations of the C-3 hydroxyl group, J. Org. Chem., 56 (1991) 3637-3642.

[45] G. Palla, R. Marchelli, G. Casnati, A. Dossena, A new procedure for indole bromination and oxidative cleavage of tryptophane peptide bonds with $t$-butyl bromide - dimethyl sulphoxide, Gazz. Chim. Ital., 112 (1982) 535-536.

[46] G. Buchi, P.R. DeShong, S. Katsumura, Y. Sugimura, Total synthesis of tryptoquivaline G, J. Am. Chem. Soc., 101 (1979) 5084-5086.

[47] P. López-Alvarado, J. Steinhoff, S. Miranda, C. Avendaño, J. Carlos Menéndez, Efficient, one-pot transformation of indoles into functionalized oxindole and spirooxindole systems under Swern conditions, Tetrahedron, 65 (2009) 1660-1672.

[48] L.H. Choudhury, T. Parvin, A.T. Khan, Recent advances in the application of bromodimethylsulfonium bromide (BDMS) in organic synthesis, Tetrahedron, 65 (2009) 9513-9526.

[49] E. Jones-Mensah, M. Karki, J. Magolan, Dimethyl sulfoxide as a synthon in organic chemistry, Synthesis, 48 (2016) 1421-1436.

[50] G. Li, L. Huang, J. Xu, W. Sun, J. Xie, L. Hong, R. Wang, Sodium iodide/hydrogen peroxide-mediated oxidation/lactonization for the construction of spirocyclic oxindolelactones, Adv. Synth. Catal., 358 (2016) 2873-2877.

[51] D. Sarraf, N. Richy, J. Vidal, Synthesis of lactams by isomerization of oxindoles substituted at C-3 by an $\omega$-amino chain, J. Org. Chem., 79 (2014) 10945-10955.

[52] M. Bodanzsky, A. Bodanszky, The practice of peptide synthesis, 2nd ed., SpringerVerlag, 1994.

[53] G. de Bruin, E.M. Huber, B.-T. Xin, E.J. van Rooden, K. Al-Ayed, K.-B. Kim, A.F. Kisselev, C. Driessen, M. van der Stelt, G.A. van der Marel, M. Groll, H.S. Overkleeft, 
Structure-based design of $\beta 1 \mathrm{i}$ or $\beta 5 \mathrm{i}$ specific inhibitors of human immunoproteasomes, J. Med. Chem., 57 (2014) 6197-6209.

[54] T. Muchamuel, M. Basler, M.A. Aujay, E. Suzuki, K.W. Kalim, C. Lauer, C. Sylvain, E.R. Ring, J. Shields, J. Jiang, P. Shwonek, F. Parlati, S.D. Demo, M.K. Bennett, C.J. Kirk, M. Groettrup, A selective inhibitor of the immunoproteasome subunit LMP7 blocks cytokine production and attenuates progression of experimental arthritis, Nat. Med., 15 (2009) 781787.

[55] E.M. Huber, G. de Bruin, W. Heinemeyer, G. Paniagua Soriano, H.S. Overkleeft, M. Groll, Systematic analyses of substrate preferences of $20 \mathrm{~S}$ proteasomes using peptidic epoxyketone inhibitors, J. Am. Chem. Soc., 137 (2015) 7835-7842.

[56] B. Luan, X. Huang, J. Wu, Z. Mei, Y. Wang, X. Xue, C. Yan, J. Wang, D.J. Finley, Y. Shi, F. Wang, Structure of an endogenous yeast 26S proteasome reveals two major conformational states, Proc. Natl. Acad. Sci. USA, 113 (2016) 2642-2647.

[57] M. Arciniega, P. Beck, O.F. Lange, M. Groll, R. Huber, Differential global structural changes in the core particle of yeast and mouse proteasome induced by ligand binding, Proc. Natl. Acad. Sci. USA, 111 (2014) 9479-9484. 


\section{Highlights}

- X-ray structures drive design of immuno- and constitutive proteasome inhibitors.

- Di- and tripeptide inhibitors are tailored in order to gain subunit selectivity.

- Enantiopure 3-hydroxyoxindolylalaninamide derivatives are efficiently synthesized.

- One, 2 or 3 activities of the proteasomes are inhibited in the nanomolar range.

- The most potent inhibitors are cytotoxic against cancer cell lines. 